\title{
EL ARMAMENTO DE LA NECRÓPOLIS DE CASTILLEJO DE LOS BAÑOS. UNA APROXIMACIÓN A LA PANOPLIA IBÉRICA DE FORTUNA (MURCIA)
}

\author{
POR \\ José Miguel García CANO y Virginia PAGe del Pozo
}

\section{RESUMEN - ABSTRACT}

Este trabajo estudia el armamento ibérico de la necrópolis de Castillejo de los Baños (Fortuna, Murcia), yacimiento que se fecha entre la segunda mitad del siglo V y la mitad del siglo IV anterior a Jesucristo. Se estudian sus características formales, tipológicas, frecuencia y asociaciones de items.

The aim of this paper is the study of the weapons recovered in the Iberian necropolis of Castillejo de los Baños (Fortuna, Murcia), dated between the second half of the fifth century and the first half of fourth century before Christ. We present the formal characteristics, typology, frecuency of the different categories and their associations

\section{PALABRAS CLAVE - KEY WORDS}

Armamento ibérico. Necrópolis. Fortuna.

Iberian Iron Age weapons. Necropolis. Fortuna.

A la memoria de Antonia Aguilar Chordá, con quién compartimos horas de trabajo y amistad en el Museo Arqueológico.

\section{UBICACIÓN Y ANTECEDENTES}

Encontramos esta interesante necrópolis ibérica en una planicie situada a $50 \mathrm{~m}$. al Oeste del Balneario de Aguas Termales de Fortuna, en la margen izquierda de la Rambla Salada. La explanada sobre la que se extiende, es atravesada por un camino de herradura que la divide en dos parcelas.

El límite norte y este del yacimiento viene determinado por una pendiente que salva el desnivel existente en el terreno de unos $3 \mathrm{~m}$. de altura aproximadamente, hasta llegar al norte a otro terreno en explotación agrícola y, al este, a la carretera comarcal. En el sur, no conocemos su total extensión, puesto que circunscribimos el área de excavación a la zona norte del camino de una superficie aproximada de $1950 \mathrm{~m}^{2}$-zona afectada por desfondes en el terreno con una pala excavadora, mientras que el otro lado permaneció intacto-, no obstan- 
te, suponemos que el espacio cementerial continuaría al menos unos metros, ya que las sepulturas excavadas en el camino así parecen confirmarlo. En el oeste, el final de la necrópolis lo marca una suave pendiente.

Se trata de un descubrimiento casual en el transcurso de unas prospecciones por la zona efectuadas en 1981 por Gonzalo Matilla y Luis Alberto García, quienes recogieron algunos fragmentos de cerámicas áticas de barniz negro. Dichas cerámicas fueron publicadas en 1982 por J. M. García Cano, como procedentes del poblado, debido a los escasos datos que de ellas se tenían (1982: 116-121) y a que en ese momento, se desconocía la existencia de una necrópolis asociada al poblado ibérico del «Castillejo de los Baños» (Fortuna, Murcia) ${ }^{1}$.

No disponemos de otras noticias que nos hablen de este yacimiento, siendo por tanto, desconocido hasta que en 1986 G. Matilla volvió a prospectar la zona, descubriendo su parcial destrucción. Efectivamente, el propietario mandó arar su parcela con el fin de delimitar los terrenos de su propiedad de los colindantes (foto 1). El arado arrasó varias tumbas y desplazó de su sitio la parte superior de la práctica totalidad de las sepulturas, dejando a la vista gran cantidad de carbones, cenizas y restos de los ajuares funerarios.

De inmediato se dio parte a la CCAA de la Región de Murcia, quién realizó una excavación de urgencia durante los meses de Abril-Junio de 1986 , en la que se pudieron documentar 43 tumbas de incineración ibéricas².

\section{CARACTERIZACIÓN DE LAS TUMBAS}

La necrópolis se caracteriza por ser bastante uniforme. Tanto por el tipo de fosas, como por los ajuares funerarios depositados en las mismas, todo ello encuadrado en un marco cronológico reducido: fines del s. $\mathrm{V}$ a. C. hasta mediados de la centuria siguiente.

Pudimos documentar un único nivel de enterramientos, es decir, no existe estratigrafía vertical ni superposiciones. Nos encontramos ante una necrópolis en extensión, en la que se concentran la mayor densidad de tumbas hacia el sureste y en menor cantidad, hacia el oeste y norte del área excavada.

De las 43 sepulturas exhumadas, reseñaremos como dato característico, la ausencia total de deposiciones con cubrición de encachado tumular de piedra y, por lo tanto, de los elementos escultóricos que los coronarían, en particular los conocidos como «pilares-estela», tan abundantes en otros yacimientos de la Región de Murcia.

Las fosas que se conservaron intactas en el momento de la excavación, estaban selladas con una capa de barro verdoso de unos 20 centímetros de grosor que serviría de protección. Las cenizas, carbones, huesos calcinados y el ajuar funerario se encontraban en el fondo de las mismas, algunas a gran profundidad.

En cuanto a su tipología formal, podemos distinguir tres modelos distintos de fosa, aunque con pequeñas variantes: rectangulares, ovales y en forma de lingote chipriota. Éste último tipo es la primera vez que lo documentamos en necrópolis ibéricas de esta Región, aunque si hay paralelos en el sur de Albacete (Villares y Pozo Moro). (BLÁNQUEZ PÉREZ, 1992: 277, láminas 2a y 2b).

1 El Poblado, asentado sobre un pequeño cerro al noroeste de la necrópolis y muy próximo a ella, sí era conocido de antiguo, aunque nunca se llevaron a cabo excavaciones oficiales, en él ha habido numerosas prospecciones desde tiempos de A. Fernández de Avilés (Marzo de 1936), estando así mismo sometido al saqueo de los clandestinos y aficionados. Para la bibliografía e historia de la investigación véase MATILLA SÉIQUER Y PELEGRÍN GARCÍA: $1987: 115-117$.

2 Los trabajos de campo fueron realizados por Virginia Page del Pozo, Francisco Ventura Fernández González, Ma José Ruiz Sánz e Isabel Pelegrín García. Los dibujos de materiales son de Da Antonia Aguilar Chordá y Da Ana Pujante. Agradecemos sinceramente a $\mathrm{D}^{\mathrm{a}} \mathrm{M}^{\mathrm{a}}$ José Acosta Malo su paciencia al pasar las láminas a tinta desinteresadamente. 


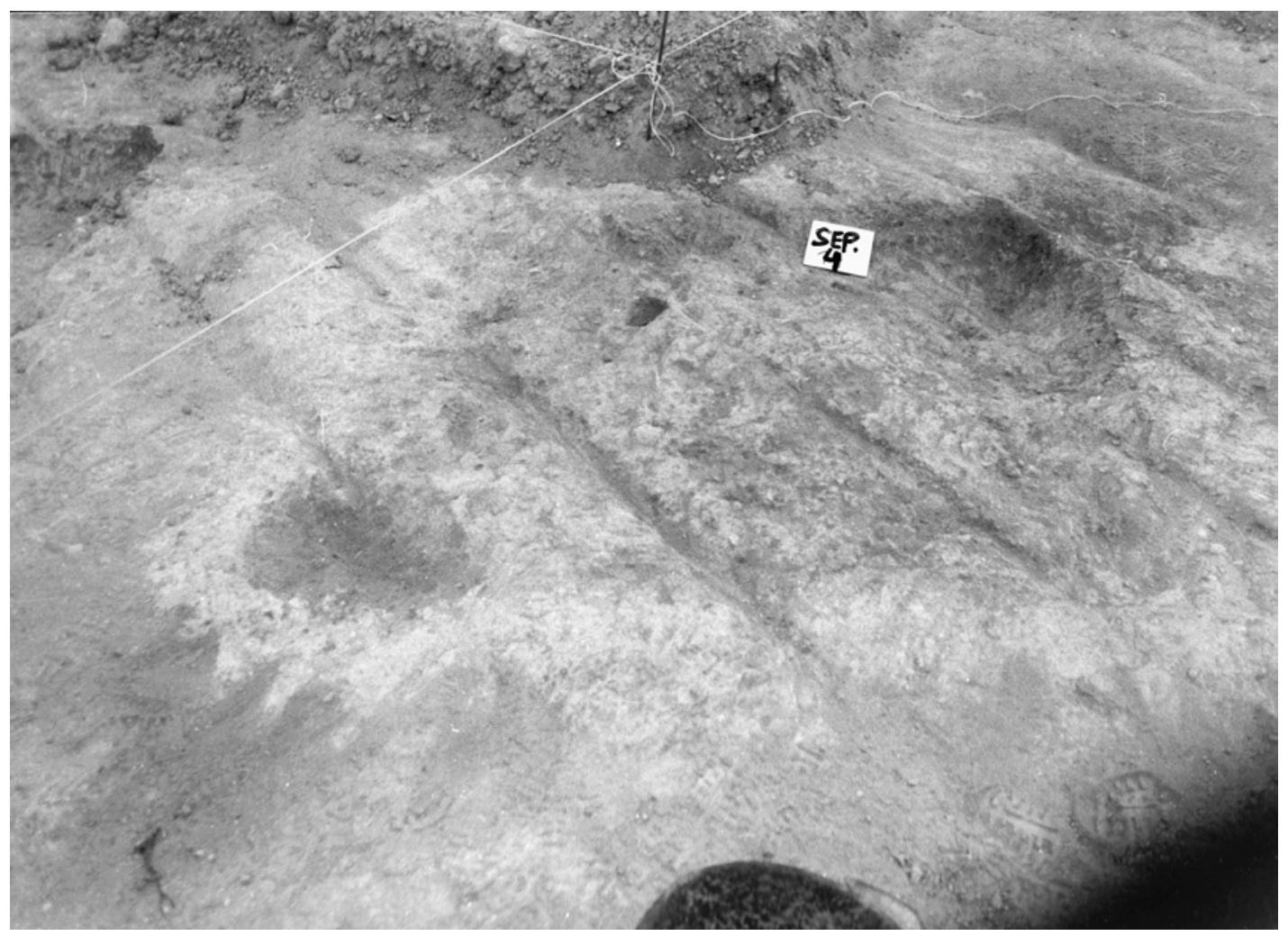

Foto 1. Vista superficial de la fosa de la tumba 4. Se aprecian los surcos del tractor.

La base orientalizante sobre la que se configura la cultura ibérica, teoría defendida por Almagro Gorbea (Almagro GoRBEA,1983: 433 y ss.) en base a la utilización, entre otras cosas, del lingote chipriota para la realización de las tumbas monumentales, en esta ocasión parece confirmarse, no como un hallazgo esporádico, si no en 18 de los 43 enterramientos excavados, lo que supondría $41.8 \%$.

Desgraciadamente no todas ellas pudieron ser delimitadas, ya que algunas habían sido arrancadas de cuajo y desconocemos, por lo tanto, su morfología exacta y orientación, con lo que el número de fosas en forma de lingote chipriota podría aumentar, en el caso de haberse mantenido intactas.

Las conservadas se orientan en dirección noreste-suroeste, con la única excepción de la tumba 24, colocada de este a oeste.

Seis fosas estaban enlucidas con revoques de color blanquecino, de forma total o parcial, es decir, únicamente en uno o en los dos lados de mayor tamaño -c. 14\%-.

Otros - concretamente 13- presentaban en su interior uno o varios adobes -30\%-. Mientras que en la tumba 4 había un rebanco hecho de adobes, dispuesto a la cabecera de la misma.

Como dato curioso, apuntar que en otras 5 fosas apareció una gran piedra depositada, bien en uno de los lóbulos de la cabecera, bien en el centro del encabezamiento.

En cuanto a la disposición de los ajuares:

- se encontraron dispersos en el interior de la fosa (16 tumbas).

- concentrados en una parte de la misma y el resto totalmente vacía (9 tumbas). 
- sin ajuar (3 tumbas).

- en el resto lo desconocemos, puesto que se encontró todo revuelto entre las cenizas.

El 23.2\% de los enterramientos (10 tumbas) posee urna cineraria de cerámica ibérica, de los cuales:

- 5 estaban en el centro de la fosa mientras que el resto en cualquier otro punto de la misma.

- Respecto al tipo de ajuar vemos que: 4 de ajuar femenino;4 de ajuar masculino; 2 de ajuar indeterminado.

La mayoría de los ajuares son muy ricos en cerámicas griegas de figuras rojas y de barniz negro del último cuarto del s. V a C. y primeras décadas del s. IV a. C., con hallazgos de estos materiales en casi el 50\% de las deposiciones, lo que determina un alto índice de importaciones.

Nos encontramos ante una necrópolis en extensión. Se trata de un dato significativo, ya que con estas características, en nuestra Región, sólo contamos con la necrópolis de la Senda de Coimbra del Barranco Ancho (Jumilla). Quizás perteneciente a una élite que se entierra en fosas con forma de lingote chipriota, la mayoría de las fosas con esta forma: contenían en su interior cerámicas de importación (15 de las 18), se caracterizan además por el gran tamaño de las mismas, son casi una cámara funeraria, la cuidada elaboración: revoques o enlucido de las paredes, colocación de adobes de gran tamaño y/o de grandes piedras en un lóbulo o sitio destacado de la fosa, cubrición con un barro verdoso diferente al de la zona y, colocación del ajuar muy profundo y con gran abundancia de elementos de prestigio presentes en varias tumbas como: rueda de carro, calderos de bronce, la cerámica de importación, la espada de frontón, etc.

\section{ENMARQUE CRONOLÓGICO}

Cronológicamente hablando, la presencia de gran cantidad de cerámicas áticas establece unos parámetros temporales de la necrópolis con una amplitud cercana a setenta u ochenta años, concretamente desde los inicios de la segunda mitad del siglo $\mathrm{V}$ hasta las décadas centrales de la centuria siguiente, anteriores a Nuestra Era, c. 440-360/350.

Efectivamente, las piezas más antiguas son unas fuentes de barniz negro y borde ligeramente saliente outturned rim bowl (F22L/F2681M) (GARCÍA CANO, 1997: 107), procedentes de la tumba 5, n. ${ }^{\circ}$ CB-107 y CB-107bis (GARCÍA CANO y PAGE, 2000: 255, figura 2, n. ${ }^{\circ} 107$ ), y la kylix-skyphos de figuras negras perteneciente al Grupo de seguidores de Haimon (BEAZLEY, 1936:562), documentada en el ajuar de la tumba 20, n. ${ }^{\circ}$ CB-277 datable a partir de c.450 antes de Jesucristo (BOARDMAN, 1958-59: 169, n. $^{\circ}$ 102). Aunque algunas copas de este Grupo recibidas en la Península Ibérica, concretamente en el poblado de Ullastret, perduran en los ajuares domésticos hasta el cambio de siglo (PICAZO, 1977:20; PICAZO, MALUQUER y MARTIN, 1984:20-21, láminas 9-6/8 y 10-1/5). En nuestro caso la incineración a la que pertenece, n. $^{\circ} 20$, contenía otro item. ático: Una pátera de barniz negro de borde reentrante $\mathrm{n}^{\circ}$ CB-278 incurving rim bowl (F21L/F2771M) con una cronología en torno a los últimos años del siglo V o primeros del siglo IV (GARCía CANO y PAGE, 2001).

El límite inferior lo determinan una amplia serie de kylikes y skyphoi de figuras rojas y copas, platos y escudillas de barniz negro datables básicamente entre 375/350 antes de Jesucristo (GARCÍA CANO y PAGE, 2000: 225-256, figuras 3 a 5). 
Cronología CERÁmicas Áticas NeCróPOlis del CASTILlejo de los BAÑos

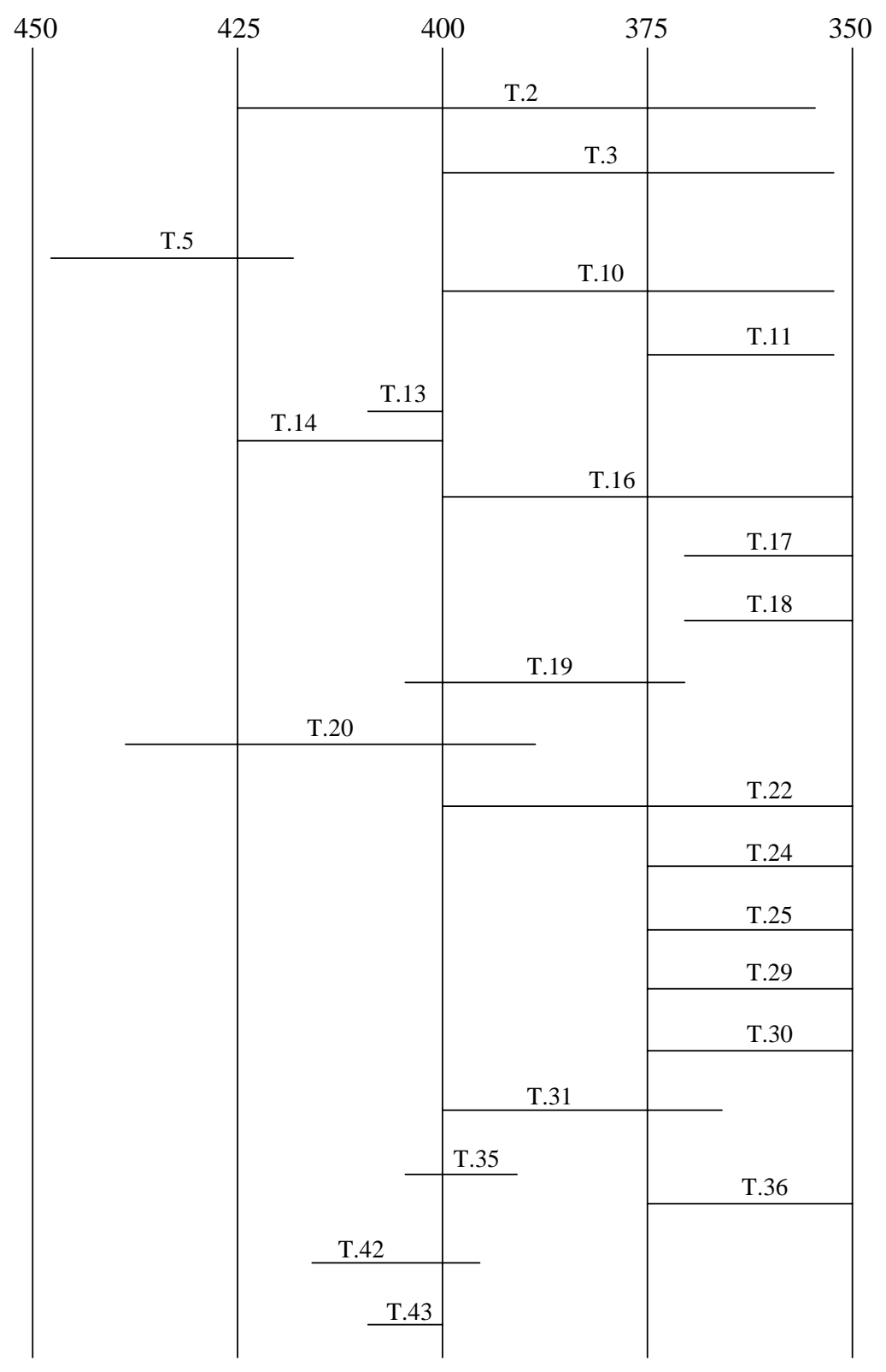

\section{ARMAMENTO}

Disponemos de un nutrido lote de 59 armas localizado en catorce de las cuarenta y tres tumbas investigadas, lo que representa un $32.5 \%$ de ajuares con armamento que, alcanza el $35.8 \%$, si únicamente nos atenemos a las incineraciones que contienen ajuar funerario. Como ha quedado dicho anteriormente la oscilación de los materiales arqueológicos de la necrópolis comprende entre c. 440 y 375/350 antes de Jesucristo. Comparando este guarismo con los datos obtenidos para la necrópolis de la Senda en Coimbra del Barranco Ancho, también con 
una cronología del siglo IV, observamos que los porcentajes de ambas son muy similares, concretamente 28.8\%/34.2\% (GARCÍA CANO, 1997:194).

La panoplia consignada en las incineraciones está compuesta por lanzas $15(25.4 \%)$ y sus correspondientes regatones 14 (23.6\%); en segundo lugar está presente la falcata con 11 items. (18.6) y una espada de frontón (1.6\%). En total las espadas alcanzarían el 20.2\%; soliferrea con 9 unidades (15.2\%); manillas metálicas de escudo tipo caetra con 7 items. (11.8\%) y por último dos cuchillos afalcatados que reúnen el 3.2\% del armamento.

\section{NÚMERO DE ARMAS EN LOS AJUARES FUNERARIOS DE CASTILLEJO DE LOS BAÑOS (FORTUNA)}

TIPO DE ARMA

LANZAS
REGATONES
FALCATAS
SOLIFERREA
ESCUDOS
CUCHILLOS AFALCAT.
ESPADA FRONTÓN

\section{UNIDADES}

15

14

11

9

7

2
Porcentaje

$25.4 \%$

$23.6 \%$

$18.6 \%$

$15.2 \%$

$11.8 \%$

$3.2 \%$

$1.6 \%$

No obstante, al considerar los fragmentos muy atomizados de armas aparecidos fuera de contexto cerrado, hemos de recordar que el yacimiento fue descubierto tras la realización de tareas agrícolas por un tractor que destrozó algunas de las tumbas. El tamaño de estos items. nos impide un estudio en profundidad que aporte datos morfológicos o tipológicos. No obstante estos fragmentos sirven a la hora de establecer porcentajes totales del número de armas que se depositaron en las sepulturas de Castillejo de los Baños. Por esta razón los contabilizaremos ahora, pero no figurarán en el estudio analítico de las armas donde nos limitaremos a consignar los items. documentados en los diferentes ajuares funerarios.

\section{NÚMERO TOTAL DE ARMAS PROCEDENTES DE LA NECRÓPOLIS DE CASTILLEJO DE LOS BAÑOS (FORTUNA)}

$\begin{array}{lcccc}\text { TIPO DE ARMA } & \text { AJUARES } & \text { Sin CONTEXTO } & \text { TOTAL } & \text { PORCENTAJE } \\ \text { FALCATAS } & 11 & 5 & 16 & 22.8 \% \\ \text { LANZAS } & 15 & 0 & 15 & 21.4 \% \\ \text { REGATONES } & 14 & 0 & 14 & 20 \% \\ \text { SOLIFERREA } & 9 & 4 & 13 & 18.5 \% \\ \text { ESCUDOS } & 7 & 1 & 8 & 11.4 \% \\ \text { CUCHILLOS } & 2 & 1 & 3 & 4.2 \% \\ \text { ESPADA FRONTON } & 1 & 0 & 1 & 1.4 \%\end{array}$

Se trata de restos de once piezas correspondientes a 5 falcatas, 4 soliferrea, una manilla de escudo y un cuchillo afalcatado ${ }^{3}$. En conjunto dispondríamos de una panoplia práctica-

3 Las armas localizadas al margen de los ajuares funerarios son: Alrededor de las tumbas 17, CB-241 fragmento de falcata Lc.: 60 mm.; T. 19, $\mathrm{n}^{\circ}$ CB-270 arranque de hoja de falcata Lc.: 74 mm.; T. 20, CB-287 esquirla de soliferreum Lc.: 37 mm.; T. 32, CB-401 fragmento de soliferreum Lc.: 45 mm.; T. 43, CB-496 fragmento de cuchillo afalcatado Lc.: $42 \mathrm{~mm}$.; Sin contexto de conjunto cerrado CB-747. Fragmento de asidero de manilla de escudo Lc.: 56 mm.; CB-831.- 
mente idéntica a la aportada por las armas de los ajuares funerarios con excepción de que las falcatas pasarían a ocupar el primer lugar y por tanto sería el arma principal.

\section{IV.1. ARMAS OFENSIVAS}

\section{IV.1.1. Falcatas}

De las catorce incineraciones con armamento once contienen falcatas, siempre un ejemplar por sepultura, es decir, el $78.5 \%$ de las incineraciones con armas poseen falcata, en todos los casos asociada a otros elementos de panoplia (Véase apartado IV.3.1 de este estudio). Las falcatas son el $18.4 \%$ del equipamiento del guerrero en contexto funerario y el $22.6 \%$ de los items. del yacimiento.

Las tumbas con falcatas se fechan a lo largo de todo el periodo de uso del cementerio, pero a través de algunos fósiles directores como las cerámicas áticas o ciertos tipos de las fíbulas anulares hispánicas hemos podido precisar determinados ejemplares. Dos items. se fechan a finales del siglo $\mathrm{V}$, tumbas 14 y 42 , gracias a la presencia de una copa ática de figuras rojas n. ${ }^{\circ} \mathrm{CB}-213$, figura 14-1 (T. 14) y a un plato de barniz negro CB-478, figura 28-1 (T. 42). Otro ajuar . $^{\circ} 10$ también con abundantes elementos áticos de figuras rojas y barniz negro se sitúa en los primeros años del siglo IV aunque puede alcanzar hasta c.375/360. En cuatro deposiciones, las cerámicas de importación griega se fechan entre 375-350 antes de Cristo, tumbas 24, 29, 30 y 36. Sin elementos de cronología absoluta tenemos el caso de cuatro ajuares, tres de los cuales tienen fíbulas anulares hispánicas de bronce, que por su morfología, pueden datarse con cierta precisión entre finales del siglo $\mathrm{V}$ y las primeras décadas del siglo IV, tumbas 4, 28 y $34^{4}$. Por último la sepultura 1 presenta una hebilla de cinturón con decoración damasquinada . $^{\circ} \mathrm{CB}-20$, figura 2-1 cuyos paralelo más evidente una hebilla de la tumba 103, n. $^{\circ} 911$ de la necrópolis del Cigarralejo, ajuar que se fecha entre 350-325 antes de Cristo por un bolsal de cerámica ática de barniz negro (CUADRADO, 1963: 162, N. 94. Para el ajuar completo véase CUADRADO, 1987: 235-238). Pese a todo, pensamos que el broche como pieza de lujo pudo ser fabricada antes de estas fechas e introducida, como elemento de prestigio, en una tumba posterior una vez amortizada. Para nuestro ajuar proponemos como mínimo una datación entre 375-350 antes de Jesucristo, ya que este es el periodo más moderno constatado hasta la fecha en la necrópolis. Cronología que por otro lado coincide con un paralelo muy próximo documentado en la necrópolis de la Hoya de Santa Ana (Albacete) datado entre 375-350 (SORIA COMBADIERA y GARCÍA MARTINEZ, 1996:53, N. ${ }^{\circ}$ 19/13).

\section{IV.1.1.1. Dimensiones}

De las once falcatas recuperadas en ajuares, sólo conservamos dos completas procedentes de las tumbas 24 y 29, n. $^{\circ}$ CB-324, figura 15-1 y CB-369, figura 20-1. Sus tamaños son 63.9 y 61.8 centímetros respectivamente. Existe un tercer ejemplar fragmentado pero reconstruible CB-172, figura 9-1 (T. 10) cuya longitud es de 59.1 centímetros. Por tanto la media cogida con comillas quedaría en 62.85 centímetros y si añadimos el ejemplar reconstruido que es algo más pequeño que los anteriores obtendremos $61.6 \mathrm{~cm}$. guarismo muy ajustado al tamaño que Fernando Quesada adjudica en su estudio sobre 189 falcatas completas de todo el área ibérica de la Península con $60.2 \mathrm{~cm}$. (QUESADA, 1997(I): 85). Medida cercana a la que

Fragmento de hoja de falcata? Lc.: $23 \mathrm{~mm}$.; CB-870.- Fragmento de hoja de falcata paralelo al dorso se aprecian cuatro acanaladuras Lc.: 53 mm.; CB-904.- Fragmento de un soliferreum ? Lc.: 65 mm.; CB-954. Esquirla de hierro posiblemente de una falcata DM.: $35 \times 21 \mathrm{~mm}$.

4 Agradecemos la información y el estudio pormenorizado de estas fíbulas a D. Angel Iniesta Sanmartín. 
muestran las falcatas de otras importantes estaciones ibéricas de Murcia, como Coimbra del Barranco Ancho con $62 \mathrm{~cm}$. (GARCía CANO, 1997: 196) o Cabecico del Tesoro con 63.7 cm.(QUESADA, 1989 (I): 236) ambas necrópolis por encima de la media «nacional».

Cronológicamente los dos items. completos ajuares de las tumbas 24 y 29 se fechan en la fase final del cementerio 375-350 antes de Cristo, mientras que la falcata reconstruible de la incineración 10 se sitúa en estas mismas fechas o quizás unos pocos años antes.

\section{MEDIDAS DE LAS FALCATAS EN CENTÍMETROS}

\begin{tabular}{|l|c|c|c|c|c|c|c|c|c|}
\hline $\mathbf{N}^{\circ}$ / Tumba & Longitud & L. Hoja & L.Empuñ. & LIE & $\begin{array}{c}\text { Filo } \\
\text { dorsal }\end{array}$ & $\begin{array}{c}\text { Angulo } \\
\text { Axial }\end{array}$ & $\begin{array}{c}\text { Anchura } \\
\text { Max.Hoja }\end{array}$ & $\begin{array}{c}\text { Anchura } \\
\text { Min.Hoja }\end{array}$ & Cronología \\
\hline CB. 324 / 24 & 63.9 & 51.8 & 12.1 & 7.7 & 28.7 & $75^{\circ}$ & 6.8 & 3.7 & $375-350$ \\
\hline CB. 369 / 29 & 61.8 & 48.8 & 13 & 7.8 & 27.3 & $65^{\circ}$ & 6.1 & 4.4 & $375-350$ \\
\hline CB. 172 / 10 & 59.1 & 48.1 & 11 & 9.7 & 24 & $77^{\circ}$ & 6.15 & 4.1 & $400-350$ \\
\hline CB. 214 / 14 & - & 44.4 & - & - & 23.7 & - & 6.2 & 4 & $425-400$ \\
\hline CB. 420 / 34 & - & 55.2 & - & - & 25.5 & - & 6.8 & 3.4 & $425-350$ \\
\hline CB. 354 / 28 & - & - & - & - & 22 & - & 6 & - & $425-350$ \\
\hline CB. 385 / 30 & - & - & - & - & $-*$ & - & - & - & $375-350$ \\
\hline CB. 448 / 36 & - & - & - & - & - & - & - & - & $375-350$ \\
\hline CB. 481 / 42 & - & - & - & - & $-*$ & - & - & - & $425-400$ \\
\hline CB. 95 / 4 & - & - & - & - & - & - & - & - & $425-350$ \\
\hline CB. 23/44 /1 & - & - & - & - & - & - & - & - & $375-350$ \\
\hline MEDIA & 61.60 & 49.66 & 12 & 8.4 & 25.2 & 72.3 & 6.34 & 3.92 & - \\
\hline
\end{tabular}

* Tienen filo dorsal pero no se conserva completo el parámetro.

\section{IV.1.1.1.1. Longitud de la Hoja}

Es el parámetro fundamental a la hora de establecer formatos dentro de las falcatas, ya que generalmente las empuñaduras se mantienen bastante constantes en sus dimensiones.

Además de los tres ejemplares analizados en el epígrafe precedente, podemos sumar las hojas de otras dos falcatas n. ${ }^{\circ}$ CB-214, figura 13-1 (T. 4) y CB-420, figura 24-1 (T. 34) ambas en estado de conservación bastante precario. La longitud tipo tiene aritméticamente $49.66 \mathrm{~cm}$., con una oscilación máxima entre 44.4 (T. 14) y 55.2 (T. 34). Magnitud que sigue siendo ligeramente superior a la referida en el global de las falcatas hispánicas de $48.9 \mathrm{~cm}$. (QUESADA, 1997(I): 85), y casi idéntica a la proporcionada por yacimientos próximos como Coimbra del Barranco Ancho donde este parámetro se encuentra en $50.2 \mathrm{~cm}$. (GARCÍA CANO, 1997: 196), Cabecico del Tesoro 50.9 cm. (QUESADA, 1989(I):237) o la Serreta de Alcoy donde la medida registra $50 \mathrm{~cm}$. redondos (REIG SEGUI, 2000:82).

\section{IV.1.1.1.2. Anchura de la Hoja}

Se han tenido en cuenta dos mediciones: la Anchura Máxima y Mínima (GARCía CANO, 1997: 195). La primera se emplaza en el tercio inferior del arma y oscila entre 6.8 y 6 centímetros. La media es $6.34 \mathrm{~cm}$., habiéndose podido tomar el parámetro en seis items. 
La Anchura Mínima suele localizarse en el inicio de la hoja donde se inicia la curvatura de la misma. En Castillejo de los Baños esta longitud se ha estudiado en cinco ejemplares. La dimensión queda comprendida entre 4.4 y $3.4 \mathrm{~cm}$. siendo el promedio 3.92 centímetros.

En el conjunto de la península las Anchuras Máxima y Mínima quedan según el profesor Quesada en 5.8 y 3.75 cm. respectivamente (1997(I): 86). La relación Anchura Máxima de la Hoja y Anchura Mínima proporciona un valor medio de 1.6 lo que refleja el carácter artesanal de la fabricación de las falcatas.

\section{IV.1.1.1.3. Filo Dorsal}

Es un segundo filo que suelen presentar una gran parte de las falcatas ibéricas, paralelo al dorso del arma en aproximadamente su tercio distal. Todas las falcatas del Castillejo donde hemos estudiado esta variable, ocho en total, presentaban filo en el dorso. En dos casos no se ha podido verificar su medida exacta, ya que se trata de una falcata incompleta $n .{ }^{\circ} \mathrm{CB}-43 / 44$, figura 1-1 (T. 1) y una punta con filo dorsal en toda la longitud del fragmento conservado 15.4 centímetros, procedente de la tumba 42, n. $^{\circ} \mathrm{CB}-481$, figura $29-2$.

En seis ocasiones se ha verificado, siendo la longitud media de $25.2 \mathrm{~cm}$., con una variación máxima de 6.7 centímetros. Los habidos entre los 28.7 de la falcata de la tumba 24 y los $22 \mathrm{~cm}$. de la procedente de la tumba 28. El valor medio del Filo Dorsal para las falcatas ibéricas lo coloca Fernando Quesada en $24 \mathrm{~cm}$., el mayor tiene 34 y el más corto únicamente 12 cm. con una Desviación estandar de 5 (1997(I):92).

No parece haber por tanto relación entre la longitud de la hoja y la del Filo dorsal, tenemos por ejemplo dos falcatas cuya hoja es muy similar 48.1 y $48.8 \mathrm{~cm}$. de las tumbas 10 y 29 respectivamente, sus Filos Dorsales son de 24 y 27.3 centímetros.

\section{IV.1.1.1.4. La Empuñadura}

Es el lugar donde se inserta la mano para el manejo del arma (CUADRADO, 1989:14). Consta de espiga, que es por donde verdaderamente se ase la falcata y, las guardas basal y lateral.

La empuñadura es posiblemente la parte mas frágil del arma y por ello el volumen de empuñaduras recuperadas suele ser significativamente menor al número de falcatas. En nuestro caso meramente contamos con un ejemplar prácticamente intacto, $n .{ }^{\circ} \mathrm{CB}-324$, figura 15 1 que corresponde a la tumba 24 y restos de otras dos empuñaduras de los ajuares 10 y 29 , donde también se ha podido estudiar la morfología de la empuñadura aunque en ninguna de las tres se ha preservado la guarda lateral.

Tienen un formato medio de $12 \mathrm{~cm}$. con una variación morfológica comprendida entre 11 del item. CB-172 (T. 10) y los 13 del n. ${ }^{\circ}$ CB-369 (T. 29). En Coimbra del Barranco Ancho esta longitud queda en 11.1 centímetros (GARCÍA CANO, 1997:196).

En la espiga y el pomo llevan habitualmente entre 3 y 5 remaches para la sujeción de las cachas, normalmente desaparecidas durante la cremación del difunto. Solían ser de madera o hueso. En Castillejo se han conservado restos de tres remaches en dos falcatas CB-324, figura 15-1 (T. 24) y CB-369, figura 20-1 (T. 29). En este último ejemplar, uno de los remaches está completo con una longitud de 8.7 milímetros, altura que viene a definir el grosor de las cachas de madera y a veces de hueso.

En un caso tenemos dos remaches muy próximos entres si en la espiga de la empuñadura CB-95/96, figura 3-2 (T. 4). Aquí los remaches abrazan una moldurita de hierro que serviría de adorno a la espiga de la empuñadura con una longitud para cada cara de unos 7 milímetros. 
En otros dos casos los remaches se rematan en cabecitas que se utilizarían tanto de adorno y resalte como de tope a las cachas. Son generalmente redondas o cuadradas, aunque también se localizado en forma de estrellas de cuatro puntas. Con esta forma hay un bello ejemplar procedente de la tumba 5 de la necrópolis del Cabezo del Tío Pío (Archena) (GARCÍA CANO y PAGE, 1990:113-114). En Fortuna disponemos de un item. redondo n. ${ }^{\circ}$ CB-362, figura 20-4, de la falcata de la tumba 29.

\section{IV.1.1.1.5. Longitud Interior Empuñadura (LIE)}

Unicamente constatado en tres ejemplares. La media proporcionada es de 8.4 centímetros, con un máximo realmente elevado para lo corriente en esta variable situado en $9.7 \mathrm{~cm}$., n. ${ }^{\circ}$ CB-172, figura 9-1 (T. 10) y un mínimo en el n. ${ }^{\circ}$ CB-324, figura 15-1 (T. 24) de 7.7 centímetros.

El resultado, un poco superior a los $8 \mathrm{~cm}$. establecidos por F. Quesada para el arma sobre 171 items. (1997(I): 103). En estaciones próximas como Cabecico o Coimbra los parámetros están ubicados en 8.1 y $7.8 \mathrm{~cm}$. respectivamente (QUESADA, 1989(I): 245 y GARCÍA CANO, 1997: 197).

\section{IV.1.1.3.2. Tipos de Empuñadura}

Tradicionalmente se han considerado dos tipos básicos: en forma de cabeza de pájaro (A) y de cabeza de caballo (B) establecido por $\mathrm{M}^{\mathrm{a}}$ E. Cabré (1934). Posteriormente Emeterio Cuadrado (1989: 15-21) ha definido en base a sus estudios sobre el Cigarralejo, otros dos subtipos de pseudopájaro y pseudocaballo con un total de 15 variantes. Finalmente Fernando Quesada, tras añadir un tipo $\mathrm{C}$ «Indeterminado» siguiendo la tipología de $\mathrm{M}^{\mathrm{a}} \mathrm{E}$. Cabré (QUESADA, 1989(I): 254), ha resuelto finalmente (1997) añadir un cuarto tipo D de empuñadura rectangular sin cabeza de animal muy poco representado por el momento, tan sólo tres items. (QUESADA, 1997(I): 102).

Los tres ejemplos que se han preservado en Castillejo de los Baños pertenecen al modelo B - cabeza de caballo - de $\mathrm{M}^{\mathrm{a}}$ E. Cabré y F. Quesada, tipo mayoritario por ahora entre los herreros ibéricos con casi el doble de hallazgos con respecto al modelo A — cabeza de pájaro- (QUESADA, 1997(I): 102).

\section{IV.1.1.2. Angulo Axial}

Se define como el ángulo medido en grados sexagesimales formado por la línea de la base de la empuñadura, cuya longitud es la anchura basal, y una línea imaginaria que va desde el límite trasero de dicha línea y la punta de la hoja de la falcata. Este valor mide el grado de curvatura de la hoja, cuanto más próximo sea a $90^{\circ}$ más recta será la falcata y por tanto al empuñarla se usará como prolongación del brazo y su empleo debería ser punzante. Cuanto menor sea el ángulo más curvada será la hoja y en consecuencia la espada se manejará como un sable, esto es, será más apta para golpear de modo tajante en detrimento del punzante (QUESADA, 1989(I): 262).

Emeterio Cuadrado ha distinguido cuatro familias en función de la abertura del ángulo axial de las falcatas por él estudiadas en Cigarralejo, comprendidas entre $55^{\circ}$ y $90^{\circ}$ : (I) $90^{\circ}$ $80^{\circ}$; (II) $80^{\circ}-70^{\circ}$; (III) $70^{\circ}-65^{\circ}$ y (IV) $65^{\circ}-55^{\circ}$. En esta clasificación son los items. más rectos los de la familia I y las más curvadas las del grupo IV. En Cigarralejo las falcatas habituales son las de la familia II, es decir, entre $80^{\circ}-70^{\circ}$. 
En Fortuna casi no tenemos ejemplos para establecer algún tipo de pauta, ya que tan sólo tres armas han proporcionado esta medida. Efectivamente, los valores son 77, 75 y 65 grados para las falcatas de las tumbas 10, 24 y 29. Por tanto cabría integrar las dos primeras en el Grupo II de Cuadrado y el tercer item. en la familia III.

El valor medio sería de $72.3^{\circ}$, similar al aportado por las falcatas de la necrópolis de la Serreta que tienen $73^{\circ}$, siendo además su parámetro más numeroso entre $70^{\circ}$ y $77^{\circ}$ (REIG SEGUI, 2000: 84), Coimbra tiene $72.8^{\circ}$ (GARCÍA CANO, 1997: 198), Cabecico del Tesoro $73.6^{\circ}$ (QUESADA, 1989(I): 263) o Cigarralejo 74 (CUADRADO, 1989: 11-12). Como resumen y valoración final puede afirmarse que este valor es muy similar en los distintos grandes yacimientos del área, apenas una amplitud de $1.7^{\circ}$, esto es, pese a su fabricación artesanal el herrero ibérico conocía perfectamente el modo de empleo dado por los guerreros ibéricos a sus armas y por tanto los resultados aquí o allá son verdaderamente parecidos.

En el estudio a nivel peninsular del Doctor Quesada se aprecia como la mayor concentración de items. se ubica entre $73^{\circ}$ y $79^{\circ}$ con 96 falcatas, aunque la variabilidad real del ángulo axial llega a cubrir desde los $56^{\circ}$ a los $90^{\circ}$ (QUESADA, 1997(I):104).

\section{IV.1.1.3. Las Acanaladuras de las Hojas}

Son las incisiones que recorren longitudinalmente las hojas de las falcatas y les hemos llamado acanaladuras, como contribución a la normalización del término tal y como ha propuesto E. Cuadrado (1989: 84) y sobre todo F. Quesada, quién además es autor de un trabajo específico sobre el tema donde aclara definitivamente uso, funcionalidad y significado de las mismas (QUESADA, 1988 y 1997(I):93-100). Su función al mismo tiempo que ornamental, fundamentalmente es para obtener un aligeramiento del peso del arma sin perder resistencia, como apuntó hace casi un siglo H. Sandars (1913: 35).

Siguiendo el esquema propuesto por el profesor Quesada (1988) hemos intentado estudiar tres aspectos de las acanaladuras de las falcatas objeto de análisis: Disposición junto a la empuñadura, en el desarrollo de la hoja y forma de las incisiones. El resultado ha sido bastante pobre, ya que de los once items. disponibles dos falcatas completas $\mathrm{n}{ }^{\circ} \mathrm{CB}-369$, figura 20-1 (T. 29) y CB-420, figura 24-1 (T. 34) están tan erosionadas y faltas de limpieza que no es posible determinar la presencia de acanaladuras que aparentemente faltan. Lo mismo ocurre con otro item. fragmentado pero bien representado $n .{ }^{\circ} \mathrm{CB}-43 / 44$, figura 1-1 (T. 1). De las restantes falcatas dos piezas han conservado únicamente el arranque de la hoja y no parece que tengan acanaladuras n. ${ }^{\circ}$ CB-95/96, figura 3-2 (T. 4) y CB-448, figura 27-5 (T. 36).

En seis items. se documentan acanaladuras, aunque el estado de conservación con una fuerte oxidación dificulta el estudio. En cuatro casos hemos podido ver el tipo. Las acanaladuras se mantienen paralelas al llegar a la empuñadura. Cronológicamente cubren todo el desarrollo de uso de la necrópolis entre c. 425-350 antes de Jesucristo. Esta disposición es la mayoritaria para el conjunto de las falcatas hispánicas, con 122 items. -65.9\%- documentados, que en el área del sureste tiene un guarismo del 64.3\% (QUESADA, 1997(I):95).

Aunque tan sólo proporcionamos un item. n. ${ }^{\circ} \mathrm{CB}-172$, figura 9-1 (T. 10) que conserve la empuñadura, esta tiene forma de cabeza de caballo, siendo sin embargo más frecuente, según F. Quesada, que las acanaladuras simples paralelas al dorso. Al desembocar en la guarda basal pertenecen mayoritariamente a empuñaduras con forma de cabeza de pájaro $71.7 \%$ frente a un 59.4\% de caballo (QUESADA, 1997(I): 95). La cronología de nuestra arma se centra en el segundo cuarto del siglo IV anterior a Cristo.

En lo que se refiere a la disposición de las acanaladuras en cuatro piezas ha sido imposible rastrear su desarrollo. En un caso CB-214, figura 13-1 (T. 14) una o varias se abren hacia el dorso aunque la conservación es muy mala c.425-400- El último ejemplo cb-354, figura 18-1 (T. 28) las estrías continúan paralelas hacia la punta de la falcata. 
Pese a los pocos items. analizados se han documentado los tres modelos propuestos por el Doctor Quesada, esto son, (A) Ancha y fondo plano - CB-172 (T. 10); (B) Ancha y fondo curvo en «V»- CB-324 (T. 24), CB-385 (T. 30) y CB-481 (T. 42) -, que es el tipo mayoritario y (C) Estrecha y fondo en «U»- CB-214 (T. 14) y CB-354 (T. 28).

Esta variabilidad viene a confirmar que las acanaladuras que muestras nuestras falcatas responden más al carácter artesanal de la producción que a otro motivo de tipo cronológico o técnico. Por ejemplo en un yacimiento cercano como Coimbra del Barranco Ancho, los porcentajes son completamente distintos, aunque igualmente los tres modelos definidos por F. Quesada están constatados (GARCÍA CANO, 1997:199).

CUADRO RESUMEN DE LAS ACANALADURAS DE LAS HOJAS DE LAS FALCATAS

\begin{tabular}{|c|c|c|c|c|}
\hline N $^{\circ}$ TUMBA & $\begin{array}{c}\text { TIPO (1) } \\
\text { ACANALADURA }\end{array}$ & $\begin{array}{c}\text { DISPOSICIÓN (2) } \\
\text { ACANALADURA }\end{array}$ & FORMA (3) & CRONOLOGÍA \\
\hline CB- $172 / 10$ & 2 & I & A & $400-350$ \\
\hline CB- $214 / 14$ & 2 & II & C & $425-400$ \\
\hline CB- 324 / 24 & 0 & I & B & $375-350$ \\
\hline CB- $354 / 28$ & 2 & III & C & $425-350$ \\
\hline CB- $385 / 30$ & $2-?$ & I & B & $375-350$ \\
\hline CB- $481 / 42$ & 0 & I & B & $425-400$ \\
\hline
\end{tabular}

(1) 0: Hay acanaladura, pero no se puede determinar el tipo.

1: Divergen al llegar a la empuñadura.

2: Se mantienen paralelas al llegar a la empuñadura.

3: No hay acanaladuras.

(2) I: No es posible determinar si se abren o van paralelas.

II: Una o varias se abren hacia el dorso.

III: Se mantienen paralelas.

(3) A: Ancha, fondo plano.

B: Ancha, fondo curvo en « $\mathrm{V} »$.

C: estrecha, fondo en «U».

\section{IV.1.1.4. Las Decoraciones}

Podemos considerar como motivos decorativos tanto las acanaladuras que recorren las hojas de las falcatas, como los remaches en forma de estrella que a veces lucen en el pomo de la empuñadura ciertas falcatas. No obstante el paradigma ornamental de estas armas consiste en la incrustación de plata sobre determinadas partes del arma, una vez que el proceso metalúrgico de fabricación hubiera concluido. Esta técnica recibe el nombre de damasquinado o ataugía (NIETO y ESCALERA, 1970: 5-6).

Los damasquinados se insertan generalmente en la guarda basal y lateral de la empuñadura y en la hoja, aunque según F. Quesada y parece lógico pensarlo los motivos decorativos debían ocupar una mayor superficie de las falcatas de las que han llegado hasta nuestros días (QUESADA, 1990: 46). 
En ninguno de los restos de once falcatas localizadas en ajuares de Castillejo de los Baños, junto a los trozos de cinco ejemplares hallados fuera de contexto funerario hemos podido distinguir motivo alguno. Esto no quiere decir que no los hubiere en origen, ya que los items. han llegado hasta el presente en malas condiciones, a lo que hay que añadir que las armas sólo han sido limpiadas mecánicamente y que por tanto la fuerte capa de óxido que las recubría no ha sido levantada por completo.

\section{IV.1.1.5. La funda}

La vaina de las falcatas debió de ser de cuero con refuerzos metálicos de finas láminas de hierro que le proporcionaban mayor consistencia al envoltorio. En Cigarralejo se han recuperado tres falcatas que llevan refuerzos metálicos para fortalecer los bordes de la funda, halladas en las tumbas 152, 332 y 212 (CUADRADO, 1989, figuras 10-11 y 22). Este modelo de recubrimiento es raro ya que el propio E. Cuadrado solo señala los tres citados en Cigarralejo y F. Quesada al estudiar el armamento ibérico a nivel peninsular afirma «en raras ocasiones la vaina de cuero se reforzaba a lo largo de toda su longitud por una armadura metálica con sección en forma de «U» que sujetaría el cuero y reforzaría el canto» (QUESADA, 1997(I): 106).

Pese a esto, en la necrópolis objeto de estudio de las once falcatas catalogadas, se conservan tres revestimientos de la clase descrita, prácticamente completos casos de las tumbas 10, CB-173, figura 9-2; 14, CB-215, figura 13-2 y 24, CB-325, figura 15-2. A ellos hay que añadir restos de al menos dos fundas similares muy fragmentadas procedentes de los enterramientos 36, CB-449, figura 27-6 y 42, CB-482, figura 29-3. También de refuerzo metálico completo es la vaina que luce la espléndida espada de frontón $n .^{\circ} \mathrm{CB}-131$, figura 5-1 aparecida en la tumba 7 (Véase epígrafe IV.1.2).

Es pues este modelo de estuche el habitual en Castillejo de los Baños. La cronología de los ajuares implicados con fundas de este modelo se materializan entre 425-375/350 antes de Nuestra Era, es decir una necrópolis con cronología relativamente alta, aunque dentro del periodo ibérico pleno.

Este modelo es el que permite reconstruir la forma del estuche que se amolda al perfil del arma. El hecho de que los refuerzos laterales de hierro sean escasos en la mayor parte de los yacimientos ibéricos indica que el grueso de las vainas únicamente dispondrían del alma de cuero, reduciéndose los elementos metálicos a la embocadura y las guarniciones o abrazaderas transversales colocadas a tres niveles a lo largo del desarrollo de la hoja del arma cada 10/15 centímetros. En estas guarniciones transversales es donde se situaban las anillas de suspensión del arma al tahalí. La posición de las anillas dos en la primera guarnición y una en la segunda muestran que las falcatas irían ligeramente oblícuas para facilitar su desenvaine. Por las representaciones que se han preservado se deduce que no había un modo único de llevar la falcata ya que esta podría ir colgada debajo del hombro o del cinto a ambos lados del cuerpo (CUADRADO, 1989: 24-27).

La vaina se remataba en una contera metálica de forma circular o arriñonada, para evitar que la punta del arma desgarrase la funda (GARCÍA CANO, 1997:201).

\section{IV.1.1.5.1. La Embocadura}

Es una pieza de chapa muy fina recortada y simétrica, doblada por la mitad, que se metería exteriormente en la funda de cuero, reforzando su boca. Estaría unida a la funda con finos remaches, que cerrarían sus extremos fijando la pieza al estuche. La parte abierta quedaba en el dorso del arma. 
En Castillejo únicamente se ha recuperado una embocadura del tipo $1 \mathrm{~b}$ de Cuadrado (1989: 22-23), esto es, extremo del dorso más alto que el del filo que también es curvo. Corresponde a la funda de la falcata de la tumba 28, CB-355, figura 18-3. Datable entre 425 y 350 antes de Jesucristo.

\section{IV.1.1.5.2. Primera Guarnición}

Es una abrazadera en forma de anillo cilíndrico aplastado que rodea la funda, a unos cinco centímetros de la embocadura. La cara interior es recta y los extremos curvos, a fin de contener la funda y la falcata en su interior. La cara externa se curva a partir de los extremos, de modo que pueda penetrar en ellos, deslizando sobre el cuero del cuchillo que suele acompañar al arma. Esta deformación curva puede ser también angular, esto es, puede producirse por un quiebro de la cinta metálica. En los extremos se alojan dos anillas, que quedan encerradas mediante un remache que une la guarnición a la vaina (CUADRADO, 1989: 24).

En nuestra necrópolis contamos con un trazo de lámina procedente de la funda de la falcata de la tumba 34, CB-421, figura 24-2 (derecha).

\section{IV.1.1.5.3. Segunda guarnición}

Es semejante a la anterior, pero sólo lleva una anilla en el extremo pertinente en el dorso de la falcata. La parte frontal de la cinta metálica sufre, junto al extremo con anilla, un quiebro angular, a partir del cual la cinta se hace recta hasta el otro extremo. Queda así un hueco más pequeño que en la primera guarnición, que permite meter en él la punta del cuchillo añadido a la funda (CUADRADO, 1989: 24).

Tenemos restos de esta segunda abrazadera en la vaina correspondiente a la falcata de la tumba 34, CB-421, figura 24-2 (arriba).

\section{IV.1.1.5.4. Tercera Guarnición}

Se trata de un anillo de cinta chafado, guardando los dos lados rectos y paralelos, y los extremos curvos a $180^{\circ}$. No lleva anillas (CUADRADO, 1989: 24).

Hemos podido recuperar restos de dos terceras guarniciones $n .{ }^{\circ} \mathrm{CB}-355 \mathrm{bis}$, figura $18-4 \mathrm{y}$ CB-421, figura 24-2 (izquierda) pertenecientes a las falcatas de las tumbas 28 y 34 respectivamente.

Además de los elementos descritos se han catalogado restos metálicos muy atomizados de fundas de falcatas en las incineraciones 4, CB-97 (no se reproduce); 29, CB-370, figura 20-2 y 30 , CB-386, figura $23-5$

\section{IV.1.1.5.5. La Contera}

Es el remate metálico de la funda de la falcata, generalmente de forma arriñonada o abombada cuyo fin principal es el buen acoplamiento del arma a la vaina evitando que la punta rompa la funda. En la necróplis ibérica de Fortuna no hemos documentado ninguna contera.

\section{IV.1.1.5.6. Botones de sujeción del tahalí}

Están formados por un pequeño eje recto rematado en dos cabezas de diferente tamaño. La exterior, más grande que la interna que da al botón estabilidad y es la empleada en unir los dos ojales. Son de bronce y suelen aparecer en parejas en los ajuares de guerrero (GARCÍA CANO, 1997: 201). 
Dos de estos botones de sujeción se han constatado en las tumbas 34, CB-415a y b, figura 24-6 y 7. Aunque prácticamente son del mismo tamaño sus características morfológicas son diferentes:

CB-415a.- Presenta la cabeza externa circular ligeramente cónica y la interior plana. Podría asignarse al tipo 1 de Cuadrado (1989: 28).

CB-415b.- La cabeza exterior es similar a la precedente, es decir, circular y ligeramente cónica sin embargo la interna es también cónica mucho más apuntada y gruesa. Se trata de un modelo nuevo de botón de sujeción de la falcata.

Estos datos nos inducen a señalar una vez más el carácter artesanal e individualizado de la panoplia ibérica, que llega al extremo de que un guerrero lleve sujeta su principal arma de rango y prestigio con dos botones, cuyo tamaño es similar y por tanto ejecutan a la perfección su trabajo, pero cuya fisonomía es bien distinta.

CUADRO RESUMEN DE DIMENSIONES DE LAS FALCATAS EN CMS.

\begin{tabular}{|l|c|c|c|}
\hline PARAMETROS & MEDIA & MÁXIMA & MÍNIMA \\
\hline Longitud & 61.60 & 63.9 & 19.1 \\
\hline Longitud de la Hoja & 49.66 & 55.20 & 44.40 \\
\hline Longitud Empuñadura & 12 & 13 & 11.1 \\
\hline LIE & 8.4 & 9.7 & 7.7 \\
\hline Filo Dorsal & 25.2 & 28.7 & 22 \\
\hline Angulo Axial & 72.3 & 77 & 65 \\
\hline A. Máxima Hoja & 6.34 & 6.8 & 6 \\
\hline A. Mínima Hoja & 3.92 & 4.4 & 3.4 \\
\hline
\end{tabular}

\section{IV.1.2. Espada de Frontón}

Disponemos de un item. hallado en la tumba 7 de la necrópolis, n. ${ }^{\circ}$ CB-131, figura 5-1. Arma que apenas supone el $1.6 \%$ de la panoplia de los ajuares funerarios y un $1.4 \%$ del total de armas exhumadas en Castillejo de los Baños. La espada estaba fragmentada pero completa incluso con la vaina con refuerzos metálicos, se trata de un ejemplar único de espada de frontón en la Región de Murcia.

Aunque morfometricamente se puede entrar en el debate de su consideración como espada o puñal de frontón, ya que su hoja escasamente supera los 27 centímetros de longitud. Fernando Quesada en su magnífico trabajo sobre la panoplia ibérica, pese a contar con pocos ejemplares, establece un parámetro, para diferenciar unos de otras, que en su momento era relativamente consistente. Efectivamente señalaba Quesada la ausencia de ejemplares entre los 26 y 28 centímetros, localizando una sola pieza hasta los $30 \mathrm{~cm}$. límite entre espadas y puñales. El propio investigador lo señalaba « caso único en la distribución de las frecuencias de las espadas peninsulares, en las que suele haber, como se ha dicho, una gradación continua» (QUESADA, 1997(I): 275, figura 159). Pese a esto, situaba alguna espada con una longitud de hoja en $24 \mathrm{~cm}$. ejemplar de Alcacer do Sal (QUESADA, 1997(I): 184 y 1997(II):848, n. ${ }^{\circ}$ 2874). Siendo la espada de mayor tamaño un item. de la necrópolis de Aguilar de Anguita n. ${ }^{\circ} 3224$ de Quesada (1997(II): 847) con unos 54 centímetros, según Sandars 21 pulgadas y media (1913: 24)5.

5 Agradecemos a D. Fernando Quesada Sanz la información sobre las medidas de las espadas de Alcacer do Sal y Aguilar de Anguita que obran en su base de datos. 
Las variables tipo reales para la definición de las espadas de frontón quedan establecidas en centímetros según F. Quesada (1997(I): 276): Longitud del arma 48.2/33.8 puñales; longitud hoja 35.3/22.6 puñales; longitud interior empuñadura 8.3 y anchura máxima de la hoja $5.9 \mathrm{~cm}$. (QUESADA, 1997(I): 184). Si atendemos a todo este elenco de proporciones creemos que nuestro item. debe incluirse provisionalmente y hasta que nuevos ejemplares permitan análisis comparativos más completos entre los puñales aunque quizás con un apelativo de grandes puñales o espada corta de frontón. Es decir, si estudiamos todos los parámetros su longitud total $40.8 \mathrm{~cm}$. la acercan a una espada aunque pequeña, pero la comparación con los valores estadísticos propuestos por Fernando Quesada tienden a relacionarla, aunque mínimamente, con los puñales de mayor formato.

Exacto, la longitud máxima media de las espadas ahora mismo está en $48.2 \mathrm{~cm}$. luego nuestra pieza queda $7.4 \mathrm{~cm}$. por debajo, mientras que en los puñales esta medida está en 33.8 $\mathrm{cm}$. Por tanto nuestro item. supera esta última variable en 7 puntos. Si esta misma comparación la hacemos con la longitud de la hoja la proximidad a la familia de los puñales es más evidente, ya que las espadas presentan $35.3 \mathrm{~cm}$. por 22.6 los puñales. La espada de Castillejo tiene 27.2, es decir, 8.1 unidades menor que la media de las espadas y sólo $4.6 \mathrm{~cm}$. que los puñales.

Un último dato que quizás permita su clasificación como Gran Puñal puede ser el hecho del conjunto de cinco acanaladuras que recorren su hoja ocupando la práctica totalidad de su longitud, pero también de su anchura una central y dos laterales a cada lado y en ambas caras en contraposición a lo que normalmente sucede en las espadas de este tipo documentadas en necrópolis cercanas como los Nietos (CRUZ PEREZ, 1990:32-33, figura 14-6) o las mejor conservadas del Tesorico (BRONCANO, MARTIN, NEGRETE y PUCH, 1985:86, figura 29) y la Serreta (REIG SEGUI, 2000: 90-91, lámina VI. Para la distribución de las acanaladuras en general véase QUESADA, 1997(I): 182, figura 98).

Es pues un arma sólida con una hoja relativamente corta como se ha visto y una anchura máxima considerable 5.7 centímetros.

La empuñadura está formada por la espiga de hierro con dos pequeños salientes geométricos hacia la mitad de su longitud en cada lado que le confieren un aspecto romboidal. Estos salientes se debieron realizar para facilitar el manejo del arma. Ha conservado parte de las cachas de hueso que la recubrían, incluso se aprecian restos de los motivos pseudoflorales de hojas lanceoladas estilizadas semejantes al dibujo del enmangue de un cuchillo afalcatado del ajuar de la tumba 294 de El Cigarralejo, datada entre 350-325 antes de Cristo (CUADRADO, 1987: 506, n. ${ }^{\circ}$ 12-3030, figura 219-12). También hay restos de otros dos objetos con esquemas similares procedentes del conjunto ibérico de Coimbra en Jumilla, concretamente una pieza de hueso de la necrópolis del Poblado cuadrícula 1-2-3-4, estrato I, n. ${ }^{\circ}$ 1104-3 (GARCÍA CANO, 1997: 256, figura 162-6 y GARCÍA CANO, 1999a:127, n. ${ }^{\circ} 1104-3$ ) y una segunda del Poblado n. ${ }^{\circ}$ J-19 (PAGE, GARCÍA CANO, INIESTA y RUIZ, 1987:67).

La tipología del pomo podría integrarse en la Serie 6 establecida por F. Quesada (1997(I):186), siguiendo el modelo propuesto en un principio por $\mathrm{M}^{\mathrm{a}}$ Encarnación Cabré con cuatro series (CABRE DE MORAN, 1990: 210-211). En efecto, lengüeta plana sobre la que se asientan directamente las cachas dando un aspecto redondeado, cajetín de la guarda recto sin muescas.

En cuanto a la tipología elaborada por el Dr. Quesada, sigue habiendo, desde nuestro punto de vista, pocos ejemplares y muchas variantes, para que ésta esté sólidamente asentada como el propio F.Quesada reconoce. No obstante con los datos actuales podríamos integrar nuestro Gran Puñal en el tipo 1 variante b (QUESADA, 1997(I): 186-187).

Por lo que respecta a paralelos formales, señalar una empuñadura idéntica, excepto por la decoración de hilo de plata, en la pieza n. ${ }^{\circ} 3043$ localizada en el departamento 48 de la Bastida (Mogente) (FLETCHER, Pla y AlCACER, 1965: 234-236, n. ${ }^{\circ}$ 78; QUESADA, 1997(II): 850). En el sureste de España mencionar un item. próximo aparecido en la tumba 7 de la necrópolis 
del Tesorico (Hellín), aunque morfológicamente tiene mayor envergadura que nuestro puñal longitud de la hoja $38.5 \mathrm{~cm}$. por $27.2 \mathrm{~cm}$. del item. de Fortuna. Ambas piezas poseen algunos elementos comunes como los refuerzos de bronce en la empuñadura o el número de acanaladuras que recorren la hoja (BRONCANO, MARTIN, NEGRETE y PUCH, 1985: 84-90, n. ${ }^{\circ} 589$, figuras 29 y 30 ).

La presencia de espadas/grandes puñales de frontón no es muy abundante en la península Ibérica, F. Quesada recoge entre completas y fragmentos 38 items. (1997(II): 847-853), por hacer una comparación diáfana este mismo autor recoge 626 falcatas o 279 espadas de antenas (QUESADA, 1997(II): 837-853).

La espada de frontón, además de escasa en cuanto al número absoluto de items. documentados, da la impresión de que es un tipo de arma antiguo. En el área de Murcia con grandes y ricas necrópolis ibéricas con las décadas centrales del siglo IV bien representadas en sus ajuares, c. 380-320 antes de Jesucristo, como: Cigarralejo, Cabecico del Tesoro o Coimbra del Barranco Ancho, no se documentan items. Entre las incineraciones de este periodo suman más quinientos enterramientos no se han hallado espadas de frontón. Unicamente podemos señalar un caso dudoso en la necrópolis del Poblado de Coimbra n. ${ }^{\circ} 2532$ del ajuar de la tumba 31, fechado hacia la segunda mitad del siglo IV (GARCÍA CANO, 1997: 391, figura 48-6 y 1999a:62-63). Tampoco se han registrado puñales de frontón, los únicos documentados corresponden a tres/cuatro puñales de antenas atrofiadas halladas en Cabecico del Tesoro (?), Cigarralejo, dos items., y Calasparra (En último lugar QUESADA, 1997(II): 857-858, n. ${ }^{\circ} 240,544,624$ y 2084 con la bibliografía precedente).

Por lo tanto nos encontramos con una espada que podriamos clasificar como antigua con relación a la cronología de la cultura ibérica del sureste, concretamente de Murcia, con una datación de la segunda mitad avanzada del siglo V para los ejemplares más pretéritos (QUESADA, 1997(I): 178). En nuestro caso el ajuar no presentaba items. que nos otorgaran una cronología absoluta, ni disponemos de otros datos arqueológicos, ya que la necrópolis no posee estratigrafía vertical ni reaprovechamiento de estructuras funerarias o superposiciones de tumbas. Pese a todo, la presencia de una hebilla de cinturón de bronce poco evolucionada n. ${ }^{\circ}$ CB-129, figura 6-2 y sobre todo una fíbula anular hispánica de bronce de timbal elipsoidal sin montantes y resorte de charnela de bisagra n. ${ }^{\circ} \mathrm{CB}-128$, figura 6-3 que puede datarse hacia finales del siglo $\mathrm{V}$ o primeros años de la centuria siguiente ${ }^{6}$. Pensamos que se puede proponer una fecha entorno al 400 antes de Cristo o muy poco después para la incineración.

Ante la actual evidencia arqueológica no creemos que estas espadas perduren más allá de los años centrales del siglo IV. La espada del Tesorico fechado c.375-350 con evidente similitud a la nuestra, sobre todo en cuanto al pomo, quizás pueda considerarse uno de los últimos modelos o bien pensar que el ejemplar pudo perdurar en uso por razones de prestigio como se ha demostrado en diversos objetos de la cultura material ibérica (GARCÍA CANO, 1999b).

No creemos que haya que elevar la cronología de éstas o de otras armas hasta los inicios del siglo $\mathrm{V}$ por su exclusiva representación en algunos de los guerreros de Porcuna (NAVARRETE, 1987). Efectivamente, este dato unido a otros aportados precisamente por la panoplia presente en Cerrillo Blanco, cuyos testimonios materiales y tangibles tienen una datación arqueológica, no estilística o artística, más baja debe hacernos reflexionar para concretar arqueológicamente la cronología del conjunto, que desde nuestro punto de vista no debe ir más allá de c.450-440 antes de Nuestra Era.

6 Agradecemos el análisis exhaustivo de la fíbula a D. Angel Iniesta. 


\section{IV.1.3. Lanzas con Asta}

Se han documentado lanzas en doce de los catorce ajuares con panoplia, es decir, el $85.7 \%$ de los enterramientos con armas poseen lanzas, combinadas en todos los casos con otras armas. En total son quince puntas de lanza, que suponen el $21.4 \%$ del total de la panoplia ibérica de Fortuna y poco más del 25\% (25.4) de las armas acreditadas en tumbas.

Los quince items. proceden de doce ajuares, en tres tumbas se han depositado dos lanzas n. ${ }^{\circ} 7,36$ y 42. Cuatro de las lanzas están presentes únicamente por trozos que no permiten su reconstrucción tipológica ejemplares de las tumbas $1, \mathrm{n}^{\circ} \mathrm{CB}-39 / 40$ (no se reproduce), 7, CB133 (no se reproduce) y 42, CB-485bis, figura 29-6. El cuarto item. CB-444, figura 27-4 (T. 36), aunque conserva $22.5 \mathrm{~cm}$. de moharra no tiene la punta ni ha preservado las mesas de la hoja, por tanto aunque debe estar cercano al subtipo $2^{\mathrm{a}}$ de F. Quesada tampoco será analizado específicamente. De este modo el estudio se centrará en los restantes once ejemplares.

Cronológicamente los ajuares en los que se integran las puntas de lanza cubren todo el desarrollo de uso de la necrópolis. Hay incineraciones claramente fechadas a finales del siglo V (T. 42) hasta sepulturas de la primera mitad avanzada del siglo IV casos 24, 29 o 36.

\section{IV.1.3.1. Tipología}

Las moharras ibéricas presentan una gran variabilidad formal así por ejemplo en Cigarralejo E. Cuadrado ha diferenciado dos grandes grupos pero 14 tipos y variantes (CUADRADO, 1989:57-61). En las necrópolis de Coimbra se han podido clasificar preliminarmente, sin pretender realizar una tipología definitiva si siquiera para el yacimiento, tres grandes modelos (GARCÍA CANO, 1997: 204-206):

1.- Estilizadas de gran tamaño con nervio central y cubo relativamente corto en relación a la hoja.

2.- De tamaño mediano y pequeño con nervio central. Las hojas tienden a ser bastante anchas en relación a la longitud completa del arma.

3.- De tamaño pequeño sin nervio, tienen la particularidad de presentar sección lenticular.

Fernando Quesada en su monumental trabajo de análisis de la panoplia peninsular ha distinguido diecisiete grandes tipos o subtipos completando hasta un total de treinta y tres variantes (QUESADA, 1997(I): 360-404. Sobre todo figuras 209 y 244). El esfuerzo realizado por sistematizar las puntas de lanza nos parece encomiable y hasta titánico por parte de este investigador, pero creemos que debe ser un punto de partida para una clasificación que hoy por hoy se nos escapa en muchos aspectos quizás debido a la variabilidad formal y morfométrica de las piezas, acrecentada por el carácter manual de su producción.

Efectivamente aunque todas las variables que puedan definir una lanza están contempladas en las propuestas del Dr. Quesada la aplicación física de los datos teóricos resulta difícil. El propio F. Quesada tras exponer la «Propuesta de clasificación» especificando las Variantes IA hasta XVI (1997(I): 360-392), remata el capítulo con otra propuesta tipológica donde agrupa armas semejantes que sin embargo habían quedado separadas al aplicar los análisis morfométricos que definen cada variante (QUESADA, 1997(I): 399-401).

Pensamos que los estudios de los Indices 1 y 2 son convenientes porque ayudan a clasificar los modelos de punta su capacidad de penetración, aerodinámica etc., pero pensamos que deben aplicarse de forma orientativa más que definitoria de cada clase de punta.

Por otro lado pormenorizados yacimiento a yacimiento ayuden a clarificar los modelos de punta por áreas, regiones etc. pudiéndose a partir de aquí realizar tipologías completas en profundidad de espacios reducidos, para posteriormente intentar abarcar todo el espacio ibérico. 
En cualquier caso finalizar estas breves reflexiones afirmando que probablemente no saquemos nada mejor que lo que hoy nos ofrece Fernando Quesada en su extraordinario estudio de la panoplia ibérica, en cuyo caso quizás deberíamos agrupar las puntas en grandes y simplificados bloques que permitan un estudio claro de cada modelo de arma teniendo como manual de consulta obligatorio para subtipos o variantes concretas el corpus elaborado por F. Quesada.

En nuestro trabajo sobre Castillejo de los Baños vamos a agrupar las puntas en tres grandes bloques teniendo como principal parámetro diferenciador el tamaño, dentro de cada grupo se establecerán las pertinentes variantes tipológicas, sin ánimo de confeccionar una nueva clasificación.

1.- Puntas de gran tamaño, estilizadas, esto es, estrechas y alargadas. Hojas de 29/30 centímetros de longitud, aunque el ejemplar mayor conservado n. ${ }^{\circ} \mathrm{CB}-443$, figura $27-3$ de la tumba 36 tiene $33.3 \mathrm{~cm}$. Para la longitud de las puntas completas solo poseemos dos items. de los ajuares 26 y 34 con 40.2 y 44.7 centímetros respectivamente, aunque el mayor item. debió de ser el n. ${ }^{\circ}$ CB-134, figura 5-2 (T. 7) al que le falta el remate del cubo y mide 44.2 centímetros.

Por lo que respecta a la adscripción de estas armas a un tipo concreto de los propuestos por F. Quesada nos encontramos con algunos problemas. Efectivamente a simple vista podrían interpretarse como del tipo 1 y 2 de la clasificación final de este autor (QUESADA, 1997(I): 401, figura 244).

Así, en el primer tipo se situarían dos puntas pertenecientes a las tumbas 29 y 42 . La punta CB-365, figura 19-5 (T. 29), pese a que está incompleta tiene la anchura máxima de la hoja junto a la base y esta parte biselada con respecto al cubo. La sección es cuadrada y pertenecería a la Variante IIA de Quesada (1997:361). El único inconveniente es la longitud del cubo precisado por F. Quesada en torno a 10/12 centímetros (1997(I): 361), pero que en nuestro ejemplar alcanza $14.2 \mathrm{~cm}$.

El segundo item. bastante más incompleto, sobre todo le falta la unión del cubo con el arranque de la hoja de la tumba $42, n .^{\circ} \mathrm{CB}-483$, figura $29-4$. Parece vislumbrarse la característica típica de este subtipo de presentar la mayor anchura de la hoja junto a la base, quizás pudiera incluso pertenecer a la Variante IA (QUESADA, 1997(I): 360, figura 209). Cronológicamente estos items. se fechan el primero en el segundo cuarto del siglo IV y la punta de la tumba 42 a finales del siglo V, cronología antigua que encaja bien en una lanza de la Variante IA.

En el tipo 2 hemos insertado cinco piezas. Dos en el subtipo 2a, que engloba la Variante VA, n. ${ }^{\circ}$ CB-327, figura 16-2 (T. 24) y CB-443, figura 27-3 (T. 36) debido sobre todo a la forma estrecha de la hoja y nervio grueso. Aunque hay que advertir como problema la aplicación del Indice 1, longitud de la hoja dividido por la anchura máxima de la hoja que sólo queda mayor de 10 , concretamente 10.7 en la punta de la tumba 36 , la segunda muestra ofrece un guarismo de 8.2 que automáticamente la colocaría como Variante VB, que para F. Quesada habría que clasificar como subtipo 5b (1997(I): 401). En cualquier caso creemos que este dato es uno de los controvertidos de la tipología y pensamos que se ajusta mejor la pieza en el subtipo 2a.

Por último las tres puntas asignables al subtipo $2 b$, especialmente por la disposición más losángica de la hoja con respecto al subtipo 2a, teniendo la anchura máxima de la hoja hacia el tercio de su desarrollo. Este modelo agrupa las Variantes VIA y VIIA, pero nuestros items. son algo más achaparrados y al aplicarles el Indice 1 longitud hoja/anchura máxima hoja los números resultantes nos sitúan entre 6.6 (T. 7 ), 7 (T. 26) y 8.8 (T. 34). Es decir, sólo la punta CB148 (T. 34) estaría cerca, sin llegar, al valor 10 que colocaría al arma en la Variante VIA de Quesada (1997(I): 358, figura 209). Consideradas las tres puntas en sentido estricto todas presentan un Indice 1 entre 5 y 10 lo que las lleva automáticamente en la Variante VIB, que en la clasificación final de Quesada pasarían al tipo 6, subtipo a (1997(I):401). Pese a lo dicho al aplicar el Indice 2, longitud máxima de la hoja/longitud del cubo, los dos items. medidos números CB-343 (T. 26) y CB-418 (T. 34) dan 2 y 2.3 puntos guarismo que encaja perfectamente en los proporcionados por los items. de la Variante VIA en torno a 3 (QUESADA, 1997(I): 373). 
Cronológicamente los ajuares a los que pertenecen las tres puntas cubren casi todo el desarrollo de utilización del cementerio entre c.425-375/350 antes de Cristo.

2.- Puntas de mediano y pequeño tamaño con nervio central marcado y cubo relativamente corto.

Dos ejemplares de los ajuares 4 y 10 se inscriben claramente dentro del subtipo 5a de Quesada, al pertenecer a la Variante VC de este mismo autor. Su Indice 1, queda establecido en 3.8 CB-93 (T. 4) y 4.1 CB-175 (T. 10) (QUESADA, 1997(I): 369-373). Los nervios son cuadrado y rectangular respectivamente, secciones 2 y 6 de Quesada, lo que también las integra dentro de los caracteres establecidos para el tipo por este autor (1997(I): 401).

Temporalmente se cubre todo el periodo de utilización de la necrópolis en el caso de la punta de la tumba 4 c.425-350, mientras que la CB-175 (T. 10) se data en la primera mitad del siglo IV, sin mayores precisiones.

Un tercer item. con variables parecidas, pero deformada y con la punta más estilizada, completa el apartado. Se trata de la punta n. ${ }^{\circ}$ CB-205, figura 11-12 de la tumba 12. En este caso y pese a la mala conservación se vislumbra la hoja un poco más fina que los ejemplares precedentes y el cubo ligeramente más grande. La sección del nervio es circular. Se fecha el ajuar entre c. 425-375 antes de Jesucristo.

3.- Jabalina

Un item. documentado en la tumba 28, CB-353, figura 18-2. Tiene una hoja de 10.9 centímetros con su anchura máxima a un quinto de la base con $2.6 \mathrm{~cm}$. A partir de aquí decrece rápidamente hasta la punta. Sección circular y sus Indices son 1/4.1 y 2/2.2. En nuestra opinión se inserta relativamente bien en la Variante XIA de Quesada (1997(I): 385) y subtipo 12a de la muestra definitiva de este mismo investigador (1997(I): 401).

En lo que se refiere a la datación el ajuar carece de fósiles directores y hay que circunscribirla a la cronología general del yacimiento c.425-350 antes de Cristo.

\section{IV.1.3.2. Los Nervios}

Las quince puntas de lanza documentadas presentan nervio central marcado, es decir, el $100 \%$ de las lanzas catalogadas en los ajuares funerarios. Se han podido distinguir tres variantes: Cuadrados, circulares y rectangulares por este orden de mayor a menor número, que se corresponden con las secciones 1, 2 y 6 de Quesada (1997(I): 357, figura 208), así como dos irreconstruibles y por tanto indeterminados.

\section{IV.1.3.2.1. Cuadrados}

Son los mayoritarios en las lanzas de Castillejo con 8 items. 53.3\% del total. Corresponden a los ejemplares de las tumbas 4, 7 (dos items.), 24, 26, 28, 29 y 36. A nivel cronológico estos ajuares abarcan todo el desarrollo de uso de la necrópolis con item. que pueden ser antiguos tumbas 4, 7, 26 o 28 mientras que otros están bien fechados c. 375-350 antes de Jesucristo como las puntas de las incineraciones 29 y 36.

En Coimbra del Barranco Ancho esta sección se documenta en ajuares exclusivamente del siglo IV (GARCÍA CANO, 1997: 207-208).

\section{IV.1.3.2.2. Circulares}

Cuatro items. estudiados en los ajuares 12, 34, 36 y 42 suman el $26.6 \%$ del número de puntas. Sus ajuares pertenecen al periodo más antiguo de enterramientos. Efectivamente el n. ${ }^{\circ} \mathrm{CB}-$ 483 (T. 42) se fecha c. 425-400, mientras que los restantes ajuares no tienen una datación pre- 
cisa. No obstante las fíbulas anulares hispánicas que ofrece cada tumba nos llevan a una fecha antigua, aunque las tumbas haya que ubicarlas a nivel general entre 425 y 350 antes de Cristo.

Este dato no se corrobora en Coimbra del Barranco Ancho donde las puntas de sección circular no han aparecido hasta el momento en la necrópolis de la Senda, la más antigua del complejo (GARCíA CANO, 1997:208).

\section{IV.1.3.2.3. Rectangular}

Unicamente un item. y no muy bien conservado hallado en la incineración 10, CB-175. Supone el 6.6 del total. Este ajuar se fecha entre 400-350 antes de nuestra Era.

Finalmente reseñar dos piezas irreconstruibles y por lo tanto de sección indeterminada de las sepulturas 1 y 42.

\section{IV.1.3.2. Regatones}

Es un elemento accesorio de las lanzas fabricado a partir de una lámina de hierro batido. Suele presentar forma cónica ligeramente apuntada en la mayoría de los ejemplares y extremo inferior agudo. Su tamaño tiene una gran variabilidad, desde muy pequeños con apenas 5-6 centímetros hasta un item. extraordinario de 35 centímetros en Cigarralejo (CUADRADO, 1989: 61) o piezas de 36 y 38.5 centímetros como los procedentes de la necrópolis de Casablanca en Cástulo (BLAZQUEZ, 1975: 221, n. 14 y 16, figura 131). Siendo el regatón más grande hallado hasta la fecha en el ámbito ibérico, entre los 859 items. recogidos por F. Quesada (1997(I): 429), un item. procedente de Mianes de 55.5 centímetros publicado en su momento por el profesor Maluquer (QUESADA, 1997(II): 908, n. $\left.{ }^{\circ} 2467\right)$.

Fernando Quesada, con su amplia visión de la panoplia ibérica señala que aunque todos los modelos conviven, sin embargo en el periodo ibérico antiguo hasta finales del siglo $\mathrm{V}$ predominan los regatones largos $>25 \mathrm{~cm}$ con la punta afilada o relativamente redondeada (1997(I): 429). Su utilidad es muy variada pero con tres usos principales, desde su originaria función de ser, esto es, permitir clavar la lanza en el suelo cuando está inactiva en el campamento, evitando el despunte de la moharra o que se astille al asta de madera. Los otros usos serían ejercer de contrapeso facilitando el empleo de la lanza y contar con una segunda punta si en el combate se rompe el astil.

Fernando Quesada ha propuesto un cuarto empleo, basándose en las representaciones del ámbito griego, rematar a los enemigos caídos al pasar sobre ellos en el avance. Según se camina, un golpe seco de regatón verticalmente hacia abajo puede atravesar fácilmente cualquier coraza o escudo (1989(I): 307-308 y 1997(I): 430).

\section{IV.1.3.2.1. Tipología}

Siguiendo el modelo propuesto por E. Cuadrado para Cigarralejo (CUADRADO, 1989: 61) los hemos dividido en tres tipos en función del tamaño, dejando un cuarto modelo para items. de formato extraordinario mayores de 20 centímetros de los que no se ha señalado ninguno en la necrópolis de Fortuna. Se han catalogado catorce regatones todos de ajuares $23.6 \%$ de las armas contextualizadas y $20 \%$ de la panoplia total de la estación.

\section{IV.1.3.2.1.1. Cortos/Pequeños $<10 \mathrm{~cm}$.}

Hemos asignado cuatro items. a la variante $28 \%$. Exclusivamente dos están completos $n .^{\circ}$ CB-344, figura 17-2 (T. 26) y CB-445, figura 26-2 (T. 36), una tercera es fácilmente recons- 


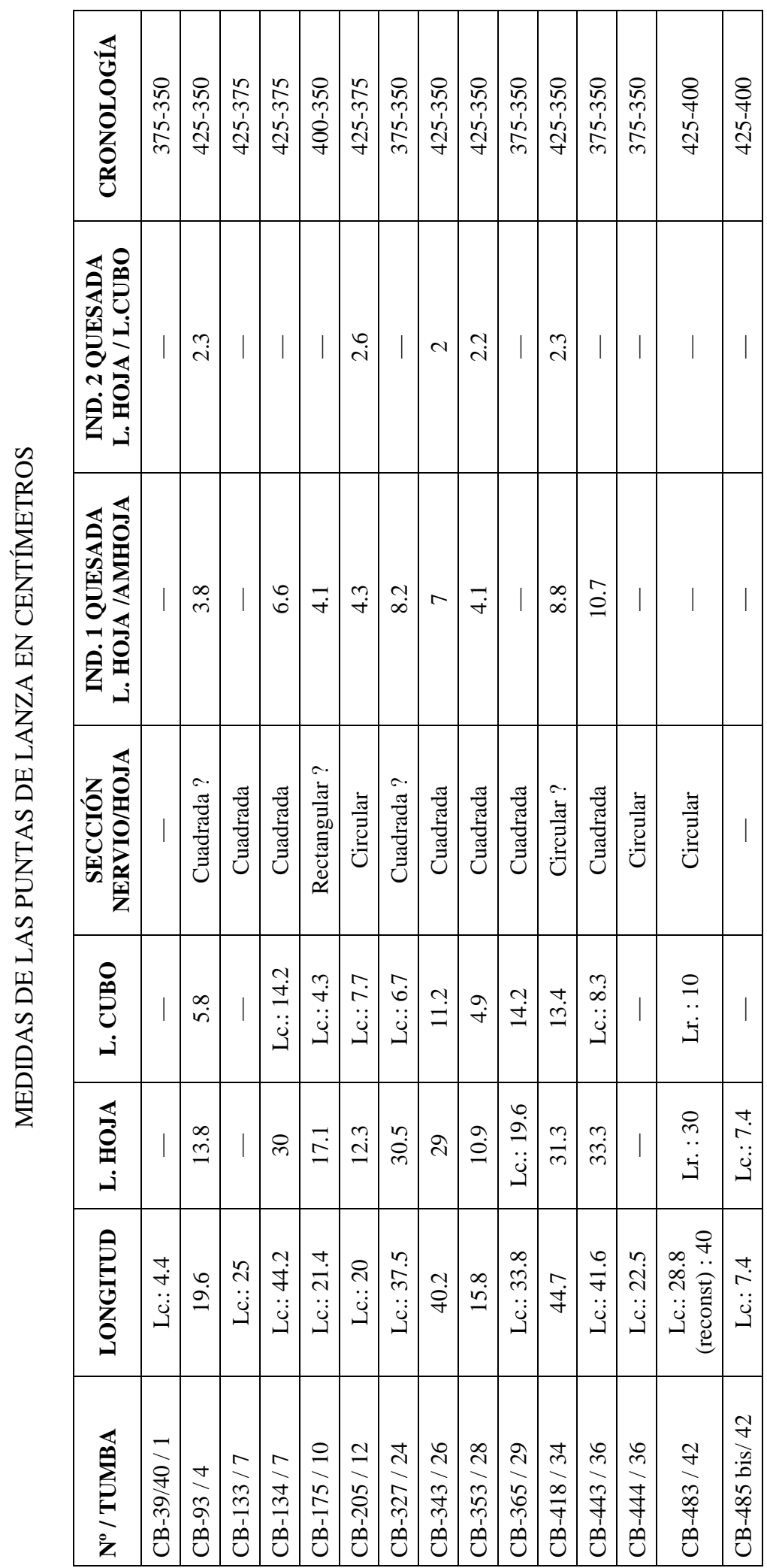


truible en su longitud total $\left(9.6 \mathrm{~cm}\right.$.). A un cuarto regatón le falta la punta $\mathrm{n} .{ }^{\circ} \mathrm{CB}-367$, figura 19-3 (T. 29). Los diámetros de la embocadura tienen entre 1.8 y 2.1 centímetros.

Cronológicamente pueden situarse en el periodo más tardío de actividad del cementerio, ya que los tres ajuares examinados 24, 29 y 36 se datan entre 375-350 antes de Jesucristo, solamente la incineración 26 muestra una cronología amplia desde fines del siglo $\mathrm{V}$ a mediados de la centuria siguiente.

\section{IV.1.3.2.1.2. Medianos. De 10 a $15 \mathrm{~cm}$.}

Son tres piezas de las que solamente una está completa n. ${ }^{\circ}$ CB-368, figura 19-4 (T. 29). Representan el $21 \%$ de los regatones. A los otros dos les falta la punta pero la longitud total es reconstruible verosimilmente quedando el CB-94, figura 4-3 (T. 4) c.12 cm. y el CB-176, figura 10-1 (T. 10) sobre 14 centímetros. Los diámetros de sus embocaduras oscilan entre 2.1 y $2.3 \mathrm{~cm}$.

Cronológicamente los tres enterramientos implicados abarcan todo el desarrollo de la necrópolis.

\section{IV.1.3.2.1.3. Largos $>15 \mathrm{~cm}$.}

Se trata de otros tres items. todos fragmentados en grado diverso, faltándoles a todos las puntas. Suponen el $21 \%$ de los regatones exhumados en Castillejo. A nivel cronológico dos ejemplares se datan entre finales del siglo $\mathrm{V} \mathrm{n} .^{\circ} \mathrm{CB}-216$ (T. 14) y primeros años del siglo IV n. ${ }^{\circ}$ CB-136 (T. 7), mientras que el tercer ejemplar n. ${ }^{\circ}$ CB-329 (T. 24) se data entre 375-350 antes de Cristo.

Hecho el análisis pormenorizado de los regatones que conservan el perfil completo no parece que rija una norma exacta a la hora de su fabricación aunque da la impresión de que los de mayor tamaño tienden a ser más antiguos como propuso el Dr. Quesada (1997(I): 429).

Entre regatones completos y reconstruibles hemos podido apreciar que el tamaño medio de los ejemplares de Fortuna queda en $12 \mathrm{~cm}$., aunque solamente se han contabilizado finalmente nueve items.

En Coimbra, yacimiento relativamente cercano a la estación objeto de estudio con una muestra de dieciocho piezas tiene una media de $10 \mathrm{~cm}$. En este segundo caso hay que tener presente la utilización de la necrópolis del Poblado hasta el inicio del siglo II antes de Jesucristo, lo que puede favorecer la disminución en la longitud media de los regatones (GARCÍA CANO, 1997: 209).

El diámetro de las embocaduras oscila entre $2.5 \mathrm{~cm}$. para el mayor, pieza que paradógicamente sólo tiene $8.4 \mathrm{cms}$. de longitud, $n .{ }^{\circ} \mathrm{CB}-445$, figura $26-2$ (T. 36) y los $1.7 \mathrm{~cm}$. del n. ${ }^{\circ} \mathrm{CB}-$ 136, figura 5-3 (T. 7) que por el contrario es un regatón de gran formato conservándose 14.1 $\mathrm{cm}$. La media aritmética sobre una base de once items. queda establecida en 2 centímetros.

\section{IV.1.3.2.1.4. Acabado Interior de los Regatones}

Mencionar el acabado interno que algunas piezas presentan para facilitar la adhesión del astil de madera en la embocadura del regatón.

Se manifiesta en el hueco dejado para la penetración del astil, cuando es inferior a la mitad de la longitud del regatón lo denominamos macizo y hueco cuando la oquedad es superior al 50\% del desarrollo del item. 
En Castillejo todos los items. reconstruibles, diez en conjunto, tienen el hueco muy superior a la mitad de la longitud del regatón (90\%), quedando una única pieza CB-344, figura 17-2 (T. 26) con una perforación reducida.

Igualmente y para facilitar el enmangue en varios items. se ha localizado restos de una lámina de bronce/cobre generalmente muy deshecha que serviría para ayudar en esta función. Efectivamente el inventario de regatones con alma de bronce asciende a seis piezas aparecidos en los ajuares 4, 24, 29(2), 30 y 36. Estas tumbas se sitúan cronológicamente entre 375-350 antes de Cristo, excepto el ejemplar de la tumba 4 con datación amplia desde 425 a 350.

Regatones con esta peculiaridad de acabado la hemos constatado en piezas de Coimbra del Barranco Ancho (GARCÍA CANO, 1997: 211).

Por último mencionar otro elemento de ayuda al buen ajuste de la lanza. La presencia de un anillo de presión o refuerzo junto a la embocadura del regatón, documentado en dos ejemplares n. ${ }^{\circ}$ CB-136, figura 5-3 (T. 7) y CB-329, figura 16-4 (T. 24). concluir que en tres casos se ha estudiado el orificio de sujeción, para insertar un clavito en el astil de la lanza regatones de los ajuares $7,10,14$ y 30 .

Un item. mostraba orificio de sujeción y anillo de presión n. ${ }^{\circ}$ CB-136 (T. 7). Incineración datada globalmente c.425-375 antes de Nuestra Era. Otro ejemplo combinaba orificio de sujeción y alma de bronce n. ${ }^{\circ}$ CB-391, figura 23-7 (T. 30) fechada entre 375-350 antes de Cristo.

Por tanto se ha visto que las asociaciones para el mejor ajuste de las lanzas a los regatones son muy variados y que en determinadas ocasiones combinan distintos elementos desde la propia construcción del regatón más o menos hueco, hasta la introducción de una laminita de bronce o cobre que termine de apretar y embutir ambos elementos, a veces se añade un orificio para un pasador que concluya la tarea de acomodar regatón y lanza.

\section{DIMENSIONES DE LOS REGATONES EN CENTÍMETROS}

\begin{tabular}{|c|c|c|c|c|c|}
\hline $\mathbf{N}^{0} /$ TUMBA & LONGITUD & $\begin{array}{c}\text { DIÁMETRO } \\
\text { EMBOCADURA }\end{array}$ & TIPO & OBSERVAC. & CRONOLOGÍA \\
\hline CB-94 / 4 & Lc.: 10.4 & 2.3 & 2 & Alma Bronce & $425-350$ \\
\hline CB-136 / 7 & Lc.: 14.1 & 1.7 & 3 & $\begin{array}{l}\text { Orificio Sujeción / } \\
\text { Anillo Presión }\end{array}$ & $425-375$ \\
\hline CB-137 / 7 & Lc.: 4 & - & - & - & $425-375$ \\
\hline CB-176/10 & Lc.: 10.6 & 2.2 & 2 & Orificio Sujeción & $400-350$ \\
\hline CB-176bis /10 & Lc.: 7.7 & - & - & - & $400-350$ \\
\hline CB-216/ 14 & Lc.: 58 & 2 & $3 ?$ & Orificio Sujeción & $425-400$ \\
\hline CB-328 / 24 & Lc.: 8.3 & 1.8 & 1 & Alma Bronce & $375-350$ \\
\hline CB-329 / 24 & Lc.: 11.2 & 2 & $3 ?$ & Anillo Presión & $375-350$ \\
\hline CB-344 / 26 & 9.7 & 2.1 & 1 & - & $425-350$ \\
\hline CB-367 / 29 & Lc.: 4.6 & 2.1 & 1 & Alma Bronce & $375-350$ \\
\hline CB-368 / 29 & 11.4 & 2.1 & 2 & Alma Bronce & $375-350$ \\
\hline CB-391 / 30 & Lc.: 2.6 & - & - & $\begin{array}{c}\text { Orificio Sujeción / } \\
\text { Alma Bronce }\end{array}$ & $375-350$ \\
\hline CB-445 / 36 & 8.4 & 2.5 & 1 & Alma Bronce & $375-350$ \\
\hline CB-484 / 42 & Lc.: 6.1 & 1.8 & - & - & $425-400$ \\
\hline
\end{tabular}




\section{IV.1.4. Soliferrea}

Se han rescatado restos de nueve soliferrea en ocho ajuares funerarios lo que representa el $57.1 \%$ de las sepulturas con armamento y el $19 \%$ del conjunto de incineraciones estudiadas en la necrópolis. También se han recuperado fragmentos de cuatro soliferrea en la estratigrafía del yacimiento fuera de contexto funerario. En total son un $18.5 \%$ de la panoplia, que referido a items. hallados en ajuares llega al $15.2 \%$.

En todos los casos se asocian con otras armas en los ajuares, y en una ocasión tumba 30, aunque los items. están muy poco presentes, había dos soliferrea juntos, ajuar que sin embargo, no aportaba más lanzas. Las restantes siete tumbas con soliferrea contenían al menos otras lanzas con astil y punta de buen tamaño de lucha empuñada.

El soliferreum es un arma altamente especializada típica de la panoplia ibérica. Solamente un item. se ha transmitido completo con una longitud de 205 centímetros superior a la media de los soliferrea peninsulares establecida por F. Quesada en $193.5 \mathrm{~cm}$. (QUESADA, 1997(I): 310). Este tamaño aproxima a nuestra arma a la banda de soliferrea de mayor formato (Véase, QUESADA, 1997(I), figura 178). Longitud muy similar al único soliferreum conservado completo de las necrópolis de Coimbra (Jumilla), hallado en la tumba 48 de la necrópolis del Poblado, con 202.5 centímetros, datado a comienzos del tercer cuarto del siglo IV antes de Cristo (GARCÍA CANO, 1997: 212), mientras que en otras grandes necrópolis del área de Murcia la oscilación es considerable, así en Cabecico del Tesoro el único item. completo alcanza $190 \mathrm{~cm}$. (T. 183) (QUESADA, 1989(II): 236-238) mientras que en Cigarralejo el soliferrea mayor llega a $215 \mathrm{~cm}$. (T. 217) (CUADRADO, 1987: 399-401, figura 171).

Las tres puntas de soliferrea que se han conservado intactas, presentan pequeñas aletas o mesas y nervio central circular (T. 4 y 30, n. $^{\circ}$ CB-383) y rectangular (T. 7) que se relacionan con el tipo $2 \mathrm{~b}$ de Quesada, ya que en ambos casos el inicio de las mesas de la punta son convexas con referencia al astil de hierro confiriendo a ésta un aspecto un tanto losángico (1997(I): 311-312, figura 179). Tambien se ha inventariado el arranque de otras dos puntas de los ajuares $30,{ }^{\circ}{ }^{\circ} \mathrm{CB}-384$ y 34.

De ellas y debido a su deterioro solo la primera, puede clasificarse ya que ha quedado el arranque de las aletas de la punta que parten completamente perpendiculares al eje del astil metálico, pudiéndose adscribir al tipo 2a de F. Quesada (1997(I): 311-312, figura 179).

DIMENSIONES DE LOS SOLIFERREA EN CENTIMETROS

\begin{tabular}{|l|c|c|c|c|}
\hline No / TUMBA & LONGITUD & PUNTA & $\begin{array}{c}\text { SECCIÓN PUNTA } \\
\text { TIPO QUESADA }\end{array}$ & CRONOLOGÍA \\
\hline CB-46 / 1 & Lc.: 51 & - & - & $375-350$ \\
\hline CB-98 / 4 & Lc.: 142 & 8.4 & Circular con aletas / 2b & $425-350$ \\
\hline CB-139 / 7 & 205 & 8 & Rectangular con aletas / 2b & $425-375$ \\
\hline CB-326 / 24 & Lc.: 136.8 & - & - & $375-350$ \\
\hline CB-364 / 29 & Lc.: 154.1 & - & - & $375-350$ \\
\hline CB-383 / 30 & Lc.: 12.7 & 9.3 & Rectangular con aletas / 2b & $375-350$ \\
\hline CB-384 / 30 & Lc.: 5.8 & Lc.: 3 & Rectangular con aletas / 2a & $375-350$ \\
\hline CB-419 / 34 & Lc.: 145.7 & Lc: 5 & Rectangular con aletas ? & $425-350$ \\
\hline CB-485 / 42 & Lc.: 5.5 & - & - & $425-350$ \\
\hline
\end{tabular}


Las longitudes de las tres puntas completas fluctúan entre 8 y 9.3 centímetros, siendo su media aritmética $8.5 \mathrm{~cm}$. vecina de la media general de los soliferrea ibéricos 8.4 centímetros, de hecho uno de los items. de Fortuna (T. 4) tiene exactamente $8.4 \mathrm{~cm}$. n. ${ }^{\circ}$ CB-98, figura 4-1).

Los diámetros varían en función del lugar donde se examine la pieza, pero hacia las partes centrales del arma tienen entre $1.9 \mathrm{~cm}$. del CB-46 (T. 1) y $1.3 \mathrm{~cm}$. del CB-419 (T. 34).

Los soliferrea de Castillejo se han encontrado tanto en tumbas antiguas como la 4,7 o 42 (c.425-375) hasta sepulturas del segundo cuarto del siglo IV como los items. de las tumbas 24 , 29 y 30 .

\section{IV.1.5. Cuchillos}

Disponemos de dos cuchillos afalcatados de las tumbas 7 y 10 y un trocito de los niveles fértiles de la necrópolis. Globalmente son el $4.2 \%$ de la panoplia del yacimiento y el $3.2 \%$ del armamento localizado en ajuares funerarios, volumen similar al estudiado en la necrópolis del Poblado (Coimbra, Jumilla) donde los cuchillos representan el 3\% de la panoplia (GARCÍA CANO, 1997:213).

En los dos casos de piezas recuperadas de ajuares, estos mostraban una espléndida panoplia. El número CB-174, figura 9-5 (T. 10) acompañaba a una falcata, mientras que el item. CB-135 (T. 7) se relacionaba con una magnífica espada de frontón. Tienen una longitud de hoja de 11 (T. 7) y 9 (T. 10) centímetros. El n. ${ }^{\circ} \mathrm{CB}-174$ ha conservado un remache de sujeción de las cachas a la empuñadura.

Los dos ajuares cubren la evolución cronológica del cementerio entre c.425 y 350 antes de Jesucristo.

\section{IV.2. ARMAS DEFENSIVAS ACTIVAS}

\section{IV.2.1. El Escudo circular ibérico: La Caetra}

Está compuesto por un cuerpo principal lígneo de material sólido orgánico, forrado de cuero o fieltro. Generalmente de forma circular que oscila entre los 25/30 centímetros y los 70/75 para los ejemplares mayores. La sujeción de esta rodela se hace mediante una manilla de hierro, formada normalmente por el asidero y dos aletas de tendencia triangular más o menos desarrolladas y complejas en función del modelo. Estas aletas son las que realizan físicamente el trabajo de engarce con la rodela mediante una serie de clavos también de hierro con cabezas redondeadas con un grosor en torno a dos centímetros, lo que nos proporciona la anchura del cuerpo orgánico del escudo. El número de estos clavos varía según la tipología de las manillas pero fluctúan entre 4 y 6 . Las aletas son las que fijan igualmente el telamón para llevar colgado el escudo en bandolera durante los momentos de transporte.

Por lo que respecta al peso, los estudios de F. Quesada hechos con paralelos de otras culturas del mundo antiguo con armas parecidas, ponen de manifiesto que ejemplares de diámetro en torno a $65 \mathrm{~cm}$. incluyendo el umbo de metal, o no, y la manilla metálica estaría sobre 5 kilogramos, pudiendo alcanzar los grandes escudos de $90 \mathrm{~cm}$. los 6-7 kilogramos (QUESADA, 1997(II): 491-493).

Se han acreditado siete manillas en ajuares funerarios $11.8 \%$ del armamento de conjuntos cerrados y un item. localizado en las tierras revueltas de la necrópolis producto de las remociones del tractor, con lo que en total las manillas de escudo evidencian el $11.4 \%$ de la panoplia ibérica de Fortuna. Todas están bastante incompletas y deterioradas.

Los seis items. se han catalogado en otros tantas sepulturas, siempre relacionadas con más armas. 


\section{IV.2.1.1. Dimensiones}

\section{IV.2.1.1.1. Longitud}

De los siete items., únicamente cuatro proporcionan datos morfométricos. Así, tres manillas han podido reconstruirse con un tamaño de 25.1, 25 y 25.2 centímetros de las tumbas 24 , 29 y 34 respectivamente. Por tanto la media aritmética de nuestras caetrae queda en 25.1 centímetros.

En los tres casos la morfología de las manillas es similar. Pequeño formato, aletas inferiores al asidero, cuyo grosor de la chapa metálica está en torno a tres milímetros. Presentan suplementos laterales y apéndices extremos. Corresponderían al tipo 9b de Cuadrado (1989: 105, figura 50) y al Grupo II, variante IIA2b de Quesada (1997(II):502, figura 290).

La cuarta manilla que aporta datos métricos está muy fragmentada, sólo conserva reconstruible el LIE, n. ${ }^{\circ} \mathrm{CB}-41$, figura 1-3 de la tumba 1. Su propio carácter nos impide adscribirla a ningún tipo, pero creemos que su amplio asidero, unido al desarrollo de la parte de la aleta recuperada, cuya forma triangular parece evidente, podría integrarla en el Grupo III, subtipo A1 o A2 del Dr. Quesada «Empuñaduras con aletas triangulares desarrolladas (1997(II): 502, figura 290). Cronológicamente se fecharía en el segundo cuarto del siglo IV antes de Jesucristo. Dos pequeños trozos son prácticamente testimoniales hallados en las tumbas 30 y 36.

La séptima manilla está representada por el roblón de cabeza hemiesférica hallada en el ajuar de la tumba 12, n. $^{\circ}$ CB-206, figura 11-13 que nos sitúa de manera genérica c.425-375 antes de Nuestra Era. Formaría parte de una manilla de madera con remaches metálicos de la sujeción del telamón para llevar el escudo colgado al hombro o en bandolera. Pertenece al Grupo O de Quesada (1997(II): 499, figura 290).

Aunque sea una serie reducida de manillas de un yacimiento con una expansión temporal muy concreta c.440-360/350, del análisis de los escudos podemos vislumbrar a nivel de hipótesis la carencia de items. en el periodo más antiguo o estos eran del Grupo 0, es decir, manillas lígneas. Aquí inventariaríamos el ejemplar de la sepultura 12. Conforme se avanza en el tiempo, se puede ajustar la datación hacia finales del siglo $\mathrm{V}$ aparecerían los modelos del Grupo IIA pero todavía de formato pequeño. Efectivamente nuestros items. son menores en relación a las dimensiones medias del subtipo enunciadas por Fernando Quesada, con una oscilación de $15 \mathrm{~cm}$., entre 20.5 y 35.5 centímetros y valor medio en $27.8 \mathrm{~cm}$. (QUESADA, 1997(II): 502).

Este dato es importante ya que se trata de pequeños escudos, evolución del tipo I de Quesada y también de Cuadrado, es decir, empuñadura metálica simple sin aletas, tipo no localizado en Castillejo de los Baños.

A nivel cronológico insistir como este tipo está presente en la necrópolis de la Senda en Coimbra con dos items. n. ${ }^{\circ}$ S-627 (T. 43S) y S-633 (T. 44S) con idéntica cronología y dimensiones muy cercanas, 25.4 y 30 centímetros, a nuestras manillas (GARCíA CANO, 1997: 216, figura 24S-6 y 30S-1. Para las piezas en concreto GARCÍA CANO, 1999a:19-20 (T. 44S) y 23-24 (T. 43S).

Es por tanto un modelo de caetra que pudiéramos definir como antiguo aunque inserto en el periodo cultural ibérico pleno. La datación de los items. de Castillejo se centra básicamente entre 375-350 (T. 24 y 29) con una posible extensión al tránsito de centuria o primeras décadas del siglo IV anterior a Nuestra Era (T. 34, figura 25-2).

Para concluir referirnos al ejemplar de la tumba $1, n .^{\circ} \mathrm{CB}-41$, figura 1-3 que aunque incompleto a modo de hipótesis podemos asignar al subtipo IIIA y pensar en su introducción como modelo de mayor porte en estas mismas fechas c.375-350, ya en la banda de uso final de la estación. 


\section{IV.2.1.1.2. El Asidero}

Es probablemente el elemento fundamental de la manilla, ya que es la parte con la que el guerrero ibérico empuñaba el arma. Siguiendo a Fernando Quesada, hemos llamado la zona de su sujeción: Longitud Interior Empuñadura (LIE) (QUESADA, 1989(II):10). Este parámetro se ha estudiado materialmente en los tres ejemplares más o menos completos o reconstruibles que ha proporcionado Castillejo, n. ${ }^{\circ}$ CB-331 (T. 24), CB-371 (T. 29) y CB-424 (T. 34). El LIE de estas piezas es $9.7,9.8$ y $9.8 \mathrm{~cm}$. Media por tanto en 9.76 centímetros. Son longitudes muy homogéneas típicas del subtipo de escudo. En los items. de este tipo hallados en la necrópolis de la Senda en Jumilla el LIE era de 9.5 y $10.2 \mathrm{~cm}$. con un tamaño medio de $9.85 \mathrm{~cm}$., quedando el conjunto de Coimbra en 10.1 (GARCÍA CANO, 1997: 214-216).

Una cuarta manilla n. ${ }^{\circ}$ CB-41 /T. 1) tiene de LIE reconstruido 13.5 centímetros, como de las aletas solamente se conserva la parte anterior de una de ellas no es posible su reconstrucción pero nos da la impresión de que corresponde a un tipo más grande de caetra.

Los asideros están confeccionados en los cinco casos estudiados mediante una lámina de hierro enrollada sobre si misma dejando el interior hueco. El diámetro es homogéneo y recorre apenas dos milímetros entre $1.9 \mathrm{~cm}$. (T. 29 y 34) y $2.1 \mathrm{~cm}$. (T. 24). La media queda en 1.98, es decir, dos centímetros.

\section{IV.2.1.1.3. Las Aletas}

Se han conservado reconstruibles en los tres ejemplares que venimos analizando de las sepulturas 24, 29 y 34. Del estudio pormenorizado de ellas y del item. de la tumba 1, hemos constatado que la chapa metálica tenía un grosor de aproximadamente 0.3 centímetros. Desde luego las piezas CB-41, CB-331 y CB-371 de los ajuares 1, 24 y 29 tienen grosor de tres milímetros y el CB-424 de la incineración $342.5 \mathrm{~mm}$. Encontramos por tanto, un guarismo medio exactamente de 0.2875 centímetros. A este parámetro hay que añadir la anchura de la rodela de madera, cuero y fieltro etc. Los clavos conservados de las manillas de las tumbas 24 , figura $15-3$ y 34 , figura $25-2$ ofrecen grosores de 1.8 y 1.1 centímetros cada uno, lo que daría como resultado final un espesor para los escudos de 2.1 y $1.35 \mathrm{~cm}$.

DIMENSIONES DE LAS MANILLAS DE ESCUDO EN CENTÍMETROS

\begin{tabular}{|l|c|c|c|c|c|c|c|}
\hline $\mathbf{N}^{\circ}$ Tumba & Longitud & $\begin{array}{c}\text { L. } \\
\text { aleta }\end{array}$ & $\begin{array}{c}\text { Asidero } \\
\text { LIE }\end{array}$ & $\begin{array}{c}\text { Diámetro } \\
\text { Asidero }\end{array}$ & $\begin{array}{c}\text { Grosor } \\
\text { Aleta }\end{array}$ & $\begin{array}{c}\text { Tipo } \\
\text { Quesada }\end{array}$ & Cronología \\
\hline CB- 41 / 1 & Lc.: 18.5 & - & Lr.: 13.5 & 2 & 0.3 & IIIA ? & $375-350$ \\
\hline CB- 206 / 12 & $\begin{array}{c}\text { Roblón cabeza } \\
\text { hemiesferica: } 3\end{array}$ & - & - & - & - & 0 & $425-375$ \\
\hline CB- 331 / 24 & 25.1 & 7.7 & 9.7 & 2.1 & 0.3 & IIA 2b & $375-350$ \\
\hline CB- 371 / 29 & $\begin{array}{c}\text { Lc.: } 13.5 \\
\text { Lr.: 25 }\end{array}$ & 7.6 & 9.8 & 1.9 & 0.3 & IIA 2b & $375-350$ \\
\hline CB- 388 / 30 & Lc.: 4.8 & - & Lc.: 4.8 & 2 & - & - & $375-350$ \\
\hline CB- 424 / 34 & Lc.: 25.2 & 7.7 & 9.8 & 1.9 & 0.25 & IIA 2b & $425-375$ \\
\hline CB- 447 / 36 & Lc.: 2.5 & - & - & - & - & - & $375-350$ \\
\hline
\end{tabular}


Quesada propone unos grosores para caetrae del siglo IV de 1.8 a 2 centímetros como máximo y en casos excepcionales. Es decir, tendríamos como espesores medios de la madera en el centro del arma en torno a $1 / 1.5 \mathrm{~cm}$., adelgazando hasta el borde hasta $0.8 / 1 \mathrm{~cm}$., a lo que se sumaría una capa de cuero o fieltro de lana de 0.5 centímetros. (QUESADA, 1997(II): 492).

\section{IV.2.2. Elementos del jinete}

\section{IV.2.2.1. Espuelas}

Señalar la recuperación de dos aguijones de hierro hallados entre el ajuar de la tumba 1, n. ${ }^{\circ}$ CB-33 y 34 , figura $1-5$ y 6 . Su longitud es de 2.2 y 1.8 centímetros. Al no haberse conservado las placas de sujeción no podemos incluirlas en ninguno de los tipos propugnados por Cuadrado (1979) o Pérez Mínguez (1992). Para la presencia de espuelas en las necrópolis del área de la Región de Murcia (GARCíA CANO, 1997: 219-220).

Nuestros items. se fechan entre 375-350 antes de Jesucristo.

\section{IV.3. ASOCIACIONES DE ARMAS}

\section{IV.3.1. Asociaciones en los Ajuares}

Hemos catalogado catorce ajuares con panoplia que representan el $32.5 \%$ de las tumbas exhumadas en Castillejo. Han aparecido seis tipos de armas: Falcatas, espada de frontón, soliferrea, puntas de lanza con sus regatones, escudos y cuchillos afalcatados.

Estas seis variables serán las analizadas para determinar la composición de la panoplia ibérica de Fortuna. En las catorce tumbas se han registrado doce combinaciones diferentes, al margen del número de items. idénticos que posea cada ajuar. La riqueza de asociaciones, si bien el número de incineraciones no es muy abundante, es grande ya que asciende al $85.7 \%$, guarismo elevado si lo comparamos por ejemplo con las necrópolis de Coimbra donde hay 47/23 (48.9\%) o Cabecico del Tesoro por citar una necrópolis con gran volumen de incineraciones con armas 125/32 (25.6\%) (GARCÍA CANO, 1997: 220-221). Sin duda en Castillejo se ha podido probar que un número elevado de diferentes tipos de armas se combinan ampliamente en pocas tumbas, lo que nos ofrece una mayor riqueza y variedad formal a la hora de intentar determinar la panoplia tipo de los pretéritos habitantes de Fortuna.

Por tanto al describir las composiciones de la panoplia de Castillejo ninguna resulta mayoritaria y esto es quizás una manifestación palpable del concepto de guerrero como soldado libre capaz de comprar su propio armamento.

Efectivamente las asociaciones más comunes son las que cuentan con varias armas concretamente falcata+soliferreum+lanza con o sin regatón y escudo. Este modelo aparece en el $24.4 \%$ de los enterramientos con armas, tumbas 24 y 29 - lanzas con regatón - y 1 y 34 - lanzas sin regatón - que probablemente no se han conservado. En esta misma línea añadir el ajuar de la incineración 36 que reemplaza el soliferreum, lanza arrojadiza, por un segundo ejemplar de lanza para emplear una empuñada y la segunda arrojadiza. Estaríamos por tanto en un idéntico modelo de panoplia que supone el $31.5 \%$ del armamento de Fortuna. Con el mismo argumento se podrían contemplar las armas de la tumba 7, la más rica e importante de la necrópolis, que cuenta con soliferreum+dos lanzas con regatón+cuchillo afalcatado y sustituye la falcata por una excelente espada de frontón $7.1 \%$. En este caso faltaría el escudo como arma defensiva principal, aunque muestra un extraordinario poder ofensivo y de prestigio con dos lanzas y soliferreum. 
Un segundo bloque lo forman una serie de ajuares con la combinación de tres items. ceñidos a cuatro tumbas que llegan al $28.4 \%$ de las ramas: Todos poseen falcata como arma principal empuñada pero alternan con soliferreum+lanza con regatón (T. 4); dos soliferrea+escudo y un regatón (T. 30); soliferreum+dos lanzas una de ellas con regatón (T. 42); y lanza+dos regatones sin puntas de lanza y cuchillo afalcatado (T. 10).

En el caso de los regatones sin lanza, situación relativamente frecuente en los ajuares funerarios ibéricos (GARCÍA CANO, 1997: 222). Puede deberse a varias razones, que no se haya transmitido la pertinente punta de lanza por algún motivo que se nos escapa a los arqueólogos del siglo XX. Fernando Quesada ha defendido que se haya mal interpretado la función de estos items, y que no se trate de regatones sino de puntas toscas y simples, una forma de fabricar una especie de chuzo sin complicaciones (QUESADA, 1989(II): 43-45). Para Castillejo hay que descartar esta hipótesis porque la tipología de los regatones que participan de esta situación no difieren morfológica ni tipológicamente de los que van acompañados por puntas de lanza.

Otra alternativa propuesta por F. Quesada es que por alguna razón regatones o puntas, en ciertos casos, no se enterraran con el cadáver. El por qué puede ser desde el simple descuido al recoger el ajuar en la pira o bien que, las lanzas se hincaran sobre las sepulturas tal y como menciona Aristóteles en la política (V-2,5), en esta coyuntura uno de los extremos de la lanza quedaría protegido pero la parte al descubierto acabaría por perderse en el transcurso del tiempo ${ }^{7}$.

Una postrera opción que explicaría estas extrañas asociaciones podría ser un motivo más simple, que los regatones hubieran perdido la lanza al quebrarse el astil en combate - muerte de un enemigo, retirada precipitada conservándose lo que se puede o atribuirlo a algún tipo de pérdida accidental sin tiempo o ganas a posteriori por sustituir la pérdida antes de efectuarse la deposición.

Conjuntos de dos armas tenemos un caso procedente de la tumba 28 con lanza (jabalina)+falcata y un segundo ejemplo en el que se mezcla arma ofensiva una lanza empuñada y un escudo (T. 12). Finalmente señalar dos asociaciones en las que el guerrero ibérico disponía de una única arma: T. 26 lanza con regatón y tumba 14 falcata y un regatón al que podemos aplicar las reflexiones expuestas líneas arriba.

Las doce asociaciones contemplan armas ofensivas. En el $63.9 \%$ de las misceláneas, nueve casos, hay presencia de tres y cuatro armas ofensivas. Siempre aparece la falcata/espada de frontón y dos o tres lanzas/soliferrea. En efecto, en cinco casos constatamos una lanza y un soliferreum (Tumbas 1, 4, 24, 29 y 34); en dos items. hay dos lanzas (T. 36) o dos soliferrea (T. 30). En los dos ejemplos con cuatro armas encontramos un soliferreum y dos lanzas (T. 7 y 42 ).

Las armas defensivas están muy poco representadas en la necrópolis no disponemos de grebas, cascos, discos coraza etc. Quizás porque todos o parte de estos caros elementos metálicos fueran sustituidos por piezas y adornos fabricados con materiales orgánicos. Unicamente se han documentado restos de siete escudos tipo caetra en los ajuares, que suman el $11.8 \%$ de la panoplia de contexto funerario. Siempre aparecen acompañando a otras armas y en todos los casos hay un ejemplar por tumba. Proceden generalmente de ajuares con panoplia rica y completa tumbas 24, 29, 36, 30, 1 y 34. Señalar sólo una excepción a esta aseveración el ajuar de la tumba 7, que tiene probablemente el armamento más suntuoso del cementerio con siete items.

La séptima manilla fue encontrada en la tumba 12 que además del escudo contenía una lanza sin regatón.

7 En la necrópolis del Poblado de Coimbra se ha documentado un caso adscribible a esta teoría en la campaña del año 2000. Se trata de una punta de lanza colocada prácticamente vertical en la cabecera norte de la tumba 121 sobresaliendo por encima de la capa de barro amasado y piedras que constituían la cubierta del enterramiento. 
En definitiva se puede barruntar que las deposiciones con gran cantidad (6 o 7) y variedad de armas, hasta cinco tipos, son los ajuares en general más ricos del asentamiento, tumbas 7 o $29^{8}$.

Finalmente se ha puesto de manifiesto que existe una panoplia pseudoestandar, aunque con variantes individuales, entre los guerreros ibéricos del campo de Fortuna donde se ha precisado que el modelo de guerra requería fundamentalmente dos o más lanzas, una arrojadiza generalmente soliferrea, completándose el ajuar con un escudo tipo caetra y falcata que en un ejemplo se sustituye por un gran puñal/espada de frontón. Aunque una pequeña cantidad de hombres sólo poseían una o dos armas, bien falcata (T. 14), lanza (T. 26) o lanza y escudo (T. 12)

Con variantes en el número de lanzas ésta suele ser la panoplia modelo señalada por el profesor Quesada para las tierras ibéricas de la Península Ibérica especialmente desde comienzos del siglo IV anterior a Jesucristo (QUESADA, 1997(II): 614, figura 350).

Por tanto la panoplia que definimos como antigua para el caso de Murcia, presenta significativas diferencias con otras necrópolis del área como Coimbra del Barranco Ancho donde lo más frecuente es el guerrero que va al combate armado con una asociación de tres items., un arma menos que en Castillejo, falcata+lanza/soliferreum +escudo que representa el $27.3 \%$ de la panoplia. Teniendo igualmente una significativa presencia 6 items./12.7\% de los soldados estudiados que sólo disponían de falcata (GARCÍA CANO, 1997: 221). Caso que no ocurre en Fortuna, pero que si enlaza con la generalidad de la costumbre en la sociedad ibérica. Exactamente, F. Quesada ha trabajado con 700 ajuares funerarios localizando 82 casos $(11.7 \%)$ en donde la falcata era la única arma depositada, hay que tener en cuenta el valor no sólo funcional sino simbólico y de prestigio que este sable representaba para los iberos(QUESADA, 1997(II): 644).

Sin embargo si examinamos los ajuares de las necrópolis de Coimbra durante el siglo IV antes de Cristo, para tener una coincidencia temporal con Fortuna, observamos que de las seis panoplias más prósperas, todas con cuatro armas, cinco se datan entre el 375-300 antes de Cristo, tumbas 22, 39, 31, 41 y 42. Solamente la sepultura 55 posee este número de items. y tiene una cronología tardía (GARCÍA CANO, 1997: 221. Para la tumba 55, véase GARCÍA CANO, 1999b: 170-174).

\section{ASOCIACIONES DE ARMAS NECRÓPOLIS DEL CASTILLEJO DE LOS BAÑOS (FORTUNA)}

$\begin{array}{lrl}\text { FALCATA+SOLIF.+LANZA+REGATONES(2)+MANILLLA } & 14.2 \% & \text { T. } 24,29 \\ \text { ESP.FRONTON+SOLIF.+LANZAS(2)+REGATONES(2)+CUCH.AF. } & 7.1 \% & \text { T. } 7 \\ \text { FALCATA+LANZA(2)+REGATON+MANILLAS } & 7.1 \% & \text { T. } 36 \\ \text { FALCATA+SOLIF.+LANZA+MANILLA } & 14.2 \% & \text { T. } 1,34 \\ \text { FALCATA+SOLIF.+LANZA+REGATON } & 7.1 \% & \text { T. } 4 \\ \text { FALCATA+SOLIF.+LANZAS(2)+REGATON } & 7.1 \% & \text { T. } 42 \\ \text { FALCATA+SOLIF.(2)+REGATON+MANILLA } & 7.1 \% & \text { T. } 30 \\ \text { FALCATA+LANZA+REGATONES(2)+CUCHILLO AFALCATADO } & 7.1 \% & \text { T. } 10 \\ \text { FALCATA+LANZA(JABALINA) } & 7.1 \% & \text { T. } 28 \\ \text { FALCATA+REGATON } & 7.1 \% & \text { T. } 14 \\ \text { LANZA+REGATON } & 7.1 \% & \text { T. } 26 \\ \text { LANZA+MANILLA } & 7.1 \% & \text { T. } 12\end{array}$

8 Para los índices de riqueza véase GARCía CANO y PAGE DEL POZO 2001 e.p. Las tumbas más ricas de la necrópolis son junto a las citadas con armas la $\mathrm{n}^{\circ} 22$ con gran cantidad de cerámicas griegas y la $\mathrm{n}^{\circ} 2$ con presencia entre otros objetos de una rueda de carro. 


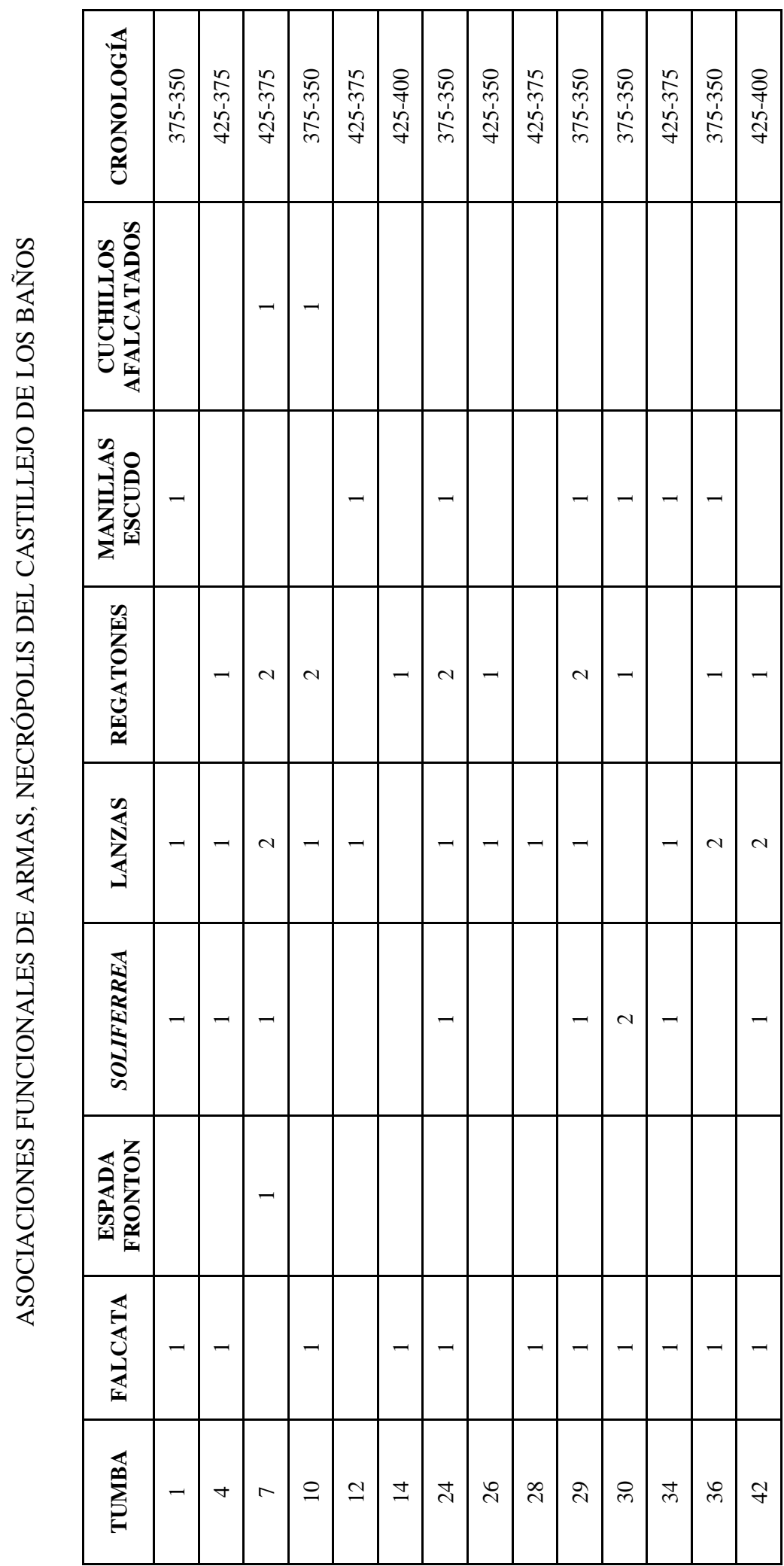


IV.3.2. Asociaciones funcionales

IV.3.2.1. Espadas

Los doce ejemplares, once falcatas y una espada de frontón, localizadas en ajuares funerarios de Castillejo lo han sido en doce sepulturas, correspondiendo por tanto en un $100 \%$ de los casos a un item. por incineración. La necrópolis de Fortuna no participa de la singularidad de estaciones como Coimbra (T. 9S y 40), Cigarralejo (T. 45 y 277) o Cabecico del Tesoro(T. 20 y 260) donde en determinados casos, generalmente ajuares suntuosos, poseen dos espadas (GARCÍA CANO, 1997: 222-223). Es más en el ajuar que tiene una completa y prestigiosa panoplia, tumba 7, se sustituye la falcata por una excelente espada de frontón.

\section{IV.3.2.2. Puntas de Lanza}

Nos encontramos con quince itms. Distribuidos en doce ajuares, $85.7 \%$ de las tumbas con armas. Es el modelo de arma más utilizado por los iberos de Fortuna. En tres casos están presentes dos lanzas empuñadas en un mismo ajuar en las deposiciones 7, 36 y 42 . El hecho de contener dos lanzas supone el $25 \%$ de las tumbas de Castillejo con armamento, cifra muy superior a la que ofrecen otras necrópolis del sureste como Coimbra 13\% (GARCÍA CANO, 1997: 223) o Cabecico del Tesoro 19.1\% (QUESADA, 1989(II): 37-38), pero que no alcanza ni de lejos el volumen de Cigarralejo con un 62.5\% (Datos elaborados a partir de CUADRADO, 1989: 68-69).

Las tumbas 7 y 42 contenían también un soliferreum con lo que el número de lanzas entre arrojadizas y empuñadas asciende a tres. En otros cinco casos, tumbas 1, 4, 24, 29 y 34, se produce la combinación lanza+soliferrea.

\section{IV.3.2.3. Lanzas Arrojadizas}

Se han registrado nueve soliferrea en ocho sepulturas a razón de uno por incineración, excepto la n. ${ }^{\circ} 30$ con dos items., aunque muy deteriorados y perdidos. El soliferreum siempre aparece asociado a otras armas y en siete de las tumbas $87.5 \%$ se combina con lanzas empuñadas y en una sola ocasión poseemos un ajuar con soliferreum sin lanza empuñada. Efectivamente se trata de la tumba 30 donde las armas estaban muy fragmentadas, pero donde se localizó un regatón, $n .^{\circ} \mathrm{CB}-391$ que pudo pertenecer a una lanza no recogida, desaparecida, etc.

Solamente una muestra de jabalina $n .^{\circ} \mathrm{CB}-353$, figura 18-2 hallada en la tumba 28 . Este ajuar mostraba una panoplia simple y era acompañada por una falcata.

\section{IV.3.2.4. Puntas de Lanza y Regatones}

Es transcendental esta relación, ya que parecería lógico que las lanzas empuñadas llevaran su correspondiente regatón. Contamos con quince lanzas/jabalinas de doce ajuares y catorce regatones de diez sepulturas.

A simple vista se aprecia un déficit de regatones, al que hay que añadir la no coincidencia en ajuares del binomio lanza+regatón al cien por cien.

Existe correspondencia lanza-regatón en ocho ocasiones tumbas 4, 7, 10, 24, 26, 29, 36 y 42. No obstante únicamente es completa la ecuación una lanza un regatón en dos casos T. 4 y 26 y en otro caso dos lanzas dos regatones tumba 7. En las restantes combinaciones aunque haya correlación ésta es parcial, porque hay o más puntas de lanza tumbas 36 y 42 o se constatan más regatones $10,24,29$ y 30 . 
Lanzas a los que le falta el regatón tenemos en las sepulturas 1, 12, 28, 34, 36 y 42, mientras que regatones sin lanza los documentamos en los ajuares 10, 14, 24 y 29. En ambos casos, rondando el $50 \%$ de presencia/ausencia.

Este grado de disfunción es semejante al que se produce en Coimbra del Barranco Ancho con el 52.2\% y 50\% respectivamente (GARCíA CANO, 1997: 225). Porcentajes que se aproximan al general de la panoplia ibérica establecido sobre el 46\% (Datos elaborados a partir de QUESADA, 1997(II), figura 350).

\section{IV.3.2.5. Escudos}

El modelo utilizado en Fortuna es la caetra de pequeño formato en torno a los 25/30 centímetros de diámetro. Es poco abundante en los ajuares habiéndose reflejado en la composición de siete $50 \%$ de las tumbas con armamento. Siempre un item. por sepultura y en todos los casos combinados con otras armas de carácter ofensivo. Es la única arma defensiva localizada en Castillejo. Excepto el ajuar de la tumba 12, donde se asociaban lanza+manilla, los restantes escudos fueron recuperados de deposiciones con amplia panoplia con cuatro/cinco items. n. ${ }^{\circ} 1,24,29,30,34$ y 36.

\section{DITRIBUCION DE LOS TIPOS DE ARMAS EN LAS TUMBAS DE LA NECRÓPOLIS DEL CASTILLEJO DE LOS BAÑOS}

\begin{tabular}{|l|c|c|c|}
\hline \multicolumn{1}{|c|}{ ARMA } & $\begin{array}{c}\text { FRECUENCIA } \\
\text { TUMBA }\end{array}$ & $\begin{array}{c}\text { PORCENTAJE } \\
\text { TUMBAS CON ARMAS }\end{array}$ & $\begin{array}{c}\text { PORCENTAJE SOBRE } \\
\text { TOTAL TUMBAS }\end{array}$ \\
\hline LANZA & 12 & $85.7 \%$ & $27.9 \%$ \\
\hline FALCATAS & 11 & $78.5 \%$ & $25.5 \%$ \\
\hline REGATONES & 10 & $71.4 \%$ & $23.2 \%$ \\
\hline SOLIFERREA & 8 & $57.1 \%$ & $18.6 \%$ \\
\hline MANILLA ESCUDO & 7 & $50 \%$ & $16.2 \%$ \\
\hline $\begin{array}{l}\text { CUCHILLOS } \\
\text { AFALCATADOS }\end{array}$ & 2 & $14.2 \%$ & $4.6 \%$ \\
\hline ESPADA FRONTON & 1 & $7.1 \%$ & $2.3 \%$ \\
\hline
\end{tabular}

\section{IV.3.2.6. Tipo de Guerra}

Los guerreros ibéricos de Castillejo de los Baños muestran una panoplia totalmente ofensiva, con apenas siete escudos sobre 59 armas en ajuares y 8/70 en el global del cementerio. Es decir, tanto atendiendo a un porcentaje como a otro $11.1 \% / 11.4 \%$ son prácticamente idénticos. No obstante, no podemos afirmar que el vuelco hacia una panoplia tan ofensiva sea definitivo porque pensamos que algunos cascos, discos coraza o grebas pudieron fabricarse con materiales orgánicos y por tanto no ha quedado reflejo de ellos con el transcurso del tiempo.

La lucha empleada responde al combate cuerpo a cuerpo con la lanza como eje principal completada por la falcata, principal elemento de prestigio pero igualmente aditamento perfecto de la lanza empuñada a la hora de luchar. La panoplia se remata con una lanza arrojadiza el soliferreum y en mucha menor porporción la jabalina, en algunos ajuares se han constatado dos puntas de lanza para empuñar tumbas 7, 36 y 42. En cualquier caso nos encontramos con la «panoplia típica o completa» de Fernando Quesada (1997(II): 650). 
Responde esta panoplia a un «ejercito» capaz de luchar en orden y cuerpo a cuerpo. En ciertas ocasiones podrían hacerlo fuera de formación. Posiblemente los hombres enterrados en Fortuna marcharían al combate agrupados en una misma unidad o clan, mandados por el aristócrata u oligarca de su pueblo, se trataría al fin y a la postre de los hombres libres de Fortuna capaces de pagar armas. Hombres que quizás no tendrían la formación militar de la falange hoplítica o de los manípulos romanos, como afirma el doctor Quesada (1997(II): 654), pero que sin duda compartían un ideal y una manera de actuar solidaria para la defensa de su forma de vida y habitat en tierras de Fortuna.

\section{IV.4. DISTRIBUCION DE LA PANOPLIA EN LAS TUMBAS}

\section{IV.4.1. Emplazamiento de las armas}

En Castillejo de los Baños es escasa porcentualmente la utilización de la urna cineraria en diez ocasiones $-23.2 \%$. Por esta razón el $76.8 \%$ de los ajuares junto con los restos óseos calcinados de los difuntos se depositaron directamente en las fosas construidas a tal efecto. Volumen muy próximo a lo acontecido en el conjunto de Coimbra del Barranco Ancho con un 78.7\% de los ajuares colocados directamente en los lóculos (GARCíA CANO, 1997: 225).

Además la necrópolis que nos ocupa, procede de una excavación de urgencia en donde la superficie del yacimiento fue arada, motivo causante de la intervención arqueológica de salvamento e investigación, pero también de la destrucción de algunas fosas lo que ha impedido el estudio completo in situ de varios de los ajuares.

De las cuatro incineraciones con urna y panoplia tumbas 10, 24, 34 y 36, 28.5\% de los enterramientos con armas, en ningún caso las panoplias se colocaron en el interior de la urna, que en todos los ejemplos era de cerámica ibérica.

Analizaremos brevemente los ejemplos en donde puede inferirse algún dato relevante:

- Ajuar tumba 4. Sin urna cineraria. Las armas se localizaron en la parte central de la fosa, a partir del rebanco de adobe paralelas al eje mayor del lóculo. El soliferreum estaba en dos grandes trozos doblados y encima de ellos se colocó la punta de lanza. La falcata quedaba un poco más hacia el noreste (fotografia 2)

- Ajuar tumba 7. Sin urna funeraria. Las armas se depositaron sin orden ni criterio fragmentadas y distribuidas por toda la fosa. La punta de la espada recta se halló orientada hacia el Sureste paralela a la cabecera del lóculo.

- Ajuar tumba 10. Urna cineraria en cerámica ibérica tosca de cocina a torno situada en el centro de la fosa boca abajo, n. ${ }^{\circ} \mathrm{CB}-167$, figura 8-6. La falcata, los regatones y el cuchillo afalcatado se hallaron en el centro del lóculo dispuestos en el sentido del eje mayor de la fosa. La punta de lanza se encontró en el lóbulo noreste del nicho en forma de lingote chipriota.

- Ajuar tumba 24. Urna cineraria en el centro del lóculo protegida por piedras. La orientación de la fosa es singular, ya que su eje longitudinal discurre de norte-sur en contraposición a los restantes enterramientos del cementerio que lo hacen este-oeste. La falcata depositada sobre el soliferreum doblado en $180^{\circ}$ junto a la urna en el centro de la fosa con la punta hacia el norte, debajo estaban el regatón y las manillas de escudo. La punta de lanza se depositó en el lóculo suroeste del nicho con la punta hacia el interior de la fosa (Fotografias 3 y 4 )

- Ajuar tumba 26. Sin urna cineraria. La lanza se colocó hacia el centro del lóculo en el sentido del eje principal de la fosa. 
- Ajuar de la tumba 28. Sin urna cineraria. El ajuar estaba disperso por el fondo de la fosa, únicamente la punta de lanza pudo documentarse junto a la cabecera este apuntando hacia el centro de la fosa.

- Ajuar tumba 29. Sin urna cineraria. La fosa rectangular con los ángulos redondeados, presentaba el soliferreum doblado en la cabecera este.

- Ajuar tumba 34. Sin urna cineraria. Armamento en la parte central del lóculo, muy fragmentado. Se pudo precisar la colocación de la manilla de escudo en el eje mayor de la fosa paralela al lado sur.

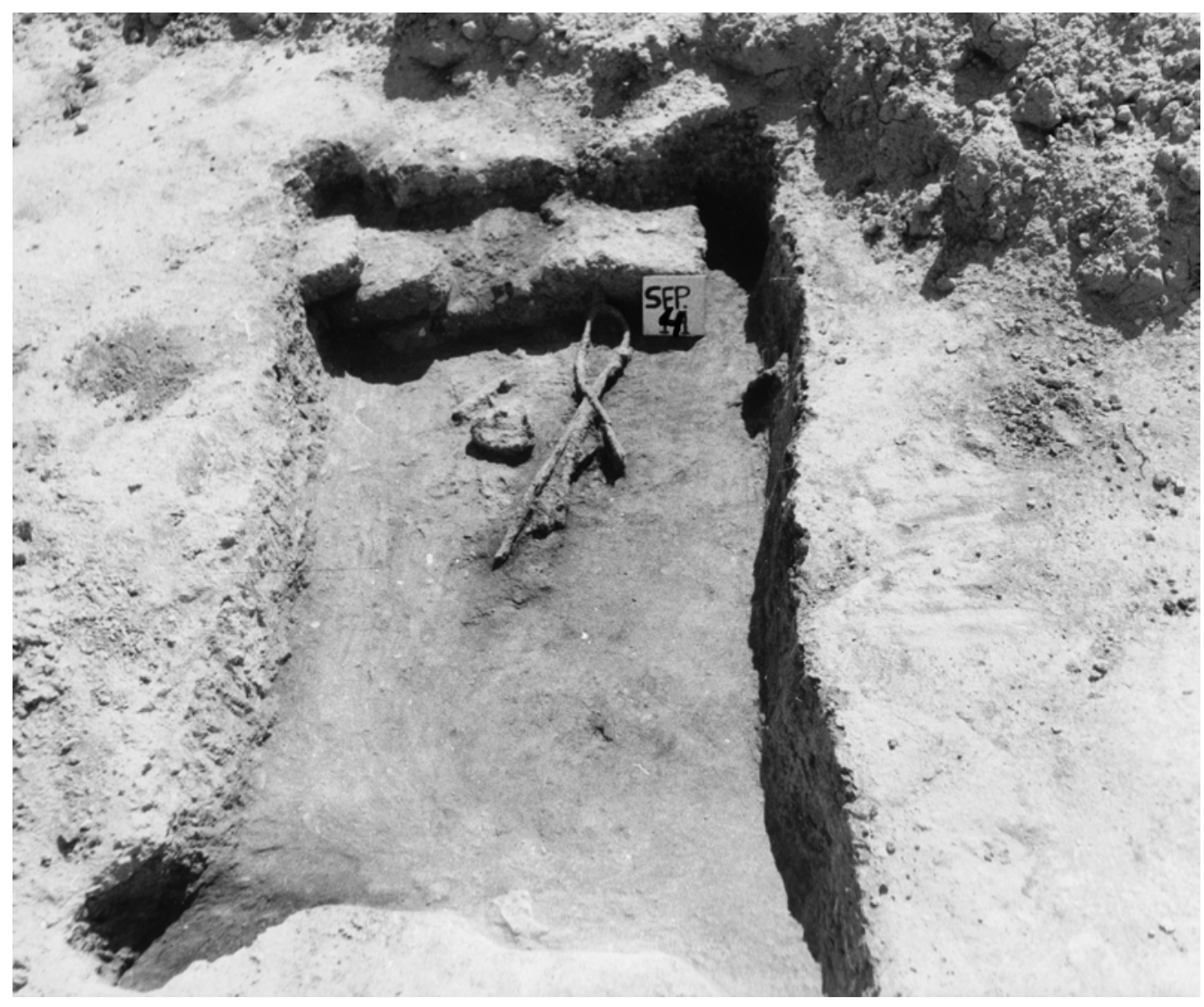

Foto 2. Fosa de la tumba 4 en curso de excavación. Se aprecia un rebanco de adobe en la cabecera y el armamento concretado en la parte central.

Pese a la escasez de ejemplos disponibles, parece vislumbrarse un ritual especial en la colocación de los ajuares en las fosas. Indudablemente, cuando la deposición emplea urna cineraria, 10 veces, esta se ubica hacia el centro del lóculo y en ciertos casos el resto de los objetos se colocan a su alrededor, tumba 24. Cuando no existe urna el armamento suele instalarse de la misma manera hacia la parte central de la fosa y en el sentido del eje mayor de la fosa, ejemplos de las tumbas 4, 10, 26 o 34.

Por último señalar la tendencia especial de determinadas puntas de lanza encontradas con la moharra hacia el centro de la fosa y el cubo hacia el exterior del nicho o en uno de los lóbulos si el enterramiento tiene forma de lingote chipriota tumbas 24 y 28 respectivamente. 


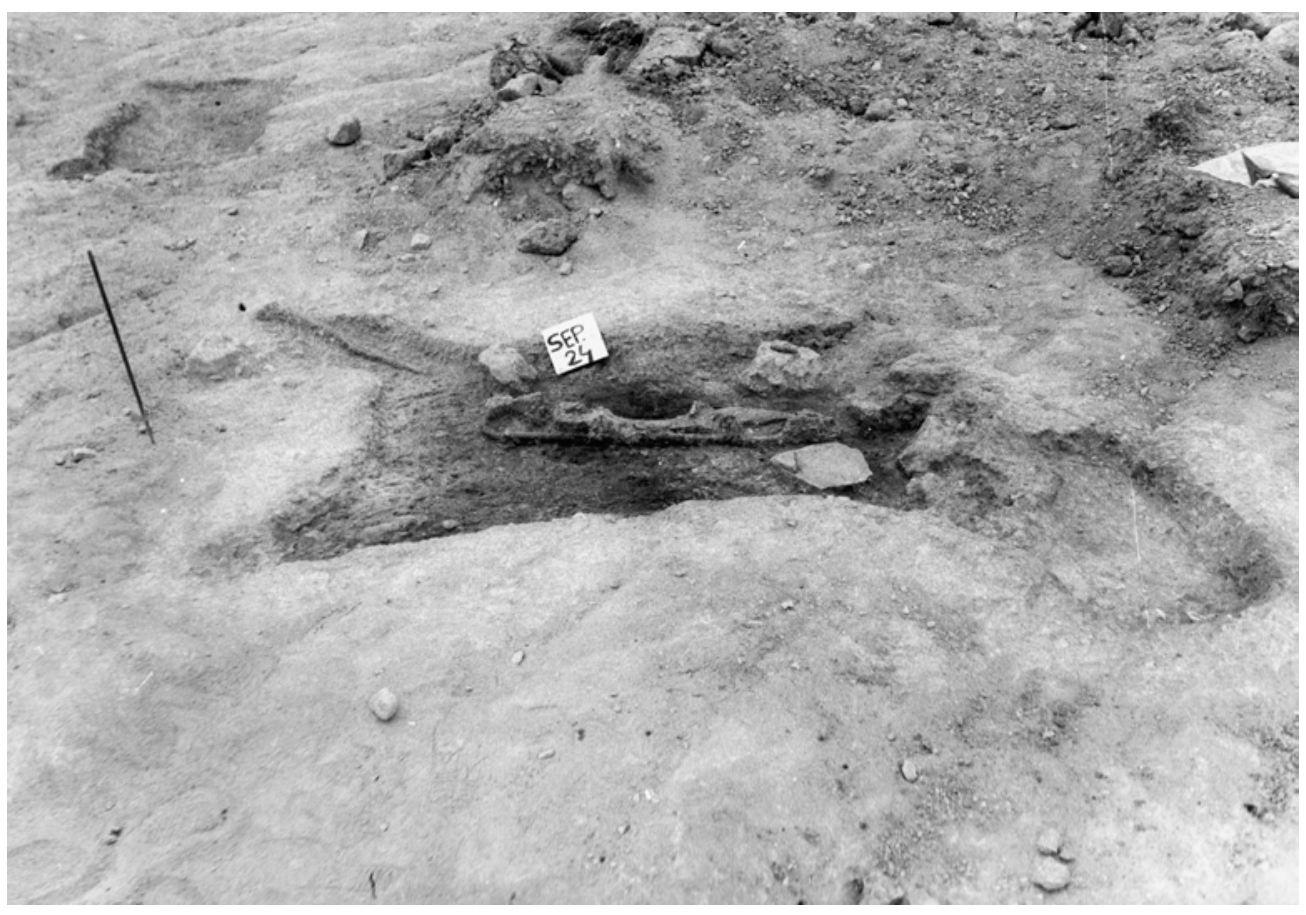

Foto 3. Vista de la fosa de la tumba 24. Ajuar concentrado en el centro. Apreciese la colocación de la punta de lanza en uno de los lóbulos.

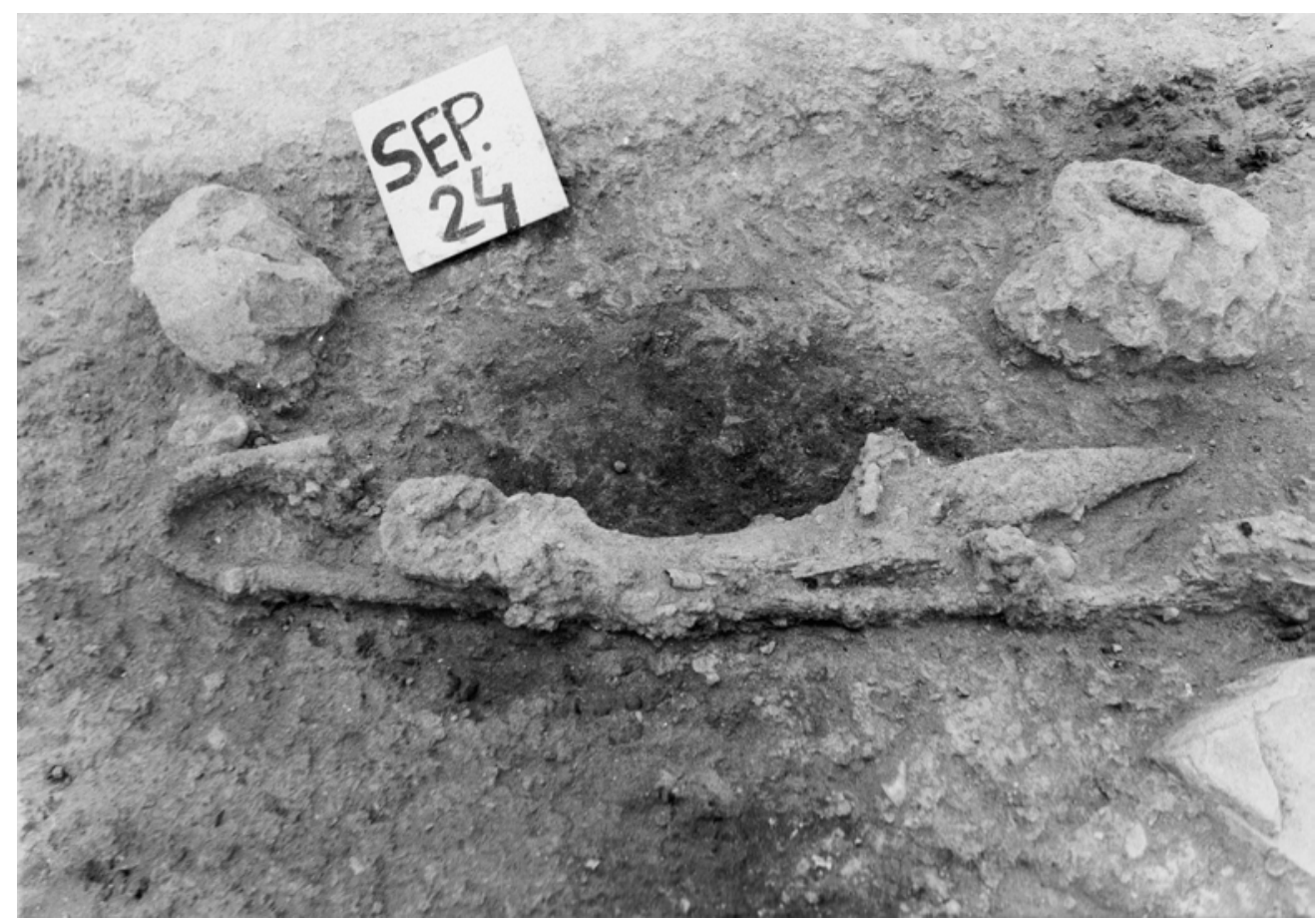

Foto 4. Detalle de la falcata y soliferreum del ajuar de la tumba 24. 


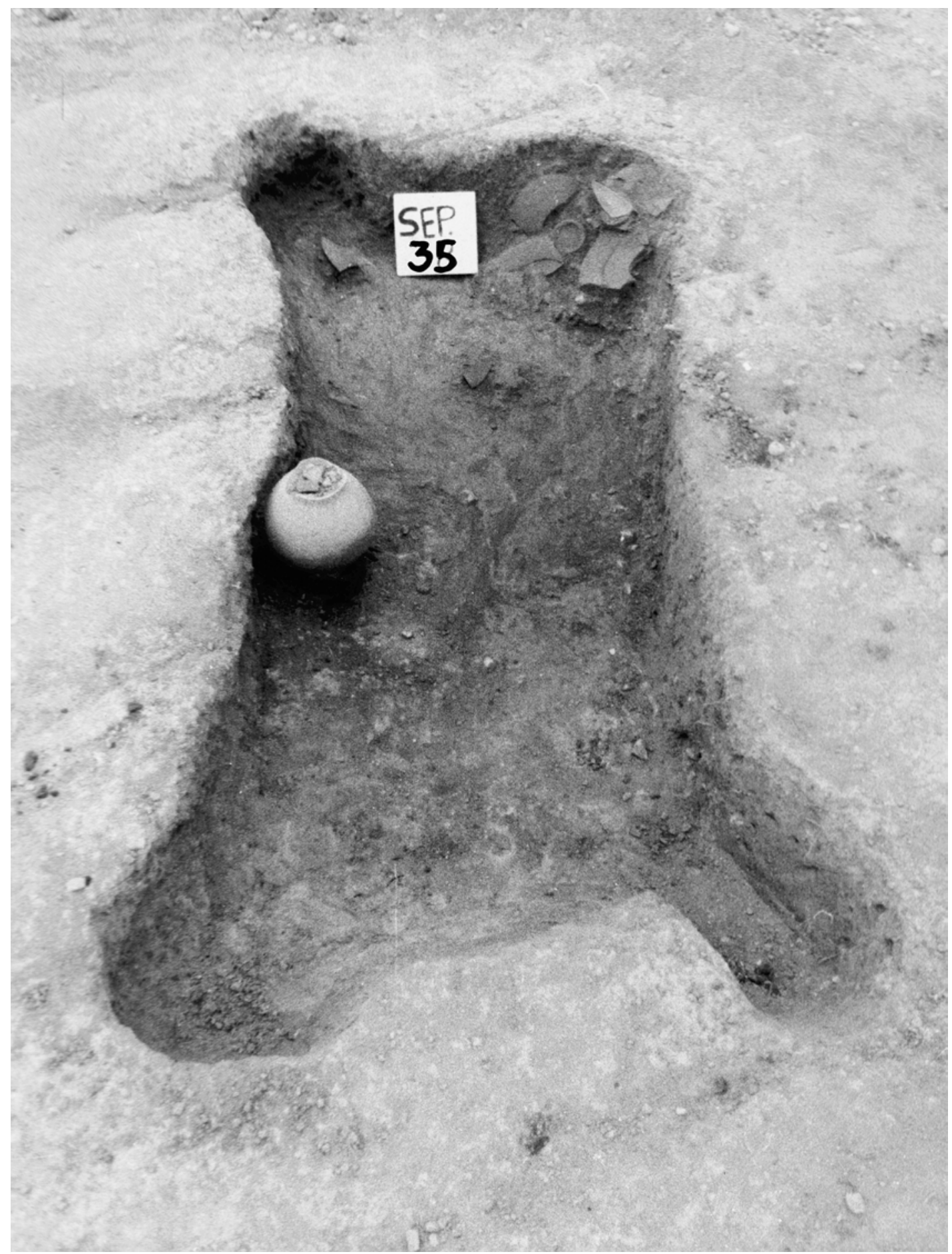

Foto 5. Fosa de la tumba 35 en curso de excavación. Ajuar concentrado en uno de los lóbulos. Urna cineraria colocada en el centro. 


\section{IV.4.2. Cremación de las armas}

En Fortuna parece evidente que las armas fueron depositadas sin sus elementos orgánicos, esto es, se quemaron previamente en la hoguera fúnebre junto al cadáver y el resto del ajuar en el ustrinum.

Se pueden traer a colación varios ejemplos, así la falcata de la tumba $24, \mathrm{CB}-324$, figura 15-1 o la n. ${ }^{\circ}$ CB-369, figura 20-1 (T. 29) presentan adherida a sus hojas restos de las guardas metálicas de la vaina.

Las puntas de lanza han sido encontradas sin relación aparente con sus regatones y algunas de ellas se colocaron de una manera especial con la punta hacia el interior de la fosa y los cubos rozando con el perfil de la fosa, de forma que queda claramente demostrada su introducción en el lóculo sin el astil de madera por ejemplo los items. de las tumbas 24 y 28. También hay un caso de un cuchillo afalcatado CB-135 que apareció solidificado a la hoja de una punta de lanza CB-134, figura 5-2 en la sepultura 7.

Finalmente reseñar el caso de una manilla de escudo n. ${ }^{\circ} \mathrm{CB}-422$, figura 25-2 encontrada paralela al lado Sur de la fosa 34, pero junto al perfil. Ubicación que imposibilita su introducción en el lóculo con la rodela de madera. Y la n. ${ }^{\circ}$ CB-371, figura 20-3 (T. 29) adherida a la punta de lanza CB-365 del mismo ajuar.

De esta misma opinión sobre cremación de las armas en ustrina son Fernando Quesada para Cabecico del Tesoro (1989(I): 225) y Emeterio Cuadrado para la necrópolis de El Cigarralejo (1989-90: 112).

\section{CONSIDERACIONES FINALES}

Se ha recuperado una considerable panoplia con 70 items., de los que 59 se hallaron en contextos cerrados. La variedad tipológica es considerable para el reducido número de incineraciones exploradas 43 de las que 14 contenían armamento.

Es una panoplia típica del sureste, donde están representados los principales modelos de armas ofensivas: falcata, lanzas empuñadas con o sin regatón y soliferrea. Morfológicamente todas ellas se integran en los parámetros establecidos por el Doctor Quesada (1997). Así las dimensiones de las falcatas y de los soliferrea quedan por encima de la media «nacional» ibérica, por el contrario las moharras de las lanzas empuñadas con aproximadamente unos 30/35 centímetros de hoja no alcanzan las variables de las lanzas de este periodo.

Por lo que respecta al armamento defensivo, es aquí donde la panoplia de Fortuna tiene una representación más pobre con un sólo tipo de item. recuperado: el escudo circular característico de la cultura ibérica la caetra, y además en una proporción menor $16.2 \%$ de las armas y de dimensiones reducidas diámetros medios que oscilan entre los 25/30 centímetros, pertenecientes al modelo IIA2b de Quesada.

Reseñar la ausencia de otros elementos defensivos de prestigio como grebas, discos coraza o cascos. Items. que quizás se suplieron con piezas fabricadas con materiales orgánicos.

Se han constatado doce asociaciones de armas lo que representa un número muy elevado de combinaciones para lo reducido de tumbas con panoplia. El grueso de los guerreros de Castillejo de los Baños disponía de varias armas, siendo el esquema tipo, aunque el número de lanzas pudiese variar, falcata, lanza empuñada con o sin regatón, lanza arrojadiza -soliferreumy escudo circular asido. Es decir una completa panoplia que Fernando Quesada ha definido como «panoplia generalizada» (1997(II): 611), típica del siglo IV anterior a Jesucristo.

Sin embargo, algunas de nuestras incineraciones se fechan en el último cuarto del siglo $\mathrm{V}$ o primeros años de la centuria siguiente, fechas éstas muy significativas para el conocimiento de la panoplia ibérica en la fase antigua de la cultura ibérica plena en el área de Murcia. 
Así, los elementos diferenciadores más claros con respecto a la panoplia característica del siglo IV podemos verlos en las fundas de las falcatas y espada de frontón con refuerzos laterales metálicos, lo reducido de las dimensiones de las manillas de los escudos, la abundancia de soliferrea o la propia presencia de una espada de frontón.

Tampoco se han localizado armas de influencia meseteña como espadas de la Tene que se documentan a lo largo del siglo IV en las grandes necrópolis de la zona como Cabecico del Tesoro o Cigarralejo. Finalmente señalar la escasez de items. de prestigio aristocrático relacionados con el mundo del caballo, solamente constatar la presencia de dos aguijones de espuela de hierro, sin arreos o bocados de équido?.

\section{CATALOGo DE MATERIALES}

\section{TUMBA 1.}

1.- Varios fragmentos de la hoja y arranque de la empuñadura de una falcata. Aunque está muy astillada y deteriorada parece presentar filo dorsal. Lc.: $258 \mathrm{~mm}$.; LcHoja: $220 \mathrm{~mm}$. N. ${ }^{\circ}$ CB-43/44, figura1-1.

2.- Numerosos fragmentos muy astillados de un soliferreum. Lc.: $510 \mathrm{~mm} . \mathrm{N} .{ }^{\circ} \mathrm{CB}-46$, figura 1-2.

3.- Fragmento de la punta de una lanza de hierro con nervio central. Lc.: $44 \mathrm{~mm}$. N. ${ }^{\circ} \mathrm{CB}-39 / 40$ (No se reproduce).

4.- Manillas de escudo tipo caetra en pésimo estado de conservación. Se ha preservado parte del asidero hueco, formado por una lámina de hierro enrollada sobre si misma y parte de una de las aletas, de las que se conservan suplementos laterales. Lc.: $185 \mathrm{~mm}$.; Lasidero reconstruido: 135 $\mathrm{mm}$. N. ${ }^{\circ} \mathrm{CB}-41$, figura 1-3. También se han recuperado las cabezas de cuatro remaches para la sujeción de las aletas. N. ${ }^{\circ} \mathrm{CB}-42$, figura 1-3.

5.- Fragmento de una anilla de hierro seguramente de unas manillas de escudo. DM.: $45 \mathrm{~mm}$. N. ${ }^{\circ}$ CB-45, figura 1-4.

6.- Posible aguijón de una espuela de hierro. DM.: $16 \times 20 \mathrm{~mm}$. N. ${ }^{\circ} \mathrm{CB}-33$, figura 1-5.

7.- Posible aguijón de bronce de una espuela muy similar al CB-33. H.: $31 \mathrm{~mm}$.; N. ${ }^{\circ} \mathrm{CB}-34$, figura 1-6.

8.- Restos de dos clavos de bronce. DM.: $18 \times 17 \mathrm{~mm}$. N. ${ }^{\circ} \mathrm{CB}-34 \mathrm{bis}$, figura 1-7.

9.- Broche de cinturón de bronce con nielados de plata. El macho o placa activa es cuadrada (80x78 $\mathrm{mm}$.) de tres milímetros de grosor. Presenta un único garfio central, casi rectangular, que es una pieza independiente de la placa unida mediante un remache. Se unía al cinturón de cuero con cuatro remaches de cabeza redondeada, situados en la parte posterior o talón, que lo aprisionaban mediante una cinta también en hierro. En la parte anterior la zona central del garfio está flanqueada por dos aletas redondeadas. La decoración nielada está muy perdida conservándose únicamente el reborde de enmarque, del motivo principal hoy desaparecido, a base de una orla de pequeños rectángulos que en otras piezas suelen ser ovas.

La hembra es una pieza más bien rectangular $(88 \times 78 \mathrm{~mm}$.). Lleva tres perforaciones rectangulares a distintas distancias en la parte central de la placa para el engarce de la placa activa. Tiene cuatro remaches de cabeza circular en el talón para la sujeción del cinturón y dos pequeños orificios en la cabecera. La decoración nielada está formada por dos grandes «S» acostadas alrededor de las perforaciones de anclaje. De estas salen pequeños tallos hacia el talón de la pieza, en la parte anterior se ha perdido la decoración, rematada en hojas de hiedra muy estilizadas. La decoración central se enmarca, al menos en tres de los lados, con una orla de rectángulos como los descritos en la placa macho. N. ${ }^{\circ} \mathrm{CB}-20$, figura $2-1$.

10.- Varias láminas pertenecientes a las tiras de bronce del cinturón. Seguramente el refuerzo o tope del cinturón de cuero sujeto por la hebilla de placa CB-20. Anchura plaquitas: $13 / 14 \mathrm{~mm}$. N. ${ }^{\circ}$ CB-21, figura 2-2.

\footnotetext{
9 En el ajuar de la tumba 2 se halló una magnífica rueda de carro de hierro.
} 
11.- Grapitas de bronce en forma de «J». En su extremo terminan en punta, siendo el otro plano y rectangular, forman parte de las láminas de bronce del cinturón objeto de análisis. N. ${ }^{\circ} \mathrm{CB}-22$, figura 2-3.

12.- Piececitas muy similares a las anteriores, n. ${ }^{\circ} \mathrm{CB}-22$, pero en hierro y muy retorcidas. Son también elementos de sujeción del cinturón. N. ${ }^{\circ} \mathrm{CB}-23$ (No se reproduce).

13.- Distintas piececitas, grapas (CB-27, figura 2-4) y láminas de hierro (CB-30, figura 2-5). Quemadas y muy deformadas, así como 16 bolitas de bronce de diferentes formatos, entre 2 y $6 \mathrm{~mm}$., que formarían parte de la sujeción del cinturón. N. ${ }^{\circ}$ CB-24 a CB-30, figura 2-4 y 5.

14.- Dos bolitas de oro. Dmedio: $4 \times 5$ y $2.5 \times 2 \mathrm{~mm}$. N. ${ }^{\circ} \mathrm{CB}-19$, figura $2-6$.

15.- Cabeza e inicio y parte de las patas de unas pinzas de depilar de bronce. Vástago de sección ovalada. Lc.: 26 mm. N. ${ }^{\circ}$ CB-32, figura 2-7.

16.- Cuenta de collar de pasta vítrea de color azul. H.: $9 \mathrm{~mm}$. N. ${ }^{\circ}$ CB-38, figura 2-8.

17.- Varios fragmentos de gachas de plomo fundido. L.: $25 \mathrm{~mm}$. N. ${ }^{\circ}$ CB-31, figura 2-9.

18.- Trece lascas atípicas de sílex. N. ${ }^{\circ}$ CB-49, figura 2-10.

\section{TUMBA 4}

1.- Varios fragmentos de una falcata. La parte conservada es el inicio del pomo de la empuñadura y el arranque de la hoja. Lc.: 146 mm. N. ${ }^{\circ}$ CB-95 y 96, figura 3-2. También se han recuperado en pésimo estado varios trozos de anillas y láminas de hierro de las guardas de la falcata. N. ${ }^{\circ}$ CB-97 (No se reproducen).

2.- Soliferreum incompleto en varios trozos, conserva la punta con dos aletas y nervio central. Sección circular. Lc.: 1420 mm.; Lpunta: 84 mm. N. ${ }^{\circ}$ CB-98, figura 4-1.

3.- Punta de lanza con mesas planas y nervio central de sección cuadrada. Cubo con restos de haber llevado un alma de bronce. Lhoja: 138 mm.; Lcubo: 58 mm. L.: 196 mm. N. ${ }^{\circ}$ CB- 93, figura 4-2.

4.- Regatón con alma de bronce. Le falta la punta. Lc.: $104 \mathrm{~mm}$. N. ${ }^{\circ}$ CB-94, figura 4-3.

5.- Varios fragmentos del fondo y mitad inferior de un vaso de cerámica grís tosca con desgrasante grueso a torno. Hc.: 64 mm.; Dbase: $84 \mathrm{~mm}$. N. ${ }^{\circ}$ CB-105, figura 3-1.

6.- Fíbula anular hispánica de timbal elipsoidal de bronce con resorte de charnela de tope osculador. Le falta el pie y la mitad del anillo. H.: $25.5 \mathrm{~mm}$. N. ${ }^{\circ} \mathrm{CB}-87$, figura 4-4.

7.- 23 fragmentos de varillas de bronce. Sección oval. Dmedio: 3.5x2 mm. N. ${ }^{\circ} \mathrm{CB}-88$, figura 3-3.

8.- Bolita de bronce. N. ${ }^{\circ} \mathrm{CB}-89$ (No se reproduce).

9.- Dos fragmentos de un objeto de pasta vítrea, quizás de una cuenta de collar. N. ${ }^{\circ}$ CB-90 (No se reproduce).

10.- Tres cuentas de collar de hueso, tienen una perforación longitudinal. Quemadas. L.: 13, 9 y 8 mm. N. ${ }^{\circ}$ CB-91, figura 4-5.

11.- Cuatro láscas atípicas de sílex. N. ${ }^{\circ}$ CB-100, figura 3-4.

\section{TUMBA 7}

1.- Espada de frontón de pomo compuesto. La hoja presenta cinco acanaladuras, una central y dos laterales a cada. Filo en ambos lados. La espiga de la empuñadura presenta en su tramo central un pequeño ensanchamiento lateral angular que le confiere un aspecto relativamente romboidal. Se remata en un frontón semicircular que lleva refuerzos en bronce. La espiga ha conservado parte de las cachas de hueso con restos de la decoración geométrica muy perdida ¿róleos abiertos? y hojas de hiedra estilizadas en contacto con la guarda basal de apariencia maciza y rectangular.

Ha conservado la parte metálica de la funda. Se trata de dos varillas de hierro de sección en «U» rematadas por una contera de forma redondeada. En el inicio de las varillas se observan dos anillas, una en cada lado, para la sujeción de la espada. L.: 408 mm.; Lhoja: 272 mm.; Amáximahoja:57 mm.; LIE: 81 mm.; Lempuñadura: 136 mm.; Lcfunda: 264 y 233 mm. respectivamente. N. ${ }^{\circ}$ CB-131 y CB-132 (funda), figura 5-1.

2.- Soliferreum completo aunque fragmentado. La punta presenta dos pequeñas aletas y nervio central de sección rectangular. L.: 2050 mm.; Lpunta: $80 \mathrm{~mm}$. N. ${ }^{\circ}$ CB- 139, figura 6-1.

3.- Punta de lanza. Parecen vislumbrase en la moharra mesas planas, nervio central de sección cuadrada. Lc.: $250 \mathrm{~mm}$. N. ${ }^{\circ} \mathrm{CB}-133$ (No se reproduce). 
4.- Punta de lanza, ligeramente incompleto el cubo, donde se aprecia el anillo de presión. Mesas planas en la moharra con nervio de sección cuadrada. Tiene solidificado un cuchillo afalcatado en la hoja y el cuello del cubo. Lc.: $442 \mathrm{~mm}$.; Lhoja: $300 \mathrm{~mm}$.; Lcubo: $142 \mathrm{~mm}$. N. ${ }^{\circ} \mathrm{CB}-134$, figura 5-2.

5.- Regatón fragmentado pero casi completo. Le falta la punta. Conserva el anillo de presión y el agujero para el pasador de sujeción del astil de la lanza con el clavito de bronce en su interior. Lc.: $141 \mathrm{~mm}$.; Dembocadura: $17 \mathrm{~mm}$. N. ${ }^{\circ} \mathrm{CB}-136$, figura 5-3.

6.- Regatón fragmentado, sólo se conserva la punta. Lc.: $40 \mathrm{~mm}$. N. ${ }^{\circ} \mathrm{CB}-138$, figura 5-4.

7.- Cuchillo afalcatado adherido a la moharra de la punta de lanza CB-134. Le falta la empuñadura. Sección plana. Lc.: $185 \mathrm{~mm}$.; Lhoja: $110 \mathrm{~mm}$. N. ${ }^{\circ} \mathrm{CB}-135$, figura 5-5.

8.- Hebilla y cinturón de bronce. Se conserva la placa activa, varias placas del cinturón y unos fragmentos casi fundidos que podían ser de la hebilla hembra. La hebilla macho tiene forma casi cuadrada, 92x92 mm., si exceptuamos la protuberancia central de la parte anterior donde se sitúa el garfio, hecho de la misma plaquita de bronce enrollada. A ambos lados de este apéndice central la cara anterior tiene dos aletas laterales poco esbozadas. En el talón se vislumbran cuatro orificios circulares para la sujeción de la placa al cinturón mediante los correspondientes remaches. Los lados largos de la placa se redondean hacia la parte anterior. En el interior de la hebilla, en su tercio anterior, a la altura de las aletas laterales se encuentran dos perforaciones alargadas y algo curvadas en posición simétrica dispuestas en diagonal con respecto al eje mayor de la hebilla.

La placa está exfoliada en tres capas, quizás el mismo número de láminas de bronce que sirvieron para su fabricación y que la acción del fuego ha ayudado a su separación. L.(con garfio): $122 \mathrm{~mm}$. N. ${ }^{\circ} \mathrm{CB}-129$, figura 6-2.

9.- Fíbula anular hispánica de bronce a la que le falta parte del anillo de timbal elipsoidal sin montantes y resorte de charnela de bisagra. H.: $24 \mathrm{~mm}$. ; L.: $51 \mathrm{~mm}$. N. ${ }^{\circ} \mathrm{CB}-128$, figura 6-3.

10.- Pinzas de depilar de bronce. L.: $59 \mathrm{~mm}$. N. ${ }^{\circ} \mathrm{CB}-127$, figura 6-4.

11.- Anillo de bronce con chatón decorado. Diámetro: $18 \mathrm{~mm}$. N. ${ }^{\circ}$ CB- 130, figura 6-5.

12.- Varios fragmentos de conchas marinas seguramente trabajadas. Se conservan dos plaquitas rectangulares. DM.: $45 \times 21$ y $40 \times 18 \mathrm{~mm}$. N. ${ }^{\circ} \mathrm{CB}-140$, figura 6-6.

13.- Varios fragmentos de plaquitas de madera carbonizadas. N. ${ }^{\circ} \mathrm{CB}-141$ (No se reproduce).

14.- Varios fragmentos de vasitos? objetos de madera carbonizados. N. ${ }^{\circ} \mathrm{CB}-142$ (No se reproduce).

\section{TUMBA 10}

1.- Falcata fragmentada y en muy mal estado de conservación. La falta parte de la empuñadura y hoja. Presenta acanaladuras de aligeramiento del arma paralelas al dorso desde el inicio de la hoja hasta el último tercio de la hoja. Filo dorsal. Empuñadura en forma de cabeza de caballo, se aprecian tres remaches en el pomo para la sujeción de las cachas. Lreconstruida: $591 \mathrm{~mm}$.; Lempuñadura: 110 mm.; Lhoja: 481 mm.; Amáximahoja:61.5 mm.; Amínimahoja: 41 mm.; LIE: 97 $\mathrm{mm}$. N. ${ }^{\circ} \mathrm{CB}-172$, figura 9-1.

2.- Varias varillas de hierro de la vaina de la falcata $n .^{\circ} \mathrm{CB}-172$. Tienen sección en «U». Se han conservado algunas de las anillas que servían para la sujeción del arma. Esta armadura metálica de la funda se utilizaba como refuerzo de los cantos de la vaina de la falcata. Lc.: $592 \mathrm{~mm}$. N. ${ }^{\circ}$ CB-173, figura 9-2.

3.- Punta de lanza en mal estado. Le falta parte del cubo. Moharra con nervio central, cuya sección es irreconstruible, puede que rectangular, mesas planas. Lhoja: $171 \mathrm{~mm}$.; Lccubo: $43 \mathrm{~mm}$.; Lc.: $214 \mathrm{~mm} . \mathrm{N}^{\circ}{ }^{\circ} \mathrm{CB}-175$, figura $9-3$.

4.- Regatón muy incompleto y exfoliado. Lc.: $77 \mathrm{~mm}$. N. ${ }^{\circ} \mathrm{CB}-176$ bis, figura $9-4$.

5.- Regatón fragmentado al que le falta la punta. Tiene el orificio del pasador para la sujeción del astil de la lanza. Lc.: $106 \mathrm{~mm}$; Dembocadura: $22 \mathrm{~mm}$. N. ${ }^{\circ} \mathrm{CB}-176$, figura 10-1.

6.- Cuchillo afalcatado al que le falta la punta y el enmangue. Solo tiene el arranque del pomo de la empuñadura con uno de los remaches para la sujeción de las cachas. Lc.: 103 mm.; Lhoja: 90 $\mathrm{mm}$. N. ${ }^{\circ} \mathrm{CB}-174$, figura 9-5.

7.- Skyphos de cerámica ática de figuras rojas. Casi completo, reconstruido y restaurado. Quemado. Perfil en «S» ligeramente marcado y pie con toro. Fondo externo en reserva con tres finas líneas de barniz. En las escenas figuradas parejas de jóvenes envueltos en mantos. Bajo las asas grandes palmetas que separan las escenas decoradas. Grupo del pintor del Fat-boy. H.: 105 mm.; Db.: $118 \mathrm{~mm} . ;$ Dp.: $70 \mathrm{~mm}$. N. ${ }^{\circ} \mathrm{CB}-160$, figura $7-1$. 
8.- Kylix-skyphos de cerámica ática de barniz negro. En el fondo interno presenta decoración impresa de una orla de ovas entre líneas incisas alrededor de un pequeño círculo central con otras seis ovas. Fondo externo reservado con una franja y una línea barnizada. H.: 65 mm. Db.: 123 mm.; Dp.: 67 mm. N. ${ }^{\circ}$ CB-161, figura 7-2.

9.- Kylix-skyphos de cerámica ática de barniz negro. Fondo interno con decoración impresa de un círculo central inciso sobre el que descansan cuatro palmetas agrupadas de pequeñas dimensiones y gran calidad. Alrededor un círculo de ovas enmarcado por dos finas líneas incisas. Fondo externo reservado con una franja y varias líneas de barniz. H.: 65 mm.; Db.: 130 mm.; Dp.: 66 mm. N. ${ }^{\circ} \mathrm{CB}-162$, figura 8-1.

10.- Pátera de cerámica ática de barniz negro small bowl later and light (F21/25AL.). Interior con decoración impresa de cuatro palmetas agrupadas alrededor de un círculo central inciso. Fondo externo reservado con una franja y dos líneas de barniz. H.: 29 mm.; Db.: 97 mm.; Dp.: 63 mm. N. ${ }^{\circ}$ CB-163, figura 8-2.

11.- Soporte anular de perfil bitroncocónico de cerámica ibérica común. Quemado. H.: 22 mm.; Dmáximo: 119 mm. N. ${ }^{\circ}$ CB-166, figura 8-3.

12.- Botellita de cerámica ibérica pintada a base de motivos geométricos. H.: $67 \mathrm{~mm}$.; Db.: $33 \mathrm{~mm}$; Dp.: 39 mm. N. ${ }^{\circ}$ CB- 164, figura 8-4.

13.- Copita de pie alto de cerámica ibérica pintada a base de motivos geométricos. Cazoleta reducida y pie alto moldurado. H.: $67 \mathrm{~mm}$.; Db.: $69 \mathrm{~mm}$.; Dp.: $56 \mathrm{~mm}$. N. ${ }^{\circ} \mathrm{CB}-165$, figura 8-5.

14.- Vaso globular de cerámica ibérica de cocina con desgrasante grueso a torno. H.: 147 mm.; Db.: 138 mm.; Dbase: $51 \mathrm{~mm}$. N. ${ }^{\circ} \mathrm{CB}-167$, figura 8-6.

15.- Cuatro fragmentos del borde, cuerpo y base de un unguentario de pasta vítrea. Están deformados por la acción del fuego, color azul intenso con decoración geométrica al menos en blanco y amarillo. H(aproximada): $81 \mathrm{~mm}$. N. ${ }^{\circ} \mathrm{CB}-168$, figura 10-2.

16.- Fíbula anular hispánica de bronce de navecilla con puente aquillado con terminales foliáceos bilobulados y resorte de charnela de bisagra. L.: $36 \mathrm{~mm}$.; H.: $18 \mathrm{~mm}$. N. ${ }^{\circ}$ CB-170, figura 10-3.

17.- Fíbula anular hispánica de bronce de timbal y charnela de bisagra, pésima conservación a la que le falta el anillo y el pie. L.: $34 \mathrm{~mm}$; H.: $22 \mathrm{~mm}$. N. ${ }^{\circ} \mathrm{CB}-171$, figura 10-4.

18.- Un cardium. L.: $58 \mathrm{~mm}$. N. ${ }^{\circ} \mathrm{CB}-169$, figura 10-5.

19.- Lasca atípica de sílex con retoques de uso. Lc.: $16 \mathrm{~mm}$. N. ${ }^{\circ}$ CB-177, figura 10-6.

20.- Once lascas atípicas de sílex. N. ${ }^{\circ} \mathrm{CB}-178$, figura 10-7.

21.- Lasca de cuarcita. Lc.: $33 \mathrm{~mm}$. N. ${ }^{\circ} \mathrm{CB}-179$, figura 10-8.

22.- Piedra redondeada de cuarcita con posible retoque de uso. L.: $12 \mathrm{~mm}$. N. ${ }^{\circ}$ CB-180, figura 10-9.

\section{TUMBA 12}

1.- Punta de lanza que presenta múltiples concreciones de óxido que impiden apreciar la forma del arma. Hoja con mesas planas y nervio central de sección circular. Le falta el inicio del cubo. Lc.: 200 mm.; Lhoja: 123 mm.; Lccubo: 77 mm.; Dcubo: 23 mm. N. ${ }^{\circ}$ CB-205, figura 11-12.

2.- Remache o roblón de cabeza hemiesférica con una anilla también en hierro. Puede pertenecer a la parte metálica de sujeción del telamón de una manilla de escudo de madera. Diámetro: $30 \mathrm{~mm}$. N. ${ }^{\circ}$ CB-206, figura 11-13.

3.- Vaso cerrado de cerámica ibérica pintada con motivos geométricos, totalmente exfoliado y degradado. Borde vuelto al exterior. Base con fondo umbilicado. Db.: $63 \mathrm{~mm}$; Dfondo: $60 \mathrm{~mm}$. N. CB-192, figura 11-1.

4.- Botella de cerámica ibérica pintada con motivos geométricos. Incompleta aunque da el perfil. Labio del borde recto ligeramente abierto en relación al cuello, cuerpo globular. Pie apuntado. H.: 78 mm.; Db.: 41 mm.; Dp.: 40 mm. N. ${ }^{\circ}$ CB-193, figura 11-2.

5.- Vasito globular de cerámica ibérica común. Borde ligeramente apuntado al exterior. Pie de anillo incipiente. Fondo plano con umbo al interior. H.: 67 mm.; Db.: 55 mm.; Dp.: 46 mm. N. ${ }^{\circ}$ CB194, figura 11-5.

6.- Vasito carenado de cerámica ibérica común. Perfil bitroncocónico con borde levemente vuelto al exterior. Pie apuntado. Le falta el fondo. H.: 38 mm.; Db.: 53 mm.; Dp.: 42 mm. N. ${ }^{\text {CB-195, }}$ figura 11-3. 
7.- Botellita de cerámica ibérica común. Le falta un tercio aproximadamente aunque completa el perfil. Borde recto y cuerpo carenado. Pie de anillo cónico Amínimahoja: $40 \mathrm{~mm}$.. Fondo externo con umbo. H.: 43 mm.; Db.: 33 mm.; Dp.: $31 \mathrm{~mm}$. N. ${ }^{\circ}$ CB-196, figura 11-4.

8.- Copita de cerámica ibérica común, le falta la mitad inferior del cuenco hemiesférico y el inicio de la caña del pie alto. Cuenco profundo con el borde ligeramente reentrante «tipo huevera». Base plana. H.: $58 \mathrm{~mm}$.; Db.: $49 \mathrm{~mm}$.; Dp.: $39 \mathrm{~mm}$. N. ${ }^{\circ} \mathrm{CB}-197$, figura 11-7.

9.- Varios fragmentos del borde y cuenco de una copita de cerámica ibérica común «tipo huevera» similar a la catalogada con el n. ${ }^{\circ} \mathrm{CB}-197$. Borde al interior y cuerpo profundo. Hc.: $30 \mathrm{~mm}$; $\mathrm{Db} .: 52 \mathrm{~mm} . \mathrm{N}^{\circ}{ }^{\circ} \mathrm{CB}-198$, figura $11-6$.

10.- Fusayola bitroncocónica con carena media. Tiene decoración incisa en zig-zag en cada uno de los lados delimitados por la carena. Perforación recta. H.: $22 \mathrm{~mm}$. N. ${ }^{\circ}$ CB-199, figura 11-8.

11.- 45 cuentas de collar de pasta vítrea de color azulado, algunas incompletas, 37 agallonadas. Hmedia: $13 \mathrm{~mm}$. N. ${ }^{\circ} \mathrm{CB}-200-201$, figura 11-14.

12.- Fíbula anular hispánica de bronce de reducidas dimensiones. Tipo de timbal elipsoidal con charnela de tope osculador. Le falta parte del aro y de la aguja. L.: $21 \mathrm{~mm}$.; H.: $14 \mathrm{~mm}$. N. ${ }^{\circ} \mathrm{CB}-202$, figura 11-9.

13.- Anillo de hierro con chatón irreconocible por el óxido. Le falta la mitad del aro. Hc.: $20 \mathrm{~mm}$. N.º CB-203, figura 11-11.

14.- Bolita de bronce. DM.: $5 \times 8 \mathrm{~mm}$. N. ${ }^{\circ} \mathrm{CB}-204$, figura 11-10.

\section{TUMBA 14}

1.- Falcata fragmentada y en mal estado. Le falta una parte de la hoja y de la empuñadura, de esta sólo tiene parte de la espiga. Se aprecian acanaladuras de aligeramiento del arma paralelas al dorso en el arranque de la hoja. Tiene filo dorsal. Lhoja (reconstruida): $444 \mathrm{~mm}$.; Lespiga(conservada): 77 mm.; Amáximahoja (reconstruida): $62 \mathrm{~mm}$.; Amínimahoja: $40 \mathrm{~mm}$. N. ${ }^{\circ} \mathrm{CB}-$ 214, figura 13-1.

2.- Numerosos fragmentos de láminas de hierro de sección en «U» pertenecientes a los refuerzos metálicos de la funda de la falcata n. ${ }^{\circ} \mathrm{CB}-214$, también se han documentado restos de las guarniciones de la vaina y anillas de suspensión del arma, una de ellas solidificada al regatón $n .^{\circ}$ CB216. Lc.: $314 \mathrm{~mm}$. N. ${ }^{\circ} \mathrm{CB}-215$, figura 13-2.

3.- Regatón de hierro fragmentado e incompleto. Se conserva la parte anterior del mismo, donde tiene el orificio para el pasador de sujeción del astil de la lanza. Lc.: $58 \mathrm{~mm}$.; Dboca: $20 \mathrm{~mm}$. N. ${ }^{\circ}$ CB-216, figura 13-3.

4.- Skyphos de cerámica ática de figuras rojas. Reconstruido y restaurado. Perfil en leve «S». Pie marcado con toro señalado. Fondo externo en reserva con punto central, circulito y dos finas líneas de barniz. Decoración. Cara A) Escena de gineceo. Una mujer vestida con peplos y envuelta en un gran manto. Va cubierta con un sakkos que únicamente deja ver un rizo del cabello. Se dirige a la derecha y lleva en su mano izquierda un gran espejo. La escena se desarrolla en el interior de una habitación donde se muestran un cofre en el suelo y una banqueta. Cara B) Escena de palestra. Un joven se dirige hacia la izquierda envuelto en un amplio himation que deja al descubierto su hombro izquierdo, aunque se aprecia mal, puede llevar en la mano derecha un estrígilo. Un disco cuelga de la pared a su espalda. Debajo de las asas grandes palmetas dobles rematadas por desarrollados róleos vegetales. H.: 129 mm.; Db.: 168 mm.; Dp.: 105 mm. N. ${ }^{\circ}$ CB-213, figura 12-1.

5.- Grapa de bronce incompleta. Cabeza redonda y aplastada. Diámetro: $8 \mathrm{~mm}$. N. ${ }^{\circ} \mathrm{CB}-218$, figura 13-4.

6.- Clavito de bronce atravesado por dos plaquitas cuadradas de hierro. Lc.: $16 \mathrm{~mm}$. N. ${ }^{\circ}$ CB-219, figura 13-5.

\section{TUMBA 24}

1.- Falcata fragmentada pero completa. Empuñadura en forma de cabeza de caballo con tres remaches para la sujeción de las cachas. Se aprecian ligeramente entre la capa de óxido que corroe la hoja restos de las acanaladuras de aligeramiento del arma, van paralelas al dorso. Presenta filo dorsal. Lleva adherida a la hoja un trozo de la parte metálica de la vaina de la falcata. L.: 639 mm.; Lhoja: 518mm.; Lempuñadura: 121 mm.; LIE. 77 mm.; Amáximahoja: 68 mm.; Amínimahoja: $37 \mathrm{~mm}$. N. ${ }^{\circ} \mathrm{CB}-324$, figura $15-1$. 
2.- Numerosos fragmentos de los refuerzos metálicos de la funda de la falcata n. ${ }^{\circ}$ CB- 324. Sección en «U», uno de ellos preserva una anilla para la sujeción del arma. Igualmente se ha conservado fuera de su lugar originario la embocadura de la falcata. Lc.: $420 \mathrm{~mm}$. N. ${ }^{\circ} \mathrm{CB}-325$, figura 15-2.

3.- Soliferreum fragmentado e incompleto. Le faltan ambos extremos. Sección circular. Lc.: 1368 mm.; Diámetro: $17 \mathrm{~mm} . \mathrm{N}^{\circ}{ }^{\mathrm{C}} \mathrm{CB}-326$, figura $16-1$.

4.- Punta de lanza fragmentada y astillada. Presenta nervio central mal conservado pero parece que de sección cuadrada. Mesas planas. Le falta la base del cubo. Lc.: $375 \mathrm{~mm}$.; Lhoja: $305 \mathrm{~mm}$; Lccubo: $67 \mathrm{~mm}$. N. ${ }^{\circ} \mathrm{CB}-327$, figura $16-2$.

5.- Regatón al que le falta la punta. Presenta alma de bronce. Lc.: $83 \mathrm{~mm}$.; L(reconstruido): $97 \mathrm{~mm}$.; Dembocadura: $18 \mathrm{~mm}$. N. ${ }^{\circ} \mathrm{CB}-328$, figura 16-3.

6.- Regatón incompleto al que le falta la embocadura y la punta. Se aprecia el anillo de presión. Lc.: $112 \mathrm{~mm}$. N. ${ }^{\circ} \mathrm{CB}-329$, figura $16-4$.

7.- Manillas de un escudo tipo caetra. Aletas de pequeño tamaño, muestran muescas de base que se aprecian mal por el grado de oxidación del arma. El asidero está hecho a partir de una delgada lámina de hierro de forma semicircular y sección plana. Conserva las anillas de suspensión del escudo y varios de los remaches de sujeción de las aletas a la rodela de madera. L.: $251 \mathrm{~mm}$.; Lasidero: $97 \mathrm{~mm}$.; Laleta: $77 \mathrm{~mm}$.; Dasidero: $21 \mathrm{~mm}$. N. ${ }^{\circ} \mathrm{CB}-330-331$, figura 15-3.

8.- Urna globular de cerámica ibérica pintada con motivos geométricos. Boca ligeramente exvasada con un baquetón que marca el inicio del cuello. Fondo umbilicado. H.: 205 mm.; Db.: $134 \mathrm{~mm}$. N. ${ }^{\circ}$ CB-319, figura $14-1$.

9.- Fragmento de la base y cuerpo de un plato de cerámica ibérica pintada con motivos geométricos. Hc.: $33 \mathrm{~mm}$.; Dp.: $50 \mathrm{~mm} . \mathrm{N}^{\circ}{ }^{\circ} \mathrm{CB}-320$, figura 14-2.

10.- Plato de cerámica ática de barniz negro, incurving rim bowl (F.21L.). Interior: decoración impresa en el fondo a base de ocho palmetas enlazadas por tallos incisos alrededor de un círculo central. Rodeando este conjunto tres vueltas de fina ruedecilla. Fondo externo barnizado con umbo señalado. Aquí lleva un grafito postcocción «X» posible TA ibérico. Superficie de reposo en reserva con uña marcada. H.: 45 mm.; Db.: $140 \mathrm{~mm}$. N. ${ }^{\circ} \mathrm{CB}-318$, figura 14-3.

11.- Fragmento de una varilla de bronce, quizás la aguja incompleta de una fíbula. Sección ovalada. Lc.: $36 \mathrm{~mm} . \mathrm{N}^{\circ} \mathrm{CB}-321$, figura $16-5$.

12.- Pequeña gacha de plomo amorfa. Lc.: $19 \mathrm{~mm}$. N. ${ }^{\circ}$ CB-322, figura $16-6$.

\section{TUMBA 26}

1.- Punta de lanza completa aunque algo astillada y erosionada. Tiene nervadura central de sección cuadrada y mesas planas. L.: 402 mm.; Lhoja: 290 mm.; Lcubo: 112 mm.; Dcubo: 25 mm. N. ${ }^{\circ}$ CB-343, figura 17-1.

2.- Regatón. L.: 97 mm.; Dembocadura: $21 \mathrm{~mm}$. N. ${ }^{\circ}$ CB-344, figura 17-2.

3.- Anillo de bronce con chatón ovalado. Diámetro: $19 \mathrm{~mm}$. N. ${ }^{\circ} \mathrm{CB}-342$, figura 17-3.

\section{TUMBA 28}

1.- Falcata a la que le falta la empuñadura y el inicio de la hoja. Se aprecian acanaladuras de aligeramiento del arma paralelas al dorso. Filo dorsal en el tercio inferior de la hoja. Lc.: $325 \mathrm{~mm}$.; Amáximahoja: $60 \mathrm{~mm}$. N. ${ }^{\circ} \mathrm{CB}-354$, figura 18-1.

2.- Punta de lanza que tiene nervio central de sección cuadrada y mesas planas. Cubo con anillo de presión. L.: $158 \mathrm{~mm}$.; Lhoja: $109 \mathrm{~mm}$.; Lcubo: $49 \mathrm{~mm}$. Dcubo: $23 \mathrm{~mm}$. N. ${ }^{\circ} \mathrm{CB}-353$, figura 18-2.

3.- Embocadura de la funda de la falcata $.^{\circ} \mathrm{CB}-354$. L.: $72 \mathrm{~mm}$. N. ${ }^{\circ} \mathrm{CB}-355$, figura $18-3$.

4.- Elemento incompleto de la guarnición de la funda de la falcata. Lc.: $53 \mathrm{~mm}$. N. ${ }^{\circ}$ CB-355bis, figura 18-4.

5.- Fíbula anular hispánica de bronce completa. De navecilla con terminales foliáceos bilobulados. Resorte de charnela de bisagra. L.: $40 \mathrm{~mm}$.; H.: $20 \mathrm{~mm}$. N. ${ }^{\circ} \mathrm{CB}-348$, figura 18-5.

6.- Nueve pequeños remaches de bronce. Uso indeterminado, probablemente para la sujeción de un objeto. Hmedia: $16 \mathrm{~mm}$. N. ${ }^{\circ} \mathrm{CB}-349$ a 351, figura 18-6.

7.- Cuenta de collar de pasta vítrea. DM.: $11 \times 9 \mathrm{~mm} . \mathrm{N}^{\circ}{ }^{\circ} \mathrm{CB}-347$, figura 18-7.

8.- Tres lascas atípicas de sílex. N. ${ }^{\circ} \mathrm{CB}-356$, figura $18-8$. 


\section{TUMBA 29}

1.- Falcata fragmentada pero completa. Empuñadura incompleta a la que le falta la guarda lateral, pero puede reconstruirse una cabeza de caballo. Tiene tres remaches en la espiga para la sujeción de las cachas. Uno de ellos se remata en una plaquita de bronce con función decorativa, posiblemente como el ojo del caballo, n. ${ }^{\circ}$ CB-362, figura 19-4. Filo dorsal. L.: 618 mm.; Lempuñadura: 130 mm.; Lhoja: 488 mm.; LIE: 78 mm.; Amáximahoja: $61 \mathrm{~mm}$.; Amínimahoja: $44 \mathrm{~mm}$. N. ${ }^{\circ}$ CB-369, figura 20-1.

2.- Varios fragmentos de láminas de hierro y arandelas de las guardas de la falcata muy poco representadas, pero de una vaina con refuerzos metálicos laterales. Sección en «U», algunos solidificados a la hoja de la falcata. N. ${ }^{\circ}$ CB-370, figura 20-2.

3.- Soliferreum fragmentado e incompleto. Sección circular conserva únicamente el extremo final. Lc.: $1541 \mathrm{~mm}$. N. ${ }^{\circ} \mathrm{CB}-364$, figura $21-1$.

4.- Punta de lanza a la que le falta el extremo. Presenta nervio central de sección cuadrada y mesas planas. Lleva adherido a la hoja restos de la manilla de escudo. Lc.: $338 \mathrm{~mm}$.; Lchoja: $196 \mathrm{~mm}$.; Lcubo: $142 \mathrm{~mm}$; Dcubo: $21 \mathrm{~mm}$. N. ${ }^{\circ} \mathrm{CB}-365$, figura 19-5.

5.- Regatón al que le falta la punta. Se aprecia en el interior el alma de bronce. Lc.: $46 \mathrm{~mm}$.; Dembocadura: $21 \mathrm{~mm} . \mathrm{N} .^{\circ} \mathrm{CB}-367$, figura $19-3$.

6.- Regatón prácticamente completo. Se observa en el interior el alma de bronce para hacerlo más maleable y restos de la madera carbonizada del astil. L.: $114 \mathrm{~mm}$.; Dembocadura: $21 \mathrm{~mm}$. N. ${ }^{\circ}$ CB-368, figura 19-4.

7.- Manillas de escudo tipo caetra en mal estado de conservacin. Le falta una aleta completa y un tercio del asidero metálico. Aleta con muesca de base. El asidero está formado por una lámina de hierro vuelta sobre si misma, que no llega a cubrir completa la circunferencia. Pequeños apéndices extremos triangulares. Se conservan las anillas que mediante una correa servirían para llevar colgada el arma, así como dos remaches de cabeza redondeada que harían la función de sujeción de la aleta a la rodela de madera de la caetra. Lc.: $135 \mathrm{~mm}$.; Laleta: $76 \mathrm{~mm}$.; L(reconstruida): $250 \mathrm{~mm}$. N. ${ }^{\circ} \mathrm{CB}-371$, figura $20-3$.

8.- Plato de cerámica ática de barniz negro, incurving rim bowl (F21L.). Interior con decoración impresa de ocho palmetas enlazadas por tallos alrededor de un circulito central inciso. El conjunto se rodea con cinco vueltas de ruedecilla. Fondo externo totalmente barnizado con umbo muy marcado. Superficie de reposo con uña señalada en reserva. El plato lleva diez agujeros de reparación. H.: 44 mm.; Db.: 140 mm.; Dp.: 90 mm. N. ${ }^{\circ}$ CB-359, figura 19-2.

9.- Vasito globular de cerámica ibérica común (?), muy deformado y estallado por la acción del fuego. Reconstruido y restaurado. H.: $120 \mathrm{~mm}$.; Db.: $89 \mathrm{~mm}$.; Dbase: $66 \mathrm{~mm}$. N. ${ }^{\circ} \mathrm{CB}-360$, figura $19-1$.

10.- Fíbula anular hispánica de bronce. Fragmentada y con el puente fundido. Este es de navecilla normal o con terminales foliáceos, charnela de bisagra. L.: $46 \mathrm{~mm}$. N. ${ }^{\circ} \mathrm{CB}-361$, figura 20-5.

11.- Cuenta de collar de pasta vítrea. H.: $15 \mathrm{~mm}$. N. ${ }^{\circ} \mathrm{CB}-363$, figura 19-7.

12.- Varios fragmentados calcinados de madera trabajada. Lc.: $63 \mathrm{~mm}$. N. ${ }^{\circ}$ CB-373, figura 19-9.

13.- Dos fragmentos de madera carbonizada quizás de una copita de madera. Hc.: 21 y $20 \mathrm{~mm}$. N. ${ }^{\circ}$ CB-374, figura 19-6.

14.- Dos lascas atípicas de sílex con restos de cortex y retoque de uso. Lc.: 30 y $14 \mathrm{~mm}$. N. ${ }^{\circ}$ CB- 375 , figura 19-8.

\section{TUMBA 30}

1.- Fragmento próximo al inicio de la hoja de una falcata de hierro. Conserva varias acanaladuras de aligeramiento del peso del arma, paralelas al dorso. Lc.: $53 \mathrm{~mm}$.; Ahoja: $36 \mathrm{~mm}$. N. ${ }^{\circ} \mathrm{CB}-385$, figura 23-4.

2.- Fragmento de una lámina de hierro con sección en «U» perteneciente a la funda de la falcata. Lc.: $26 \mathrm{~mm} . \mathrm{N}^{\circ}{ }^{\circ} \mathrm{CB}-386$, figura $23-5$.

3.- Punta con nervio central de sección rectangular y mesas planas de un soliferreum. Falta el resto del arma. Lc.: 127 mm.; Lpunta: 93 mm.; Diámetro: $11 \mathrm{~mm}$. N. ${ }^{\circ}$ CB-383, figura 23-3.

4.- Restos de una punta probablemente de un soliferreum. Se conserva el inicio de las mesas planas. Lc.: 58 mm.; Diámetro: 13 mm. N. ${ }^{\circ}$ CB-384, figura 23-6. 
5.- Varios fragmentos de la embocadura de un regatón. Se aprecia en su interior alma de bronce. Conserva el pasador para el clavo que fija el astil de madera de la lanza al regatón. Lc.: $26 \mathrm{~mm}$. N. ${ }^{\circ}$ CB-391, figura 23-7.

6.- Restos de unas manillas de escudo tipo caetra. Solo se ha preservado un trozo del asidero metálico, hecho mediante una lámina de hierro vuelta sobre si misma, completando el círculo y dejando el interior hueco. Dos remaches de sujeción de las aletas y arandelas para la sujeción del escudo al telamón. Lc(asidero): $48 \mathrm{~mm}$. N. ${ }^{\circ} \mathrm{CB}-387-388$ y 389, figura 23-8.

7.- Kylix de pie bajo de cerámica ática de figuras rojas. Asas de lazo incompletas y pie moldurado. Reconstruida y restaurada. Quemada. Interior: medallón central con la representación de un joven envuelto en un gran manto hacia la dercha. Los pliegues del manto son finas líneas de barniz. Tiene el brazo izquierdo extendido y sostiene un bastón. El labio interno del borde llevó originariamente decoración de tallos y frutos de laurel sobre pintados en blanco hoy muy perdidos. Exterior: La escena principal de cada cara se compone por dos jóvenes envueltos en himatia enfrentados de factura muy grosera y aspecto deforme. Bajo las asas una gran palmeta arqueada por dos enormes róleos. Lado interno de las asas sin barnizar. Fondo externo: Alternancia de franjas barnizadas y reservadas. Zona de reposo en reserva sin uña. Grupo del Pintor de Viena 116. H.: 43 mm.; Db.: 165 mm.; Dp.: 78 mm. N. ${ }^{\circ}$ CB-380, figura $22-1$.

8.- Patera de cerámica ática de barniz negro, small bowl with broad base (F21/25BIIL./F2711M). Quemada. Interior: Presenta decoración impresa de cuatro palmetas agrupadas. Exterior: Fondo externo totalmente barnizado con umbo señalado. Superficie de reposo en reserva. H.: $28 \mathrm{~mm}$;; Db.: 87 mm.; Dp.: $58 \mathrm{~mm}$. N. ${ }^{\circ}$ CB-381, figura $23-1$.

9.- Plato de borde saliente de cerámica ática de barniz negro outturned rim bowl (F22L./F2681M.). Le falta gran parte del fondo y pie. Interior: se aprecian restos de la decoración impresa a base de círculos de estrías hechos con ruedecilla, que debían acompañar a un grupo de palmetas enlazadas. Hc.: 47 mm.; Db.: $137 \mathrm{~mm}$. N. ${ }^{\circ} \mathrm{CB}-382$, figura 23-2.

10.- Dos fragmentos de una lámina de bronce. Lc.: 22 y 19 mm. N. ${ }^{\circ}$ CB-390, figura $23-9$.

\section{TUMBA 34}

1.- Falcata incompleta a la que la falta la práctica totalidad de la empuñadura y una sección de la hoja. Presenta filo dorsal. Lc.: 614 mm.; Lhoja(reconstruida): 552 mm.; Amáximahoja: 68 mm.; Amínimahoja: $34 \mathrm{~mm}$. N. ${ }^{\circ} \mathrm{CB}-420$, figura 24-1.

2.- Varios fragmentos de las guardas de la falcata entre ellos de la segunda y tercera guarnición, así como dos anillas de sujeción de la funda. L.: $79 \mathrm{~mm}$ (tercera guarnición); Lc.: $38 \mathrm{~mm}$. (segunda guarnición). N. ${ }^{\circ} \mathrm{CB}-421$, figura $24-2$.

3.- Soliferreum fragmentado e incompleto muy exfoliado. La punta aunque se ha preservado está muy erosionada pero parece presentar aletas y nervio central. Lc.: $1457 \mathrm{~mm}$.; Lc (punta): 50 mm.; Diámetro: $13 \mathrm{~mm}$. N. ${ }^{\circ} \mathrm{CB}-419$, figura 25-3.

4.- Punta de lanza completa aunque reconstruida y bastante exfoliada. Moharra con mesas planas y nervio central de sección circular ?. Lleva anillo de presión en la base del cubo. L.: 447 mm.; Lhoja: 313 mm.; Lcubo: $134 \mathrm{~mm}$.; Dcubo: $25.5 \mathrm{~mm}$. N. ${ }^{\circ} \mathrm{CB}-418$, figura 25-1.

5.- Manillas de escudo, fragmentadas pero reconstruibles de tipo caetra. Aletas triangulares con una pequeña muesca de base y apéndice triangular extremo. Asidero hecho con una lámina de hierro vuelta sobre si misma completando prácticamente el círculo, interior hueco. Se conservan cuatro clavos de sujeción de las aletas a la rodela de madera (N. $\left.{ }^{\circ} \mathrm{CB}-422\right)$. Una de las aletas tiene la anilla que con una correa servía para llevar colgado el escudo. Laleta: $77 \mathrm{~mm}$.; LIE: $98 \mathrm{~mm}$; L(reconstruido): $252 \mathrm{~mm}$.; Diámetro cabeza remaches: $18 / 20 \mathrm{~mm}$. N. ${ }^{\circ} \mathrm{CB}-422$ y 424, figura $25-2$.

6.- Dos botones de bronce de sujeción de la falcata al tahalí. H.: 15 y 16 mm.; Dmáximo: 23 y 23 mm.N. ${ }^{\circ}$ CB-415a y 415 b, figura $24-7$ y 6 respectivamente.

7.- Dos grandes anillas de hierro muy exfoliadas y erosionadas. Diámetro: 56 y $53 \mathrm{~mm}$. N. ${ }^{\circ} \mathrm{CB}-425$, figura $25-4$.

8.- Vaso tipo craterisco de cerámica ibérica con motivos geométricos complejos. Superficie muy descascarillada. Borde vuelto al exterior que deriva en un amplio cuello recto, levemente moldurado. Carena casi a mitad de su altura que se abre a un cuerpo globular. Descansa en un bajo pie de anillo. H.: 175 mm.; Db.: 149 mm.; Dp.: 48 mm. N. ${ }^{\circ}$ CB-412, figura 24-3. 
9.- Pinzas de depilar de bronce. Presentan un estrangulamiento en la base de la cabeza en el inicio del desarrollo de cada brazo y un juego de molduras en esta parte. L.: $88 \mathrm{~mm}$. N. ${ }^{\circ} \mathrm{CB}-413$, figura 24-4.

10.- Fíbula anular hispánica de bronce, resorte de charnela de bisagra. Timbal hemiesférico con montantes salientes. L.: $39 \mathrm{~mm}$.; H.: $27 \mathrm{~mm}$. N. ${ }^{\circ} \mathrm{CB}-414$, figura $24-5$.

11.- Anillo de bronce . Diámetro: $28 \mathrm{~mm}$. N. ${ }^{\circ} \mathrm{CB}-416$, figura 24-8.

12.- Varios fragmentos de una cuenta de collar de pasta vítrea estallada. N. ${ }^{\circ}$ CB-417 (No se reproduce).

\section{TUMBA 36}

1.- Fragmento del inicio de la hoja de una falcata. Se vislumbran restos de la guarda basal. Lc.: 68 mm.; Lchoja: $50 \mathrm{~mm}$. N. ${ }^{\circ} \mathrm{CB}-448$, figura $27-5$.

2.- Seis fragmentos de láminas de hierro con sección en «U» de la funda de la falcata del tipo de refuerzos metálicos laterales. Lc.: 55 y $45 \mathrm{~mm}$. N. ${ }^{\circ} \mathrm{CB}-449$, figura $27-6$.

3.- Punta de lanza. Moharra con mesas planas y nervio central de sección cuadrada. Le falta el inicio del cubo. Lc.: 416 mm.; Lhoja: 333 mm.; Lccubo: 83 mm.; Dcubo: $20 \mathrm{~mm}$. N. ${ }^{\circ}$ CB-443, figura 27-3.

4.- Punta de lanza fragmentada a la que le falta la punta y parte de las mesas de la moharra. Sección circular. Tiene dos anillos de presión en el cubo. Lc.: $225 \mathrm{~mm}$.; Dcubo: $21 \mathrm{~mm}$. N. ${ }^{\circ}$ CB-444, figura $27-4$.

5.- Regatón casi completo pero con pésima conservación. Se aprecia en el interior alma de bronce. L.: $84 \mathrm{~mm}$.; Dembocadura: $25 \mathrm{~mm}$. N. ${ }^{\circ} \mathrm{CB}-445$, figura 26-3.

6.- Pequeño trozo de hierro posiblemente de la aleta e inicio del asidero de una manilla de escudo tipo caetra. DM.: 25x25 mm. También pueden ser de este escudo las dos anillas CB-446. DM.: $27 \times 27 \mathrm{~mm} . \mathrm{N} .{ }^{\circ} \mathrm{CB}-447$, figura $27-7$.

7.- Vaso globular de cerámica ibérica pintada con decoración geométrica, utilizada de urna en el ajuar. Borde ligeramente exvasado y cuerpo globular acusado a partir de un estrecho cuello de transición. Fondo umbilicado. H.: 173 mm.; Db.: 122 mm.; Dbase: 84 mm. N. ${ }^{\circ}$ CB-439, figura 26-1.

8.- Skyphos de cerámica ática de barniz negro. Reconstruido y restaurado. Quemado. Perfil en «S», pie con toro señalado. Fondo externo en reserva excepto un punto central y dos circulitos de barniz a su alrededor. Zona de reposo sin barnizar. H.: 105 mm.; Db.: 116 mm.; Dp.: 55 mm. N. ${ }^{\circ}$ CB-437 mm, figura 27-2.

9.- Plato de borde entrante de cerámica ática de barniz negro, incurving rim bowl (F21L./F2771M.). Incompleto aunque conserva el perfil. Quemado. Interior: Con decoración impresa de la que se conservan restos de dos palmetas enlazadas rodeadas por cuatro vueltas de ruedecilla. Fondo externo barnizado. Zona de reposo en reserva con uña marcada. H.: 63 mm.; Db.: 185 mm.; Dp.: $104 \mathrm{~mm}$. N. ${ }^{\circ} \mathrm{CB}-438$, figura $27-1$.

10.- Pendiente de oro amorcillado. Los extremos concluyen en sendos aritos donde engarzaría el pasador de sujeción hoy desaparecido. H.: $18 \mathrm{~mm}$. N. ${ }^{\circ} \mathrm{CB}-440$, figura $26-2$.

11.- Fíbula anular hispánica de bronce. Puente de navecilla aquillada con terminales foliáceos bilobulados. El resorte debió de ser de charnela de bisagra. L.: $46 \mathrm{~mm}$.; H.: $18 \mathrm{~mm}$. N. ${ }^{\circ} \mathrm{CB}-441$, figura 27-9.

12.- Pequeñas láminas de bronce muy alteradas por la acción del fuego. DM.: $33 \times 18 \mathrm{~mm}$. N. ${ }^{\circ}$ CB442, figura $27-8$.

\section{TUMBA 42}

1.- Punta de una falcata. Se aprecia el arranque de las acanaladuras de aligeramiento del arma que corren paralelas al dorso. Filo dorsal. Lchoja: $154 \mathrm{~mm}$. N. ${ }^{\circ} \mathrm{CB}-481$, figura 29-2.

2.- Varios fragmentos de láminas de hierro pertenecientes a los refuerzos laterales de la funda de la falcata. Sección en «U». Lc.: 109 mm. N. ${ }^{\circ}$ CB-482, figura 29-3.

3.- Fragmento de hierro adscribible a un soliferreum. Sección circular. Lc.: $55 \mathrm{~mm}$. Diámetro: 11 mm. N. ${ }^{\circ}$ CB-485, figura 29-5.

4.- Punta de lanza fragmentada pero reconstruible. Hoja con mesas planas y nervio central de sección tendente a la circular. Conserva en el arranque del cubo los dos agujeros para los pasadores de sujeción del astil de madera. Lc.: $288 \mathrm{~mm}$.; L(reconstruida): $400 \mathrm{~mm}$.; Lcubo(reconstruido): 100 mm.; Lhoja: 300 mm.; Dcubo: $21 \mathrm{~mm}$. N. ${ }^{\circ} \mathrm{CB}-483$, figura 29-4. 
5.- Punta de lanza totalmente exfoliada e irreconocible. Conserva el inicio del cubo. Lc.: $74 \mathrm{~mm}$. N. ${ }^{\circ}$ CB-485bis, figura 29-6.

6.- Regatón incompleto. Lc.: $61 \mathrm{~mm}$.; Dembocadura: $18 \mathrm{~mm}$. N. ${ }^{\circ} \mathrm{CB}-484$, figura $29-8$.

7.- Plato de borde vuelto al exterior de cerámica ática de barniz negro, outturned rim bowl (F22L./F2681M.). Incompleto aunque da el perfil. Quemado. Interior: Decoración impresa a base de palmetas combinadas. Irreconstruible pero parece tener en el centro del plato un grupo de palmetas agrupadas/simétricas alrededor de las que se sitúa una orla de ovas en donde se apoya un conjunto de palmetas enlazadas por tallos. Exteriormente otro círculo de ovas rodeadas a su vez por un grupo de palmetas enlazadas por tallos incisos. Fondo externo: Alternancia de franjas barnizadas y en reserva. Zona de reposo sin barnizar ni uña. En el lado interno del pie, barnizado, se aprecian restos de un grafito postcocción trazos de una letra. H.: 80 mm.; Db.: 211 mm.; Dp.: $110 \mathrm{~mm}$. N. ${ }^{\circ} \mathrm{CB}-478$, figura $28-1$.

8.- Vasito globular de cerámica ibérica muy fragmentado faltándole la boca. Hc.: $85 \mathrm{~mm}$. N. ${ }^{\circ} \mathrm{CB}-$ 479, figura $28-2$.

9.- Vasito cerrado de cuerpo ligeramente cilíndrico de cerámica ibérica pintada con motivos geométricos. Borde al exterior con cuello marcado por una doble moldura. Le falta la mitad inferior, puede relacionarse con los vasos de perfil quebrado. Quemado. Hc.: $60 \mathrm{~mm}$.; Db.: $40 \mathrm{~mm}$. N. ${ }^{\circ}$ CB-480, figura 29-1.

10.- Fragmento de un vaso calado de bronce, quizás se trate de un soporte. DM.: $36 \times 30 \mathrm{~mm}$. N. ${ }^{\circ} \mathrm{CB}-$ 486, figura 29-7.

11.- Doce lascas atípicas de sílex, cinco de ellas presentan restos del cortex (N. ${ }^{\circ}$ CB-488). N. ${ }^{\circ}$ CB487 y 488 , figura $29-9$.

José Miguel García CANO

Universidad de Murcia.

Virginia PAGE DEL PoZO

Museo Monográfico «El Cigarralejo». 


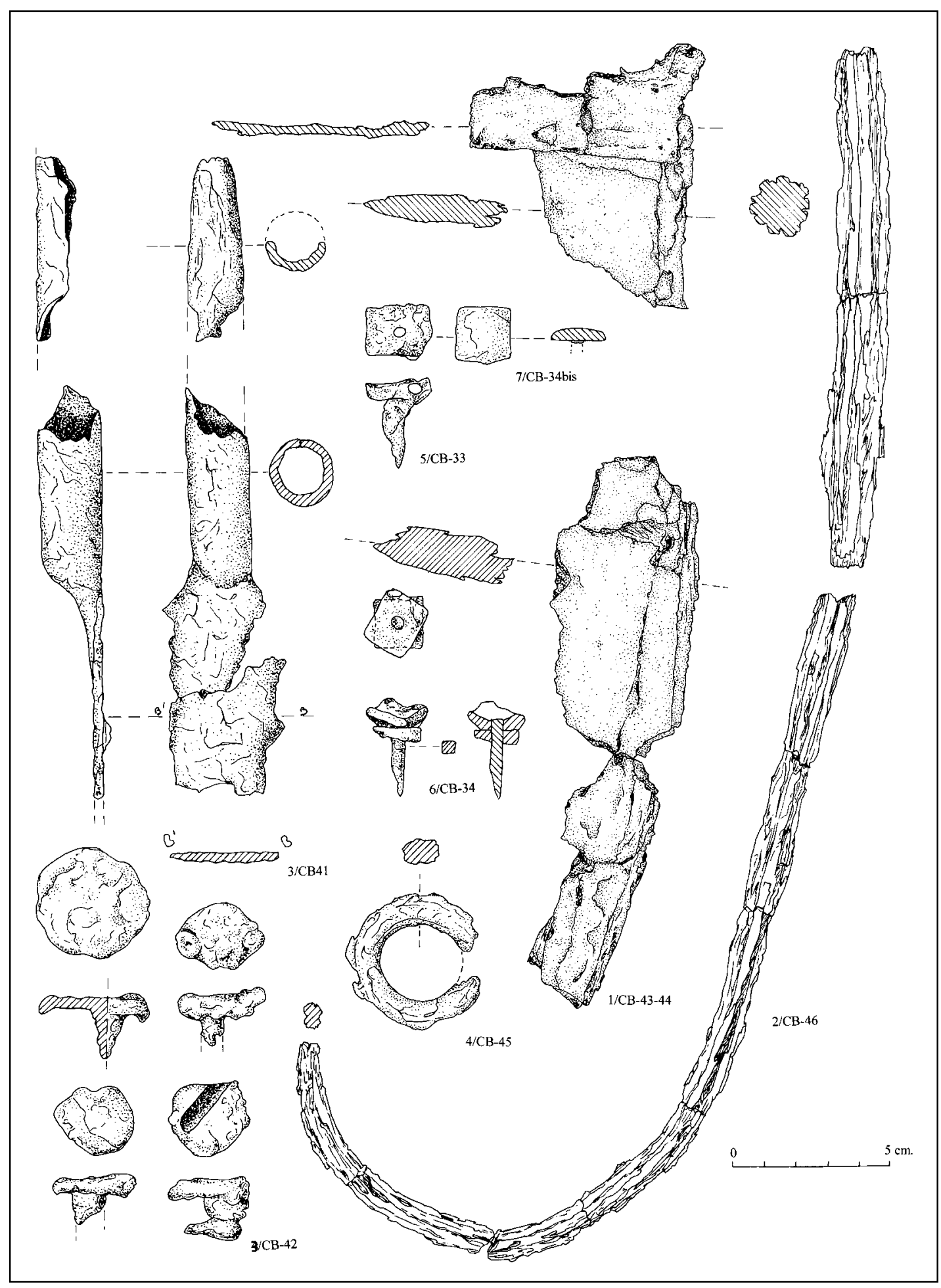

Figura 1. Ajuar Tumba 1. 

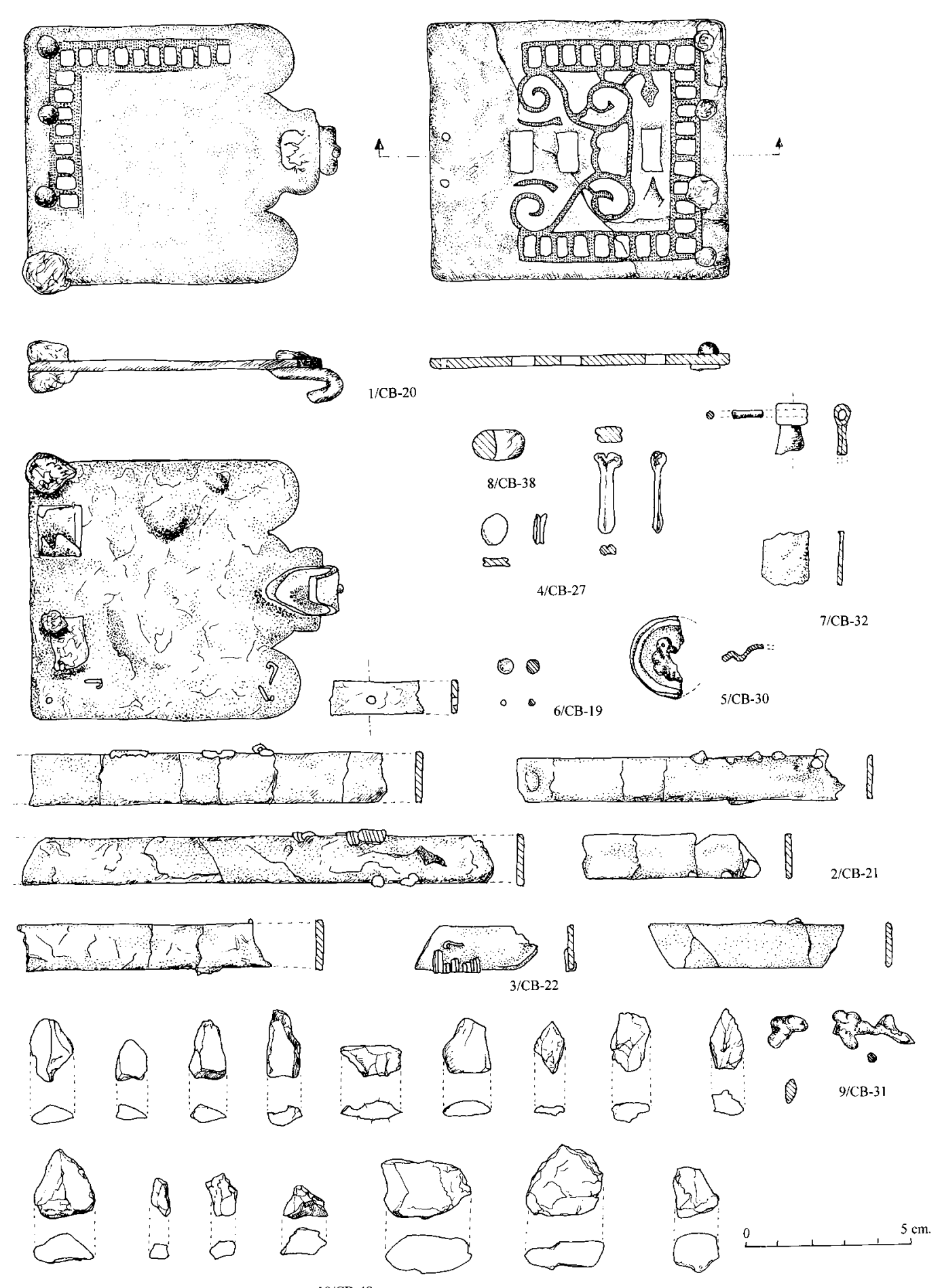

10/CB-49

Figura 2. Ajuar tumba 1. 


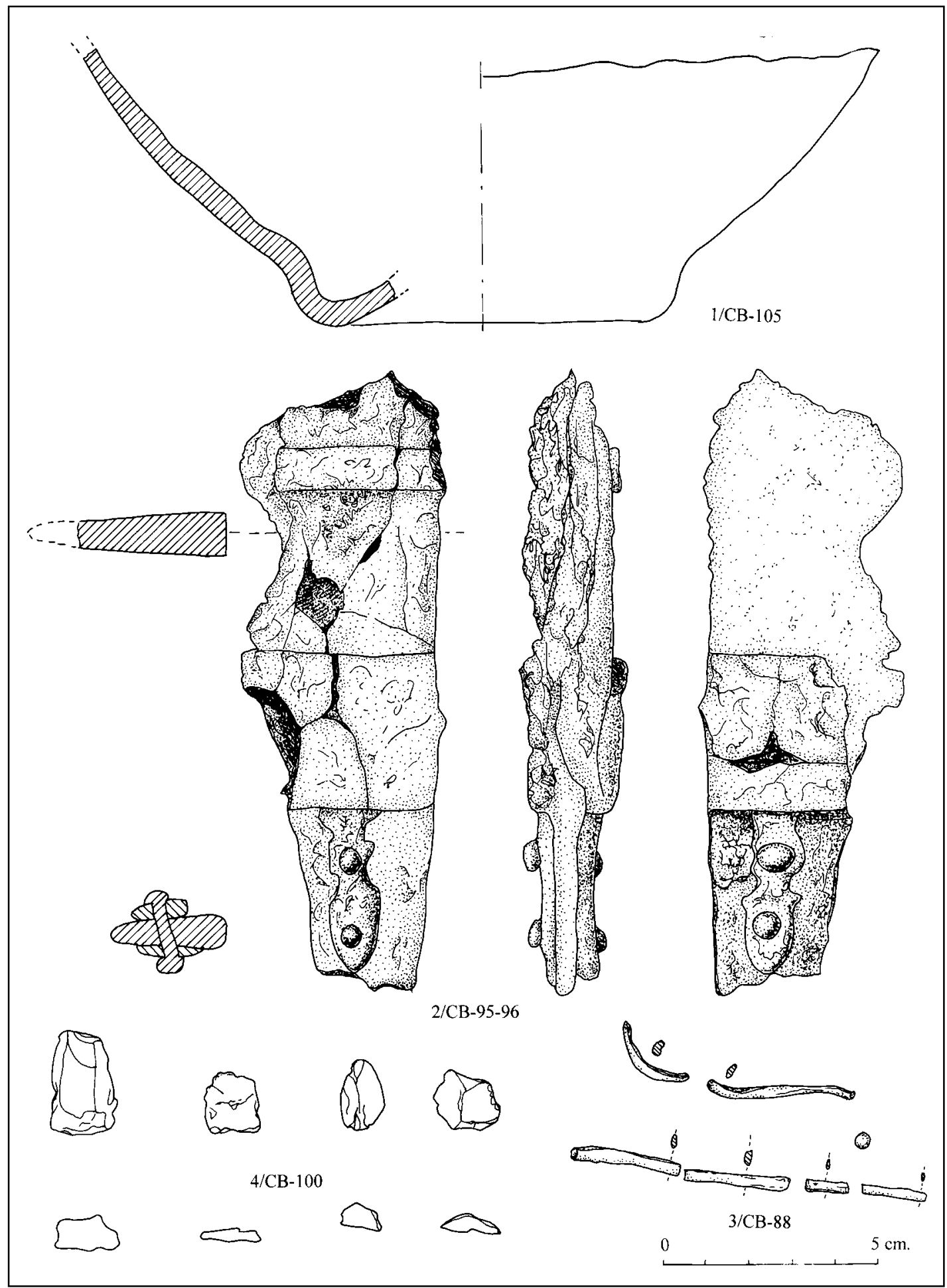

Figura 3. Ajuar tumba 4. 


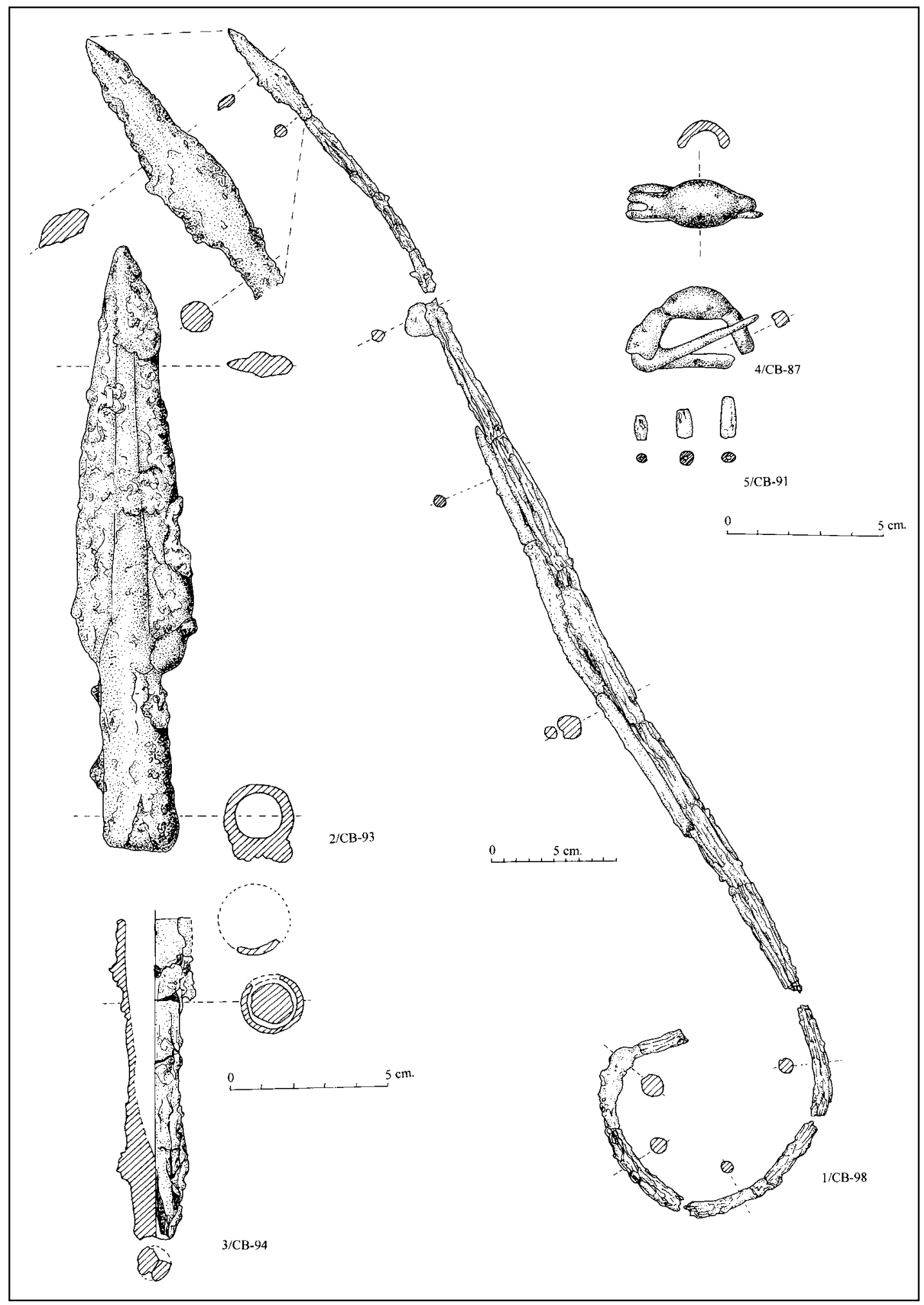

Figura 4. Ajuar tumba 4. 


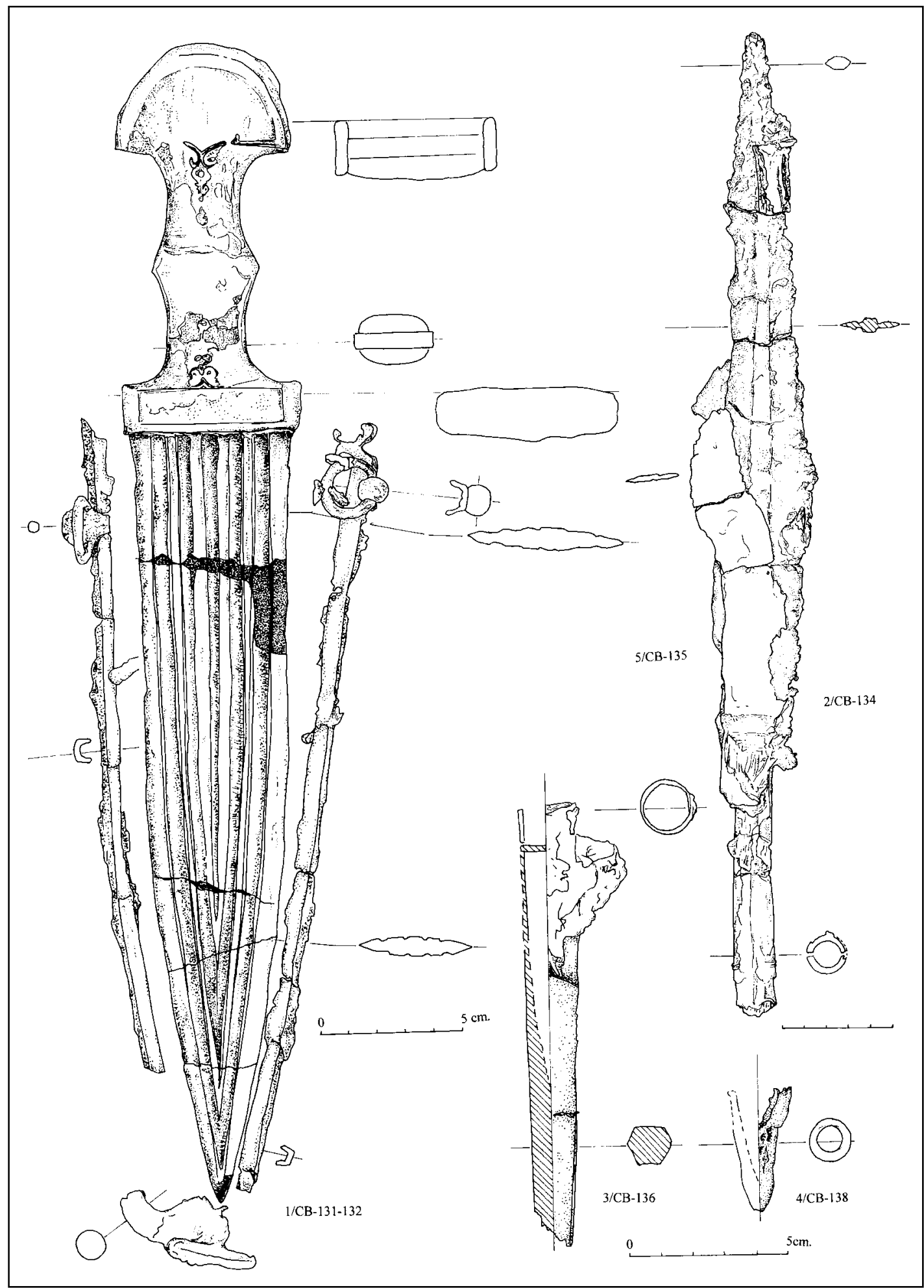

Figura 5. Ajuar tumba 7. 


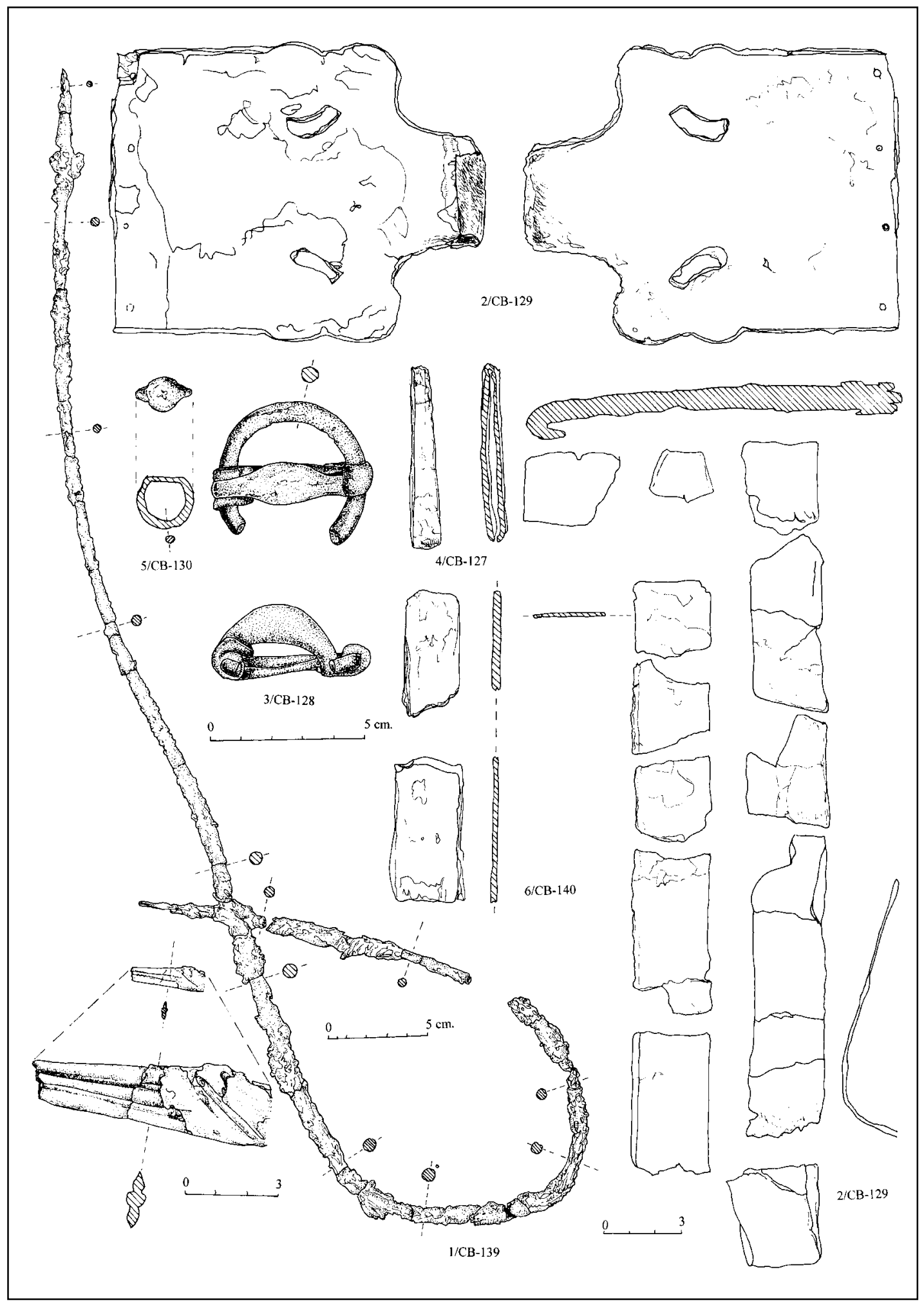

Figura 6. Ajuar tumba 7. 


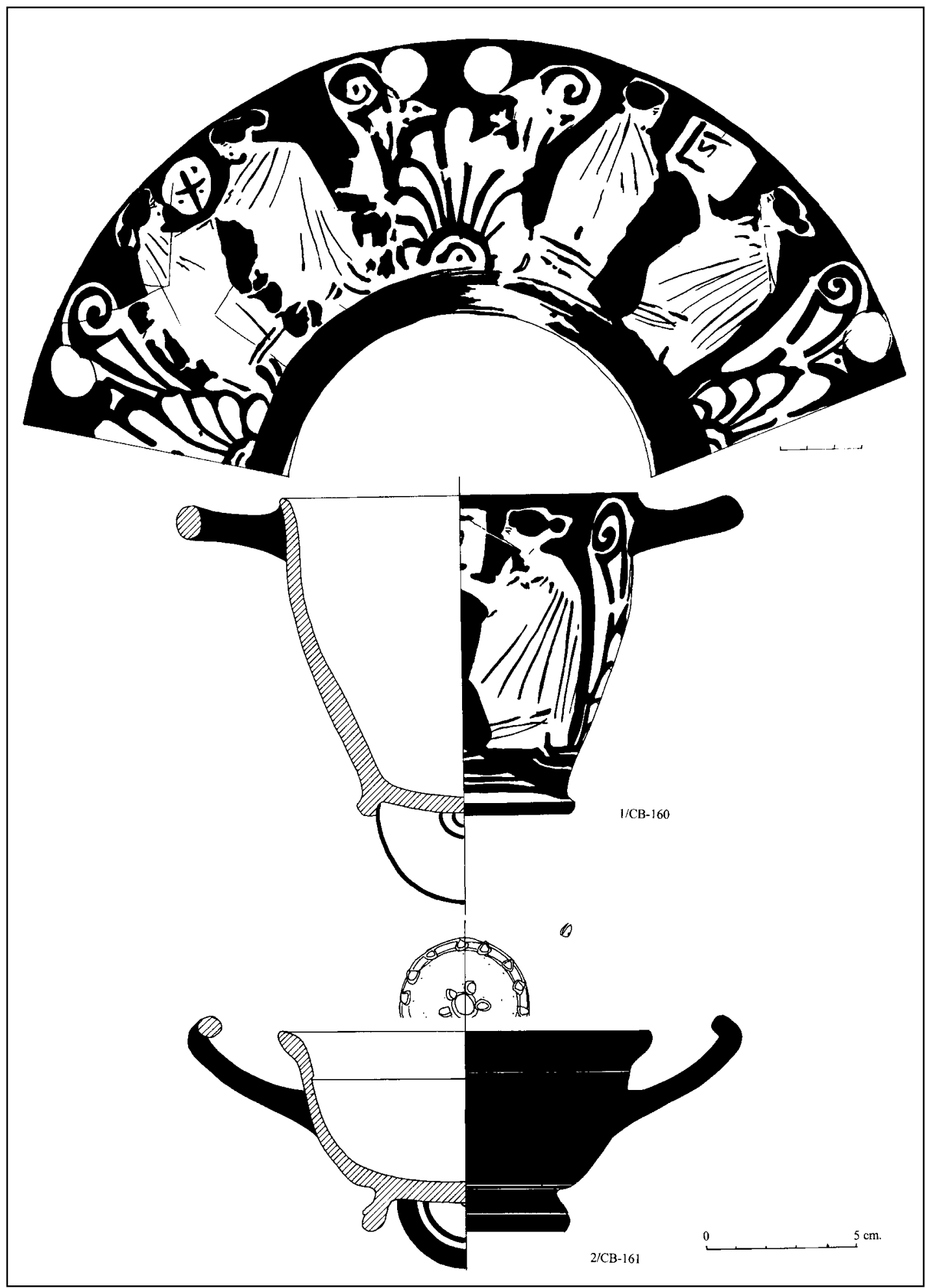

Figura 7. Ajuar tumba 10. 


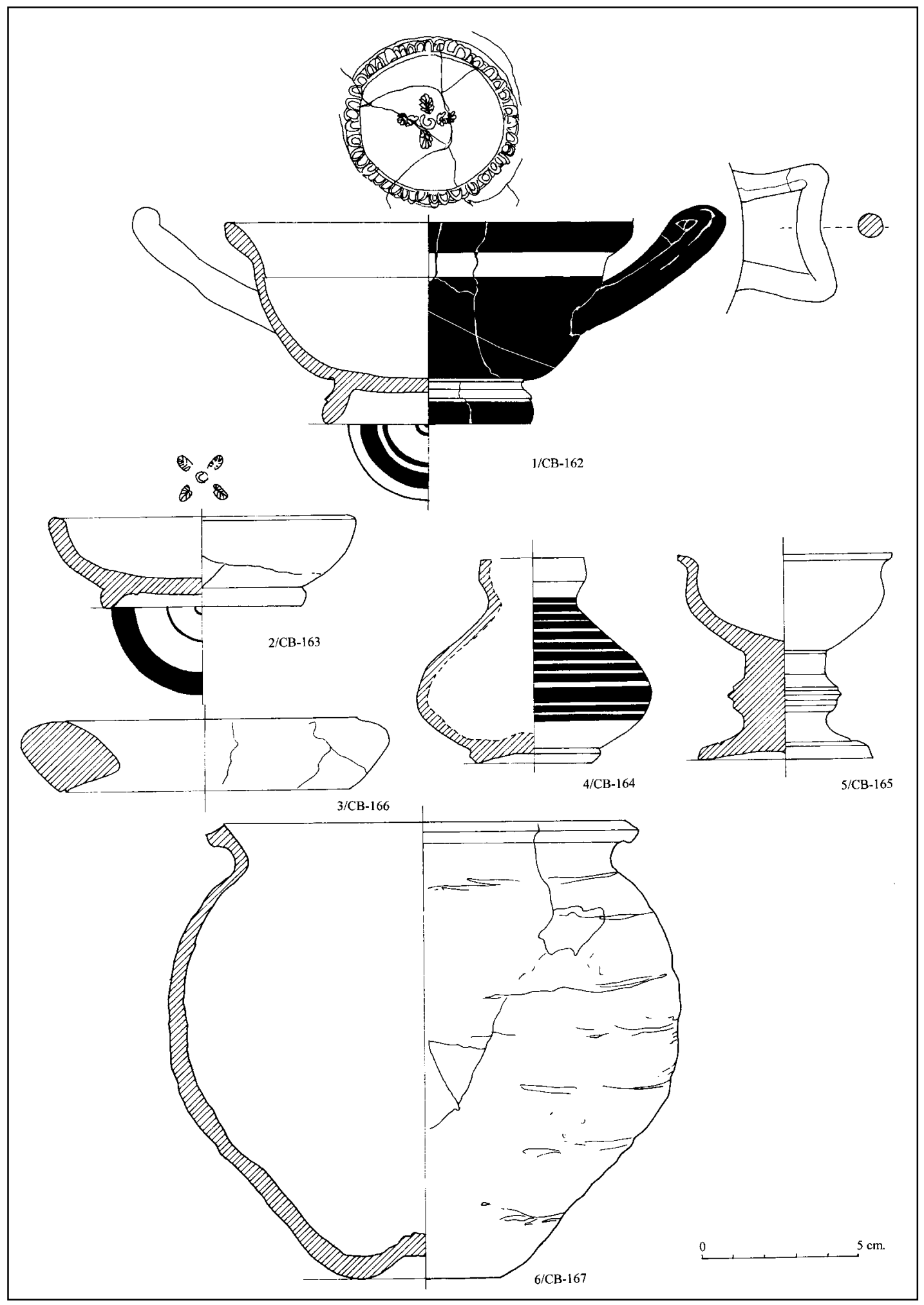

Figura 8. Ajuar tumba 10. 


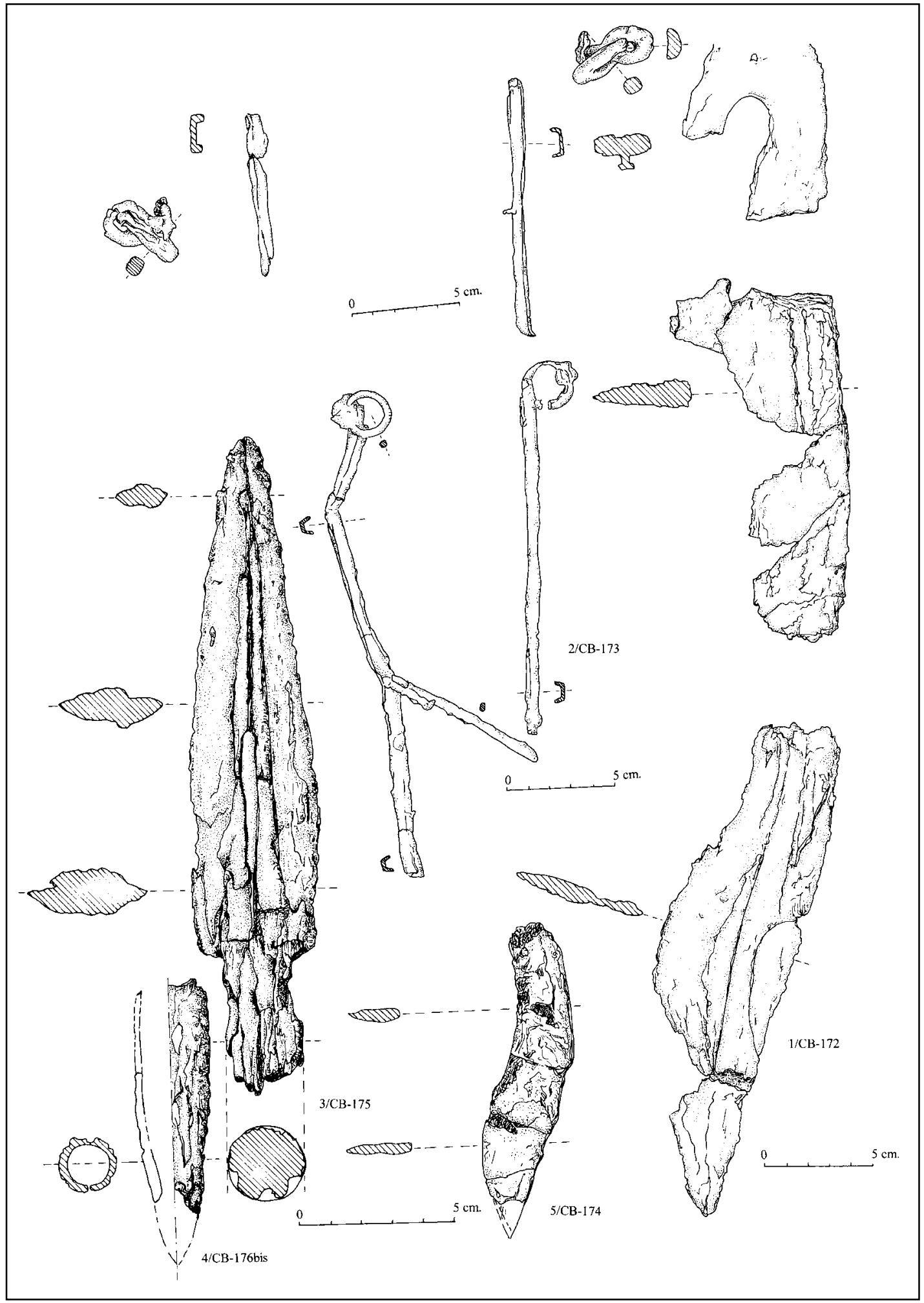

Figura 9. Ajuar tumba 10. 


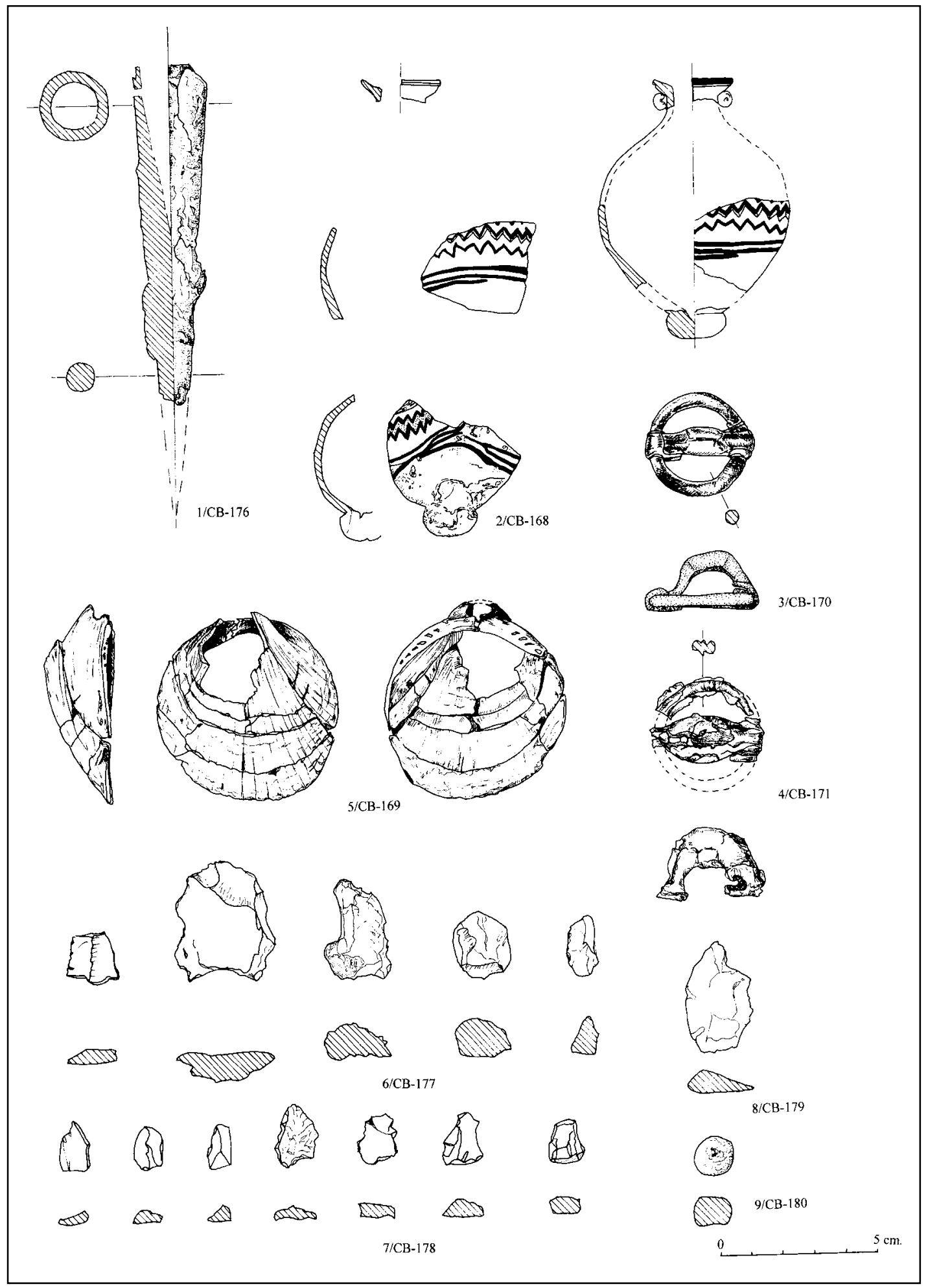

Figura 10. Ajuar tumba 10. 


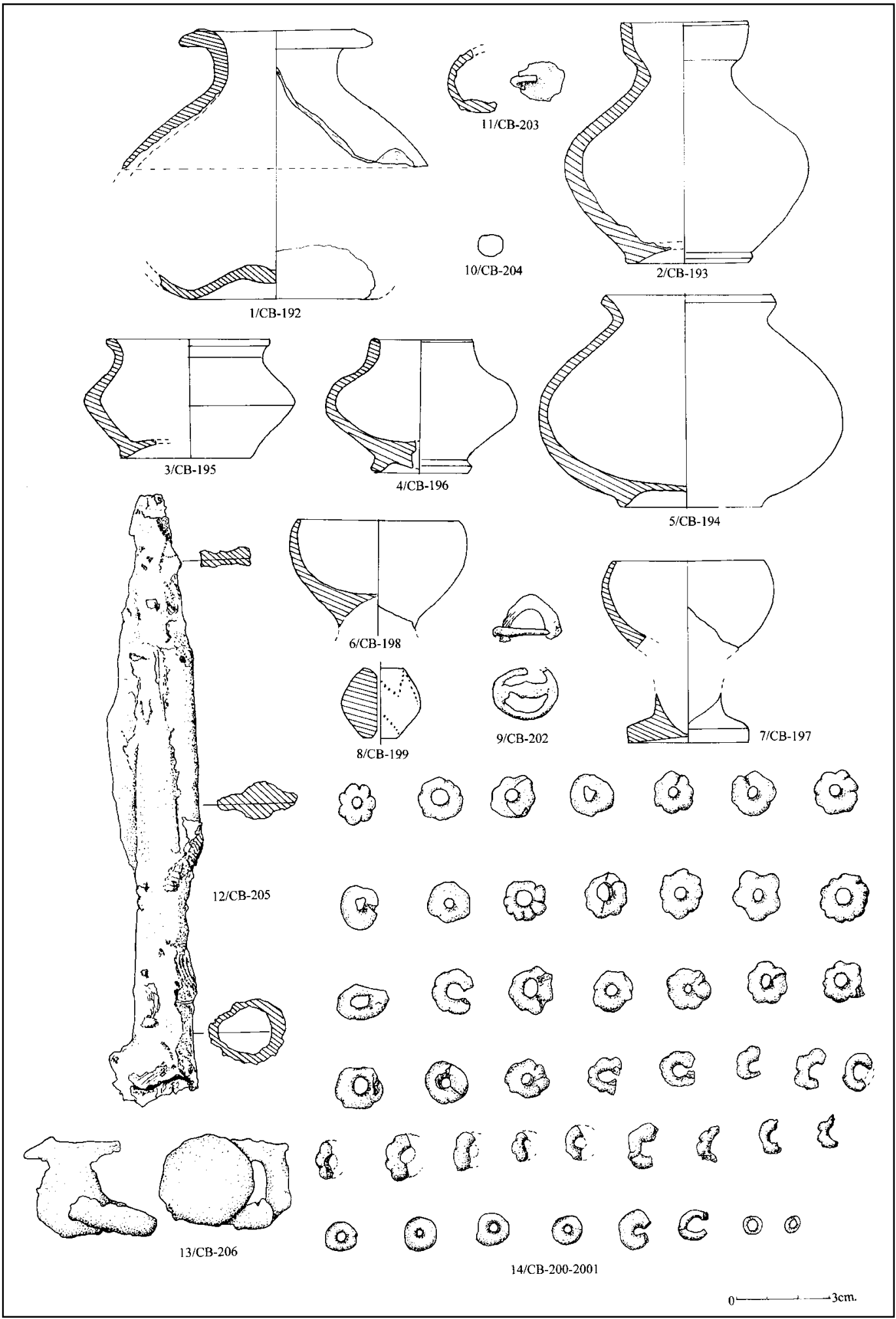

Figura 11. Ajuar tumba 12. 


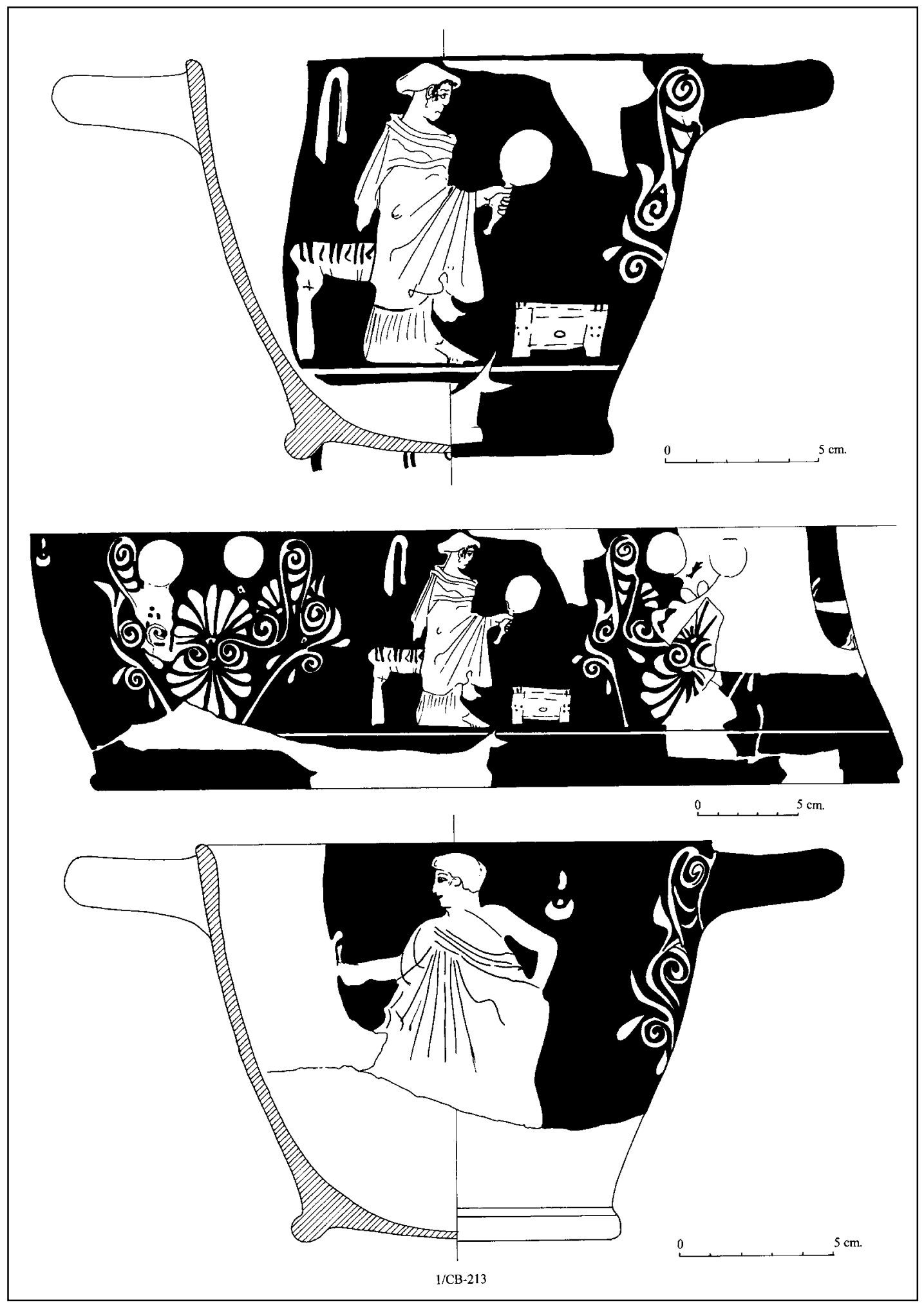

Figura 12. Ajuar tumba 14. 


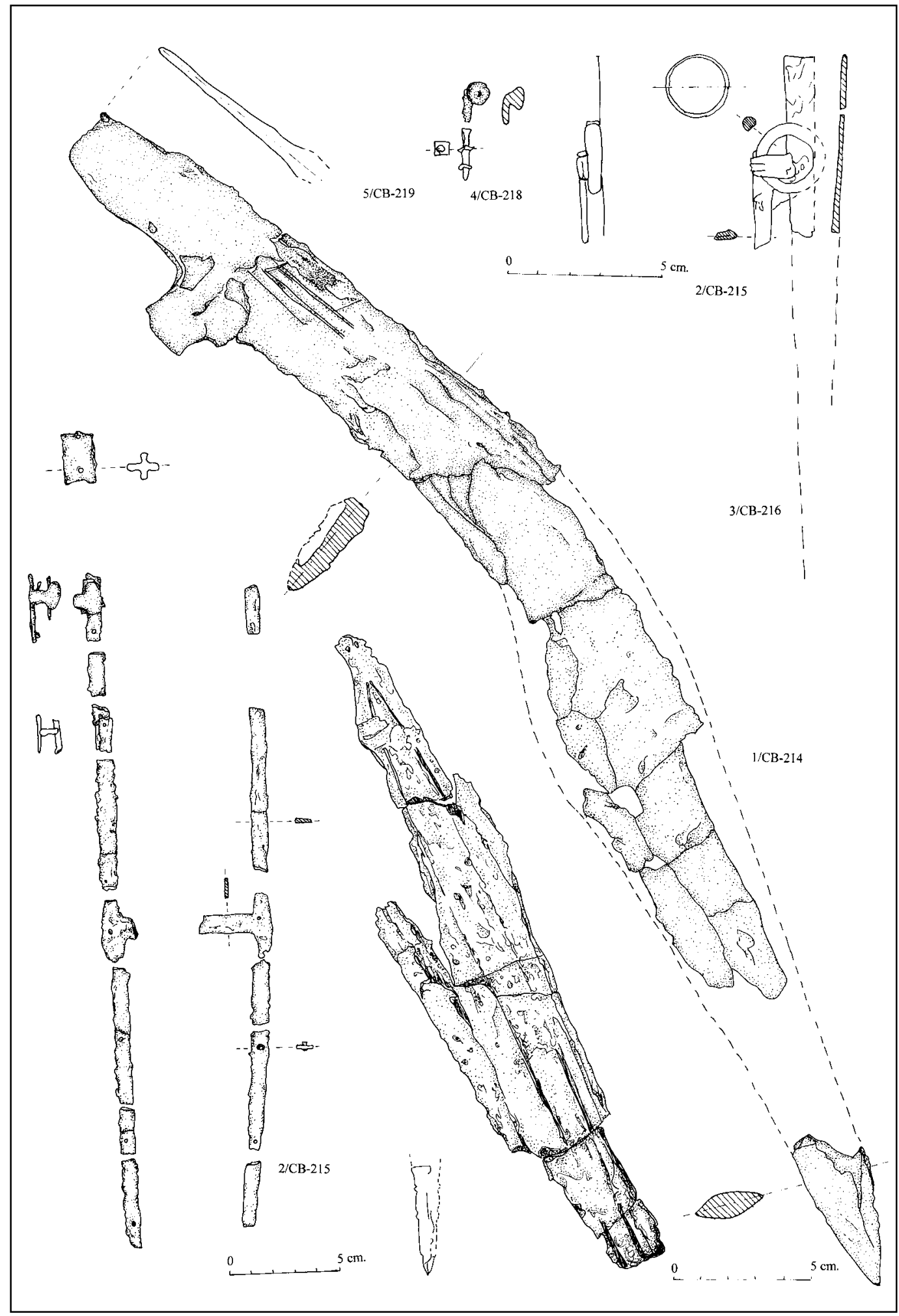

Figura 13. Ajuar tumba 14. 


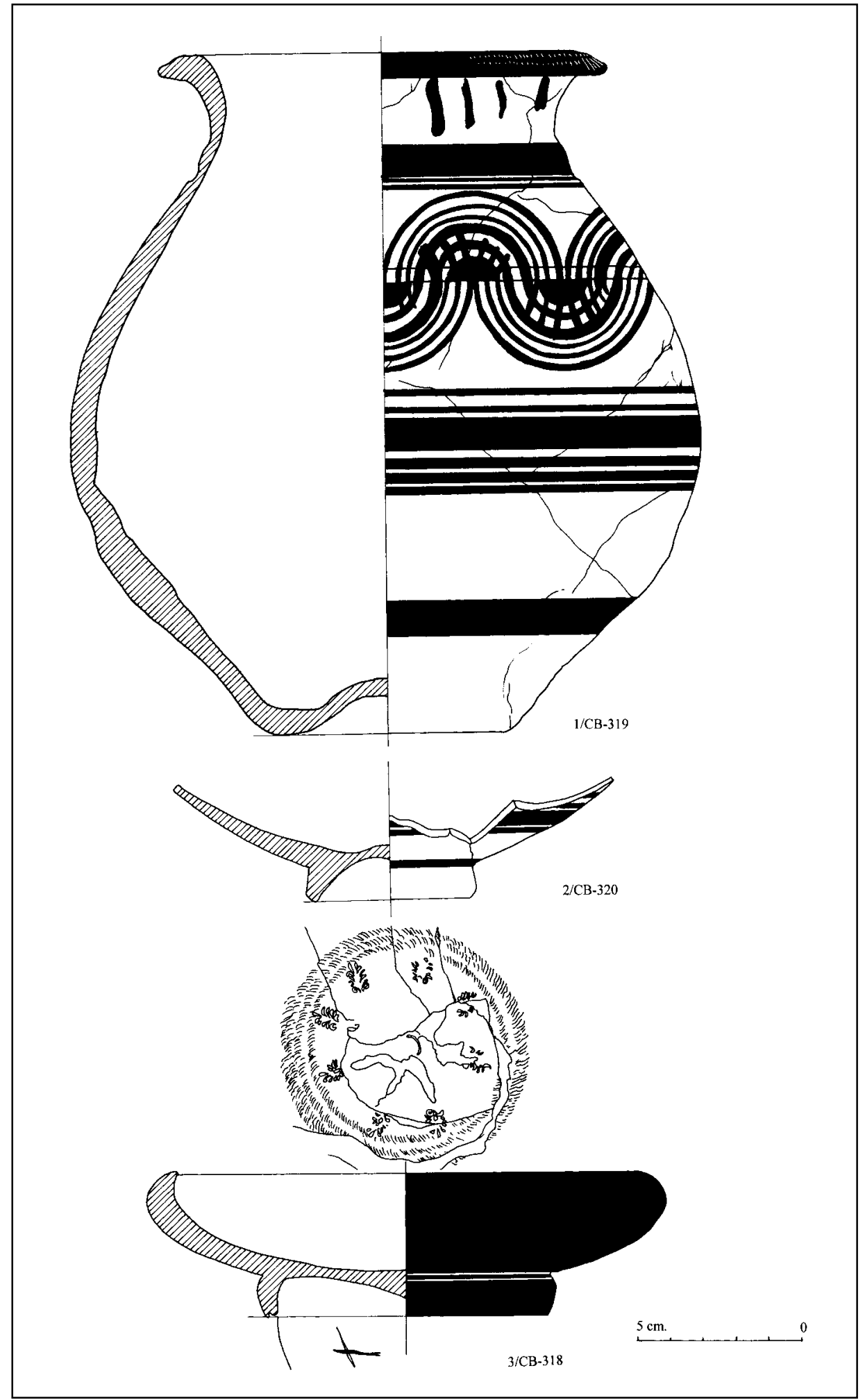

Figura 14. Ajuar tumba 24. 


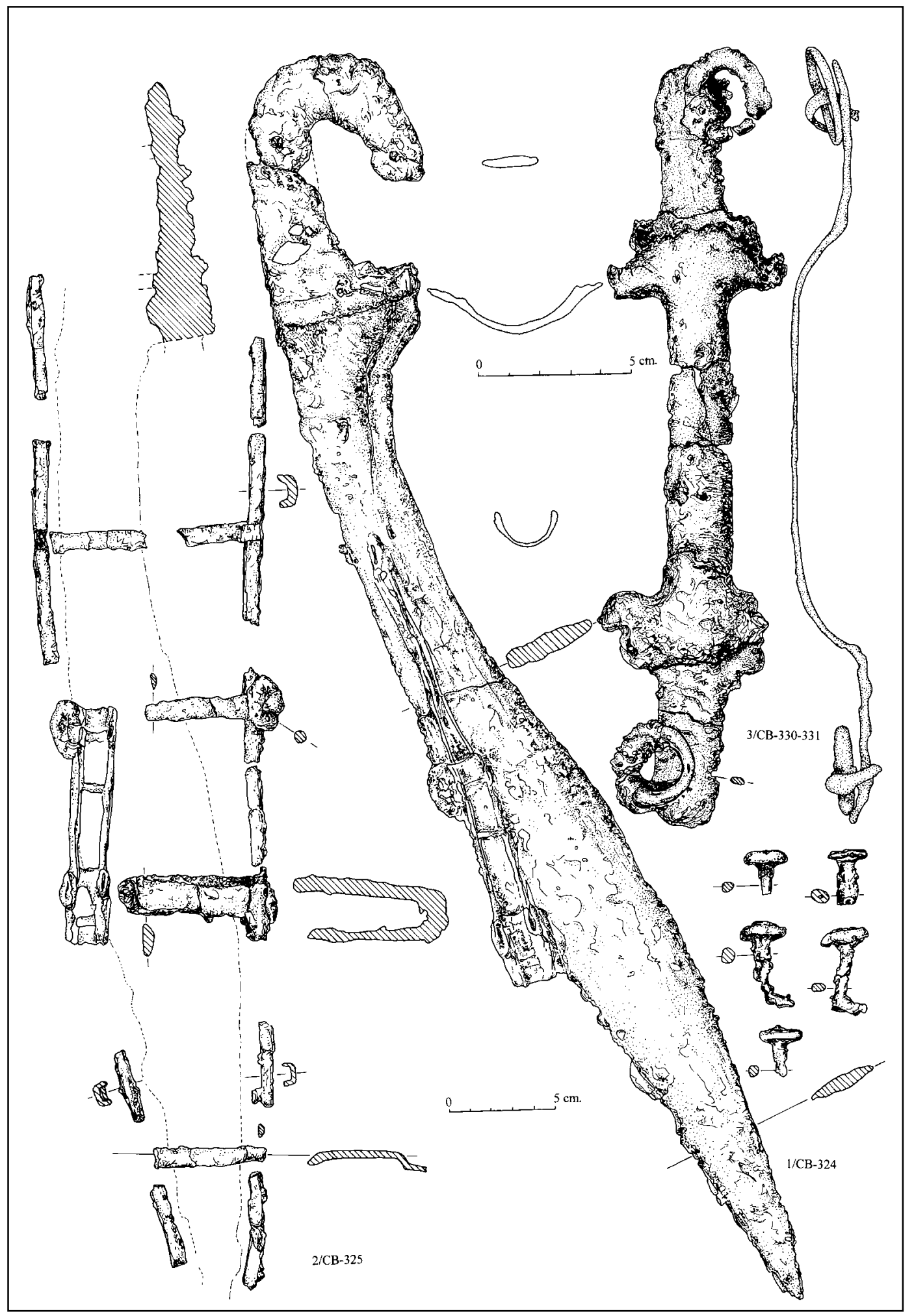

Figura 15. Ajuar tumba 24. 


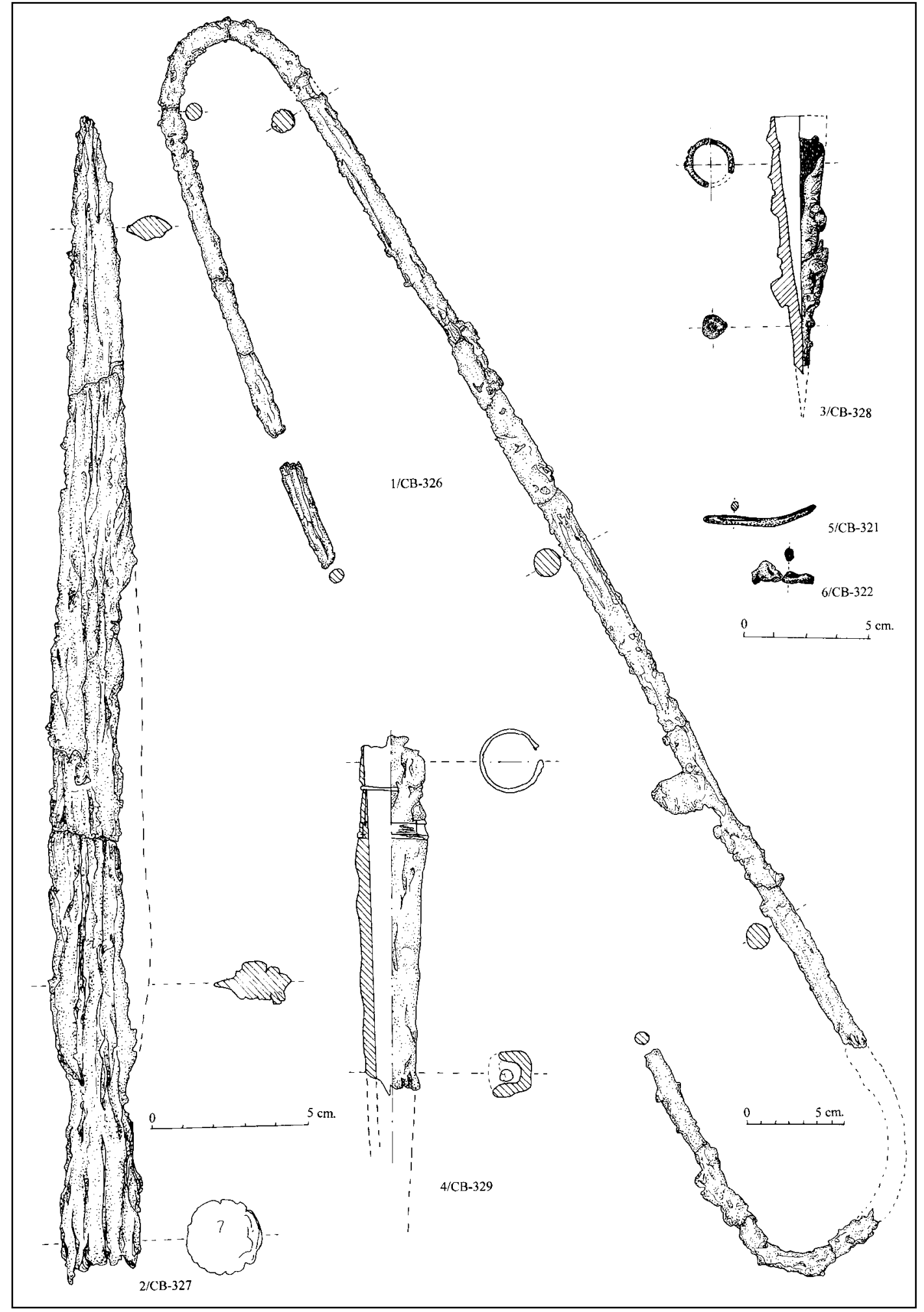

Figura 16. Ajuar tumba 24. 


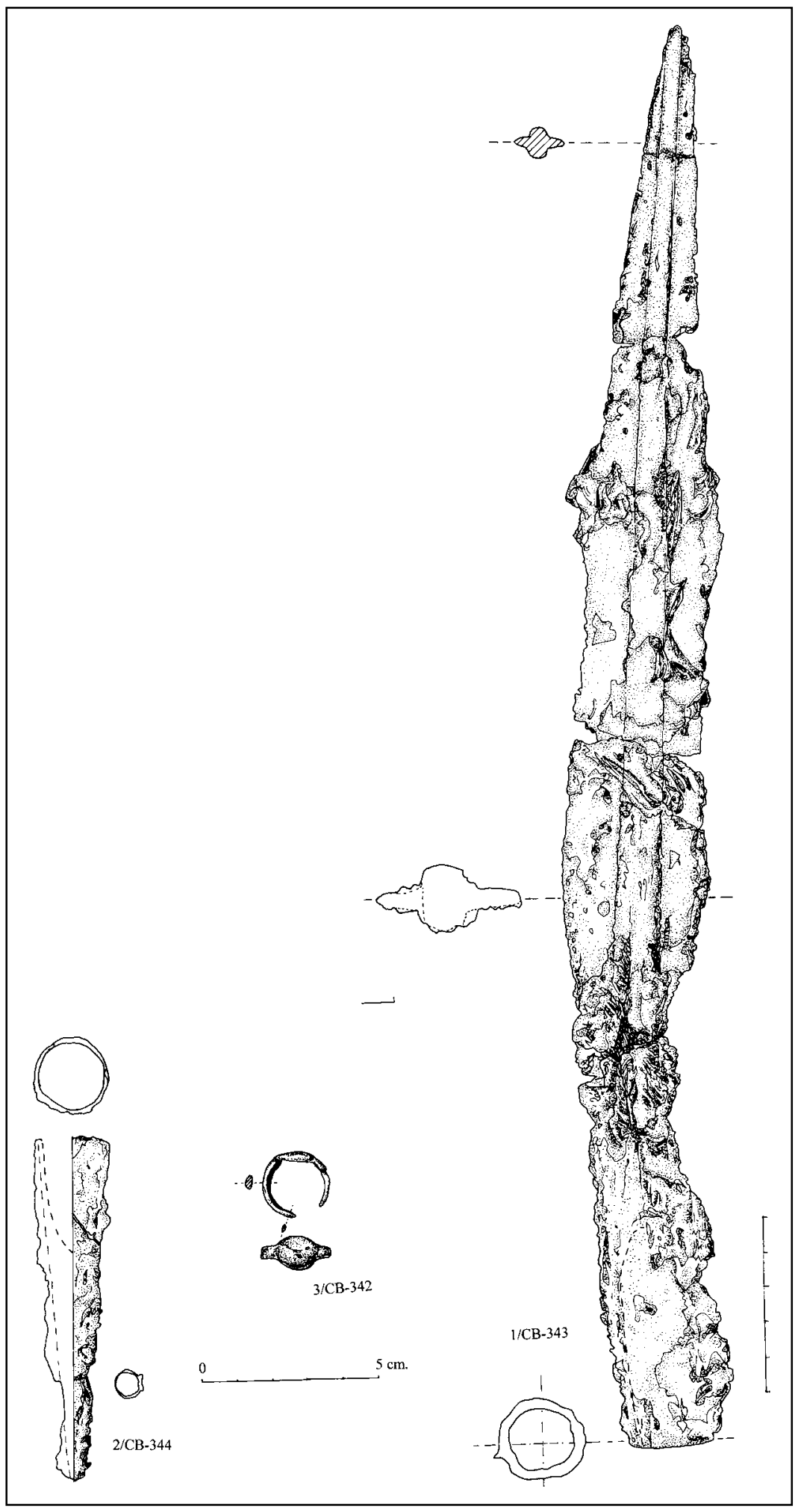

Figura 17. Ajuar tumba 26. 


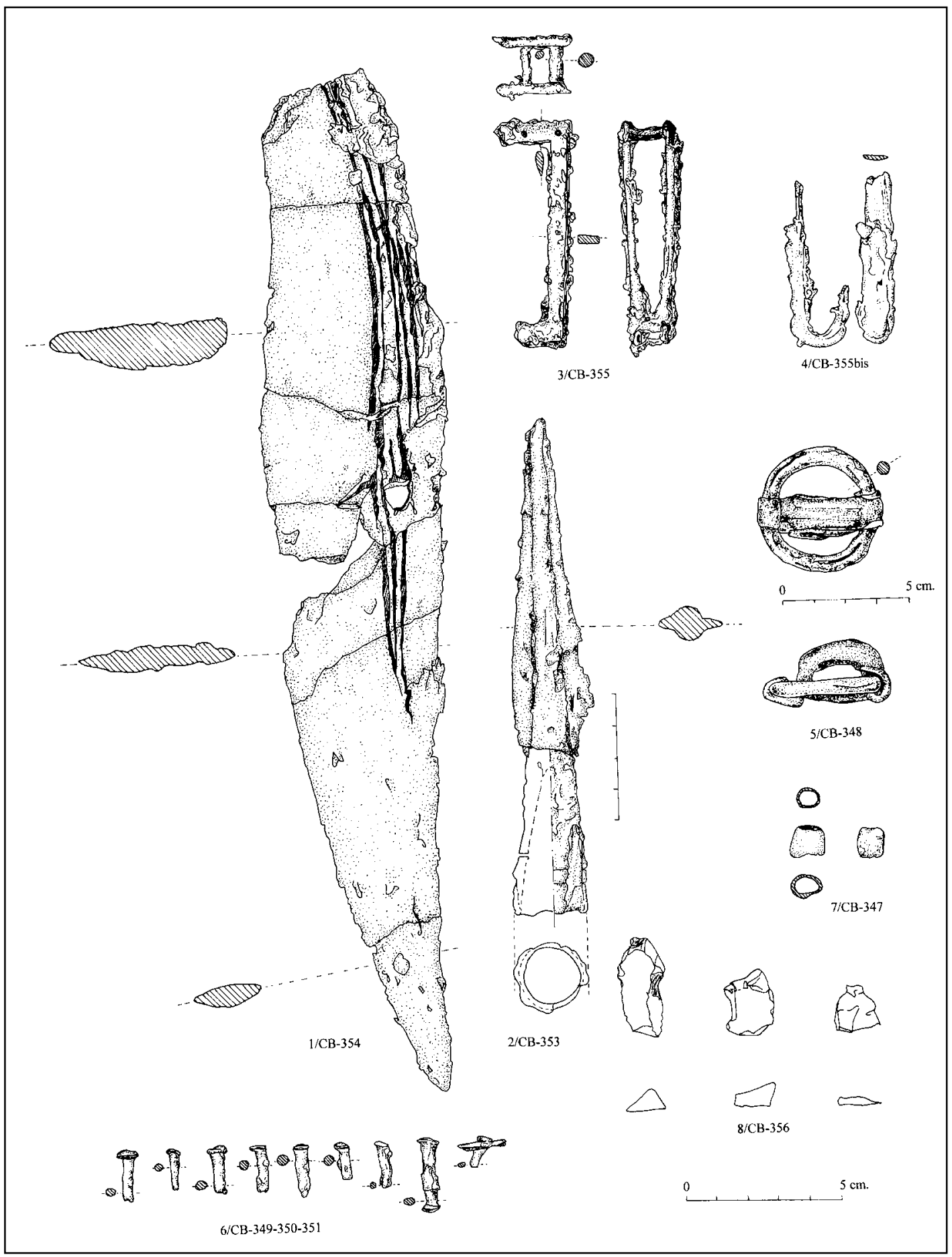

Figura 18. Ajuar tumba 28. 


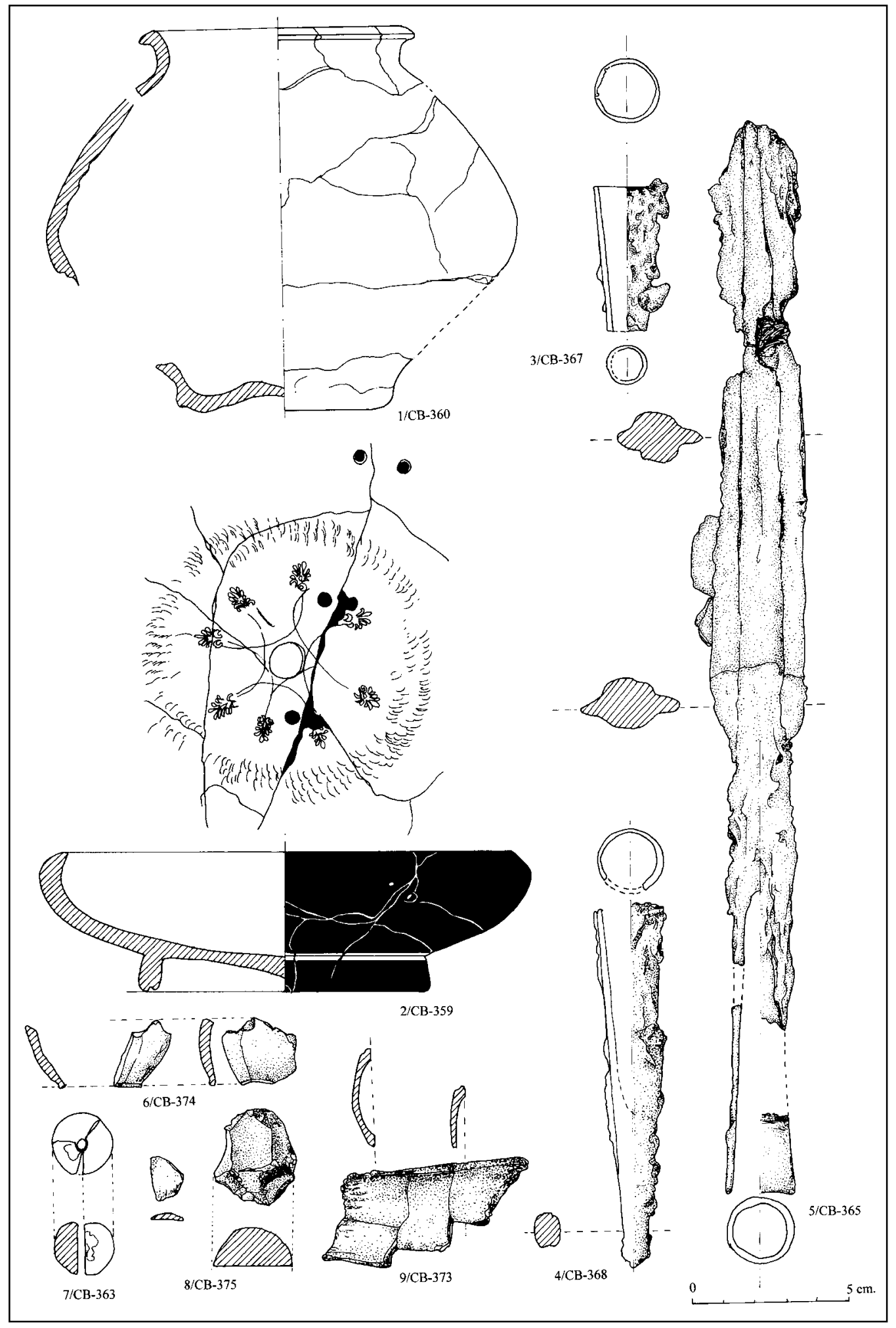

Figura 19. Ajuar tumba 29. 


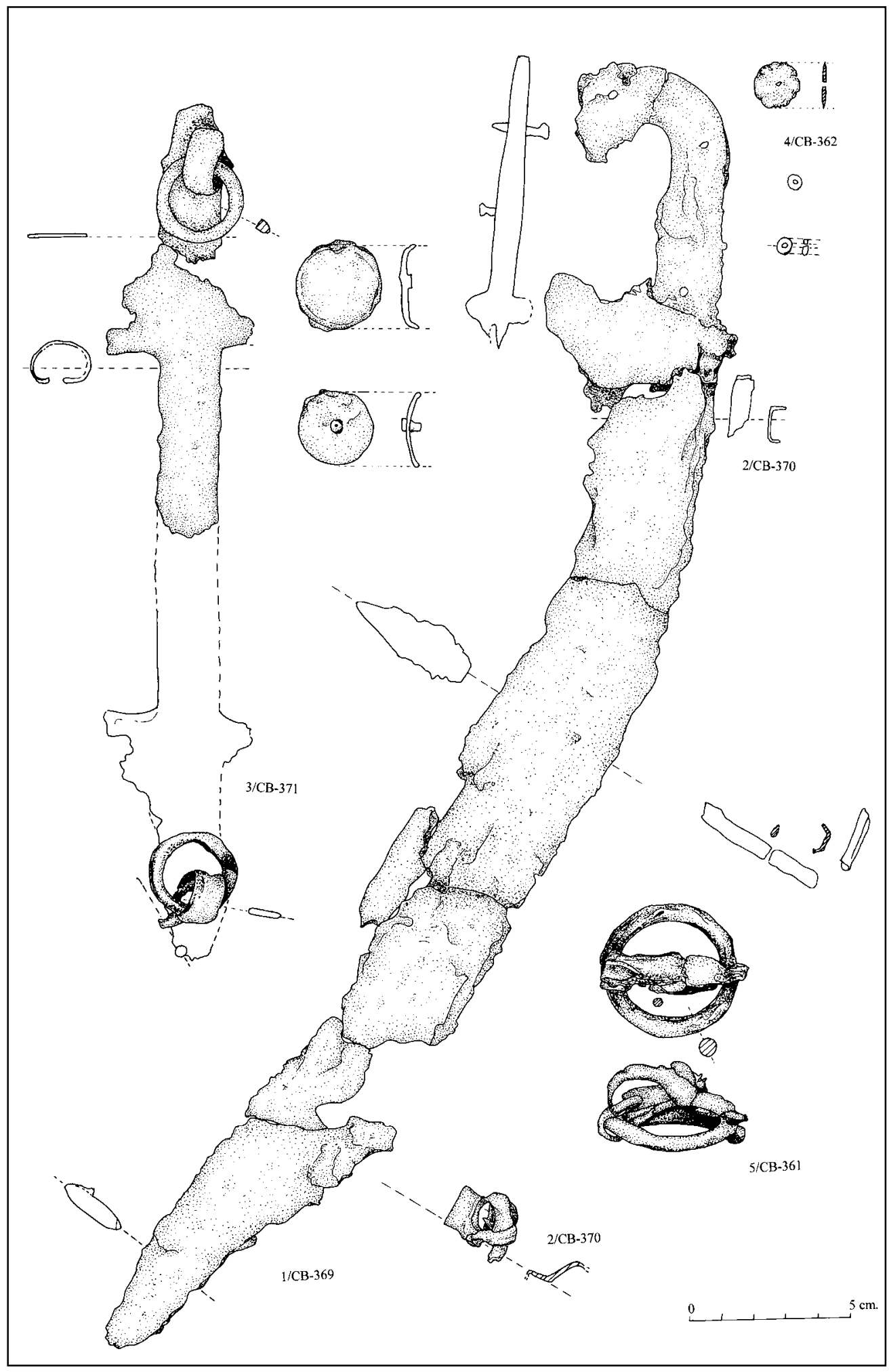

Figura 20. Ajuar tumba 29. 


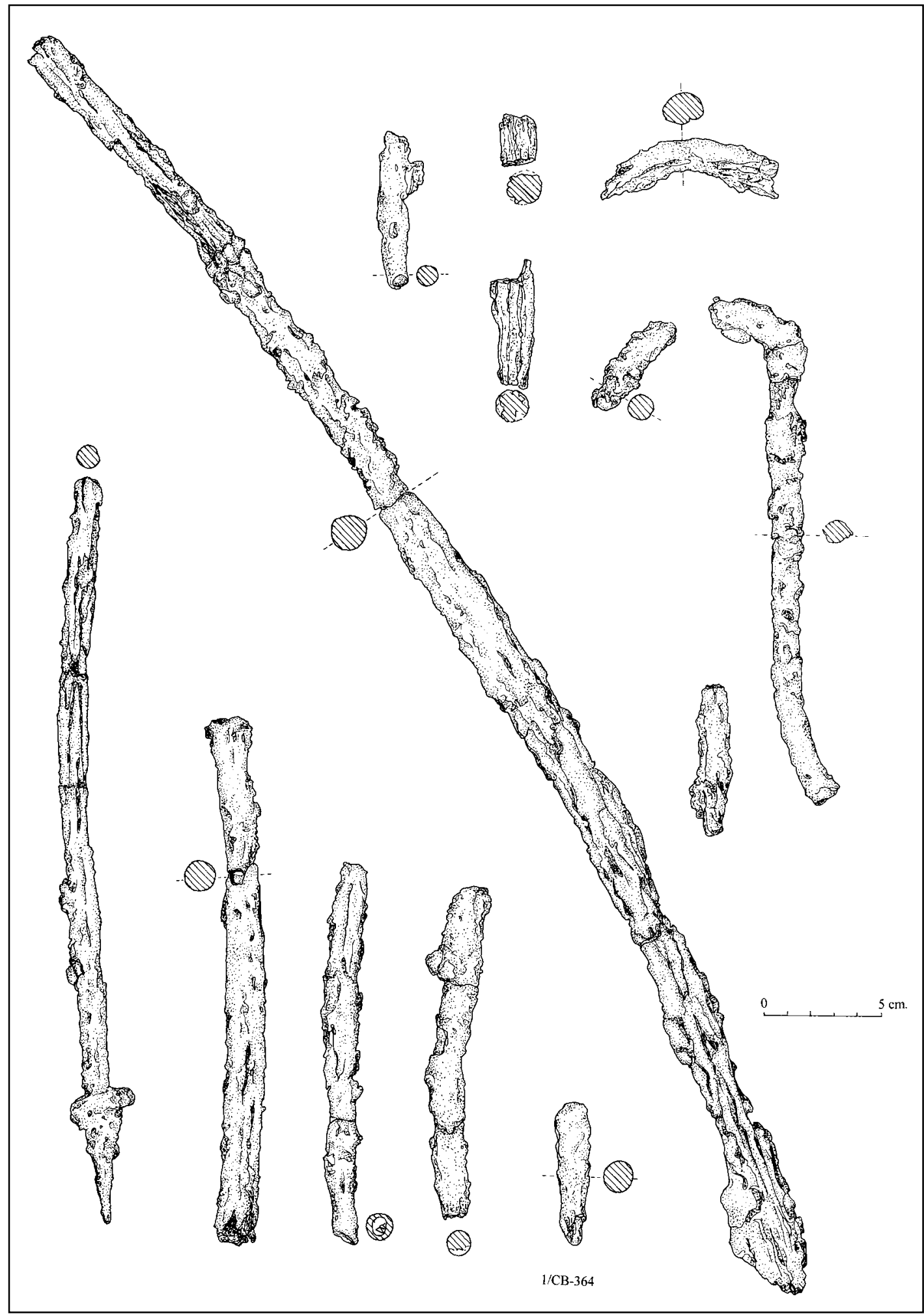

Figura 21. Ajuar tumba 29. 


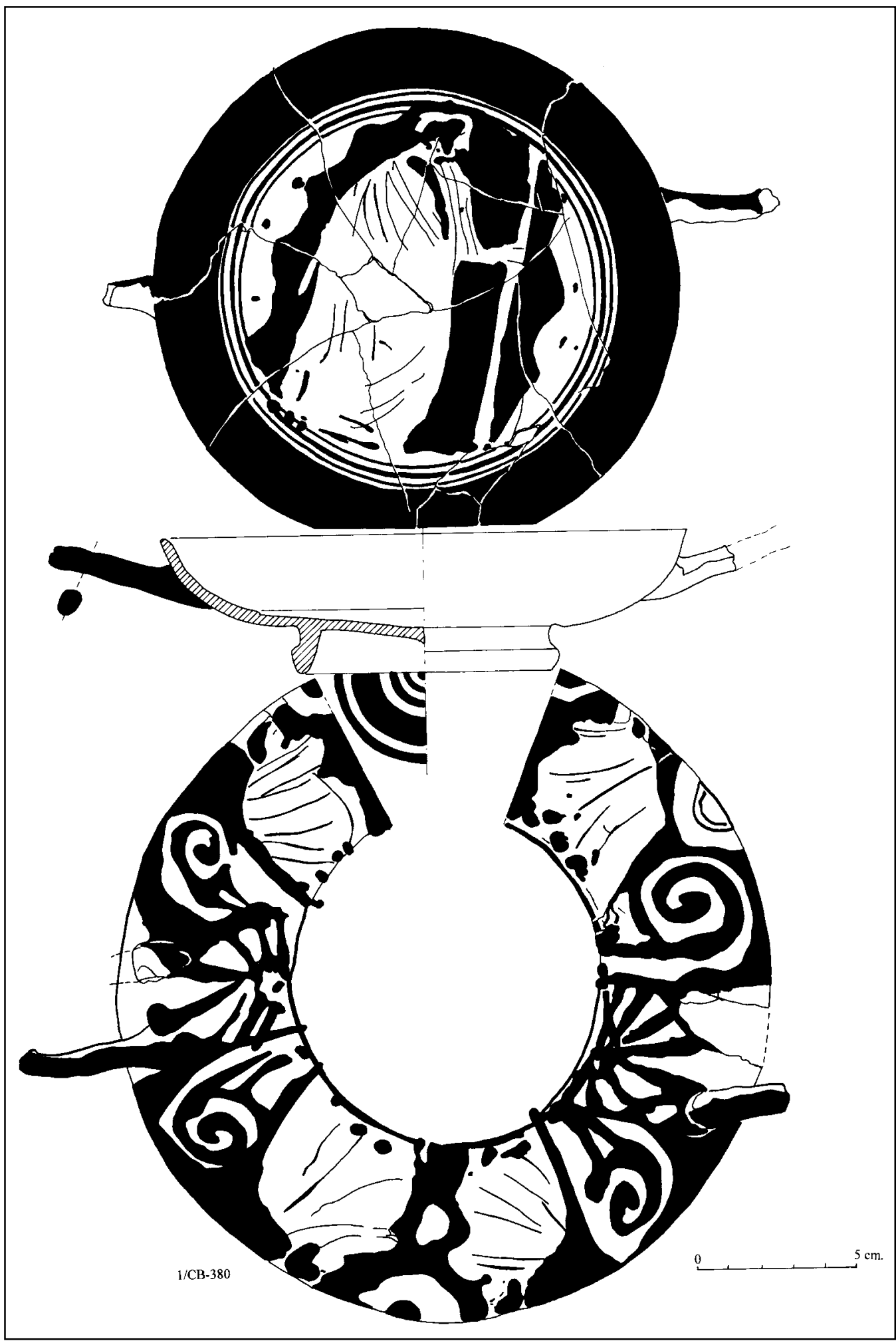

Figura 22. Ajuar tumba 30. 


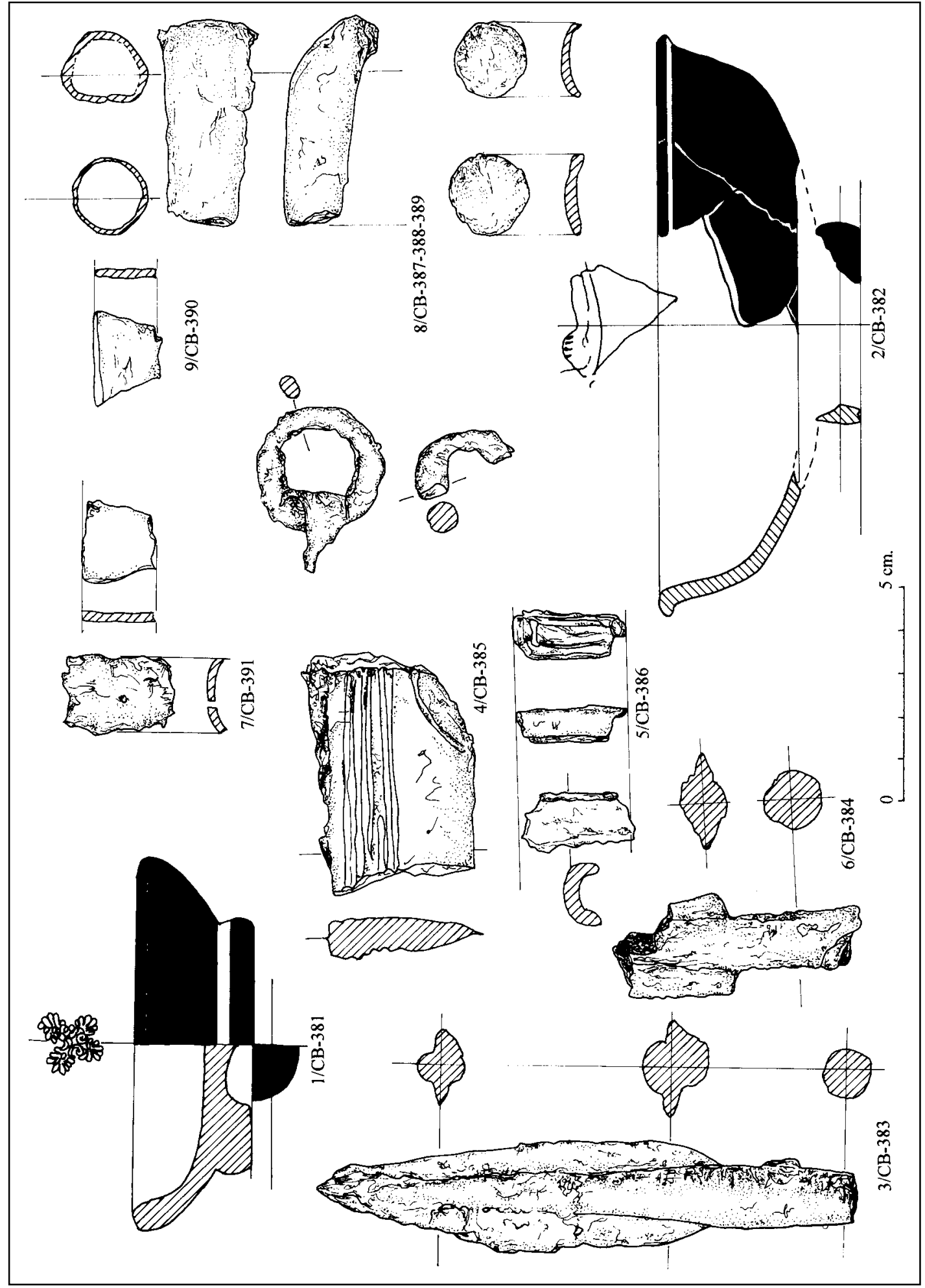

Figura 23. Ajuar tumba 30. 


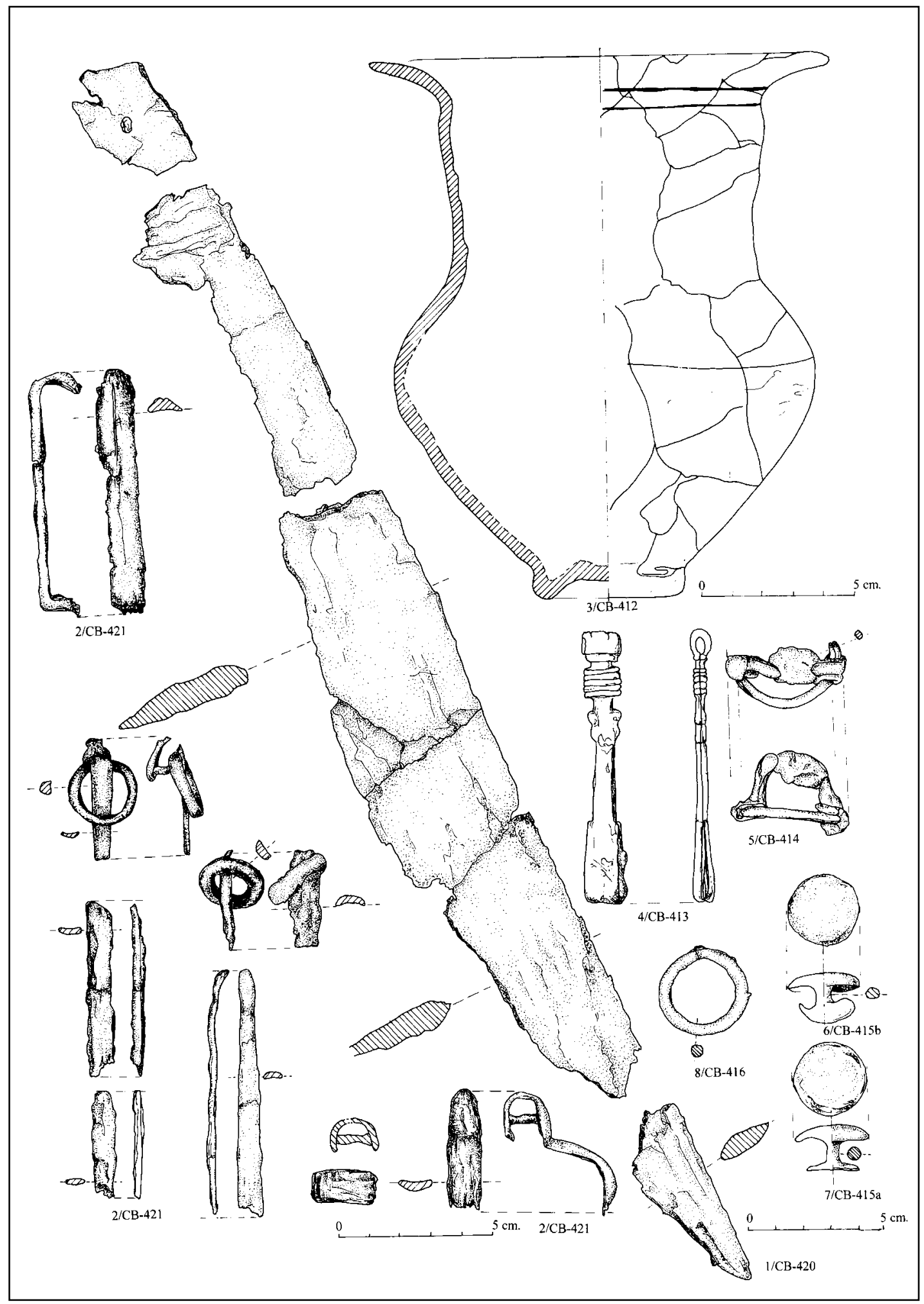

Figura 24. Ajuar tumba 34. 


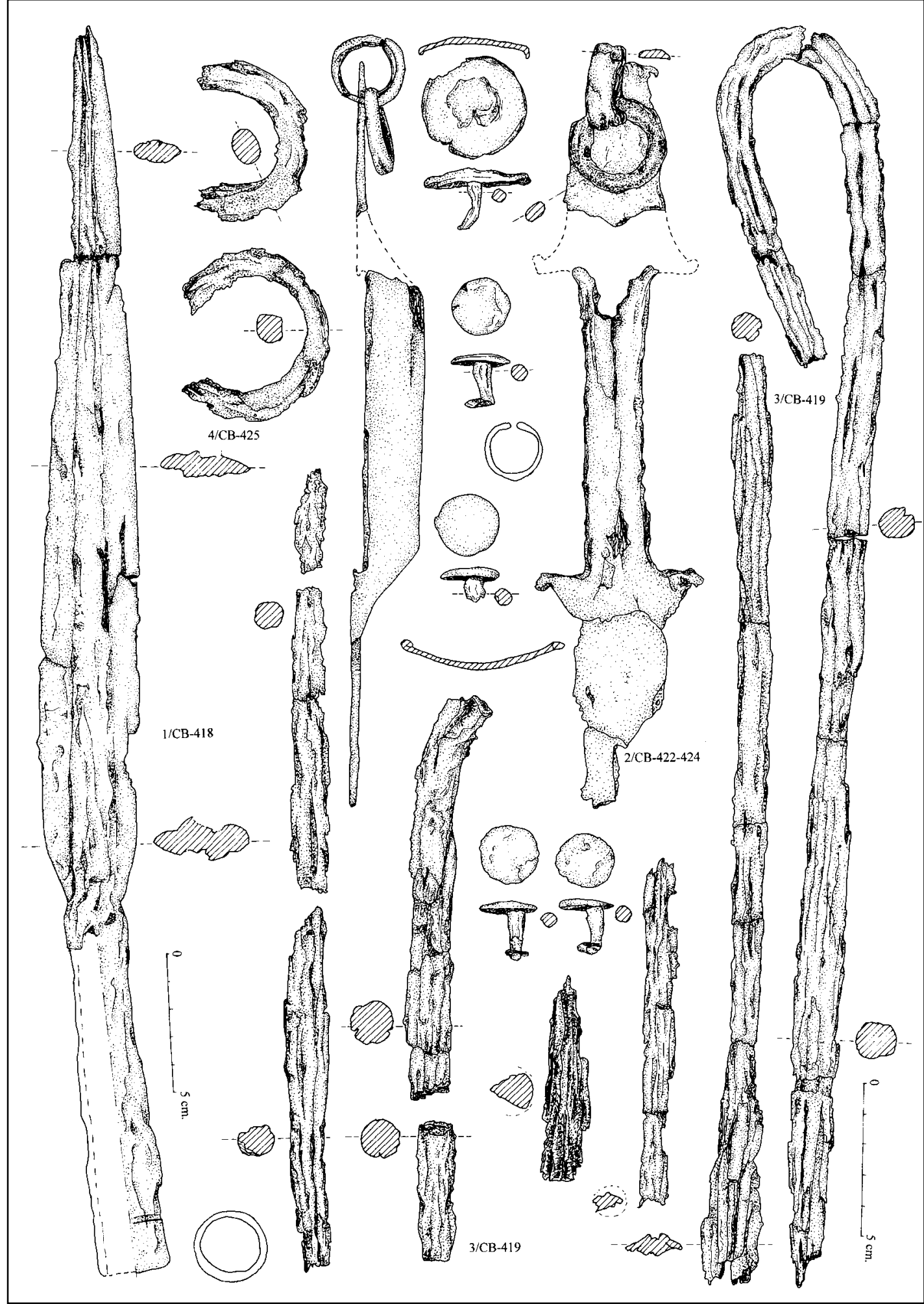

Figura 25. Ajuar tumba 34. 


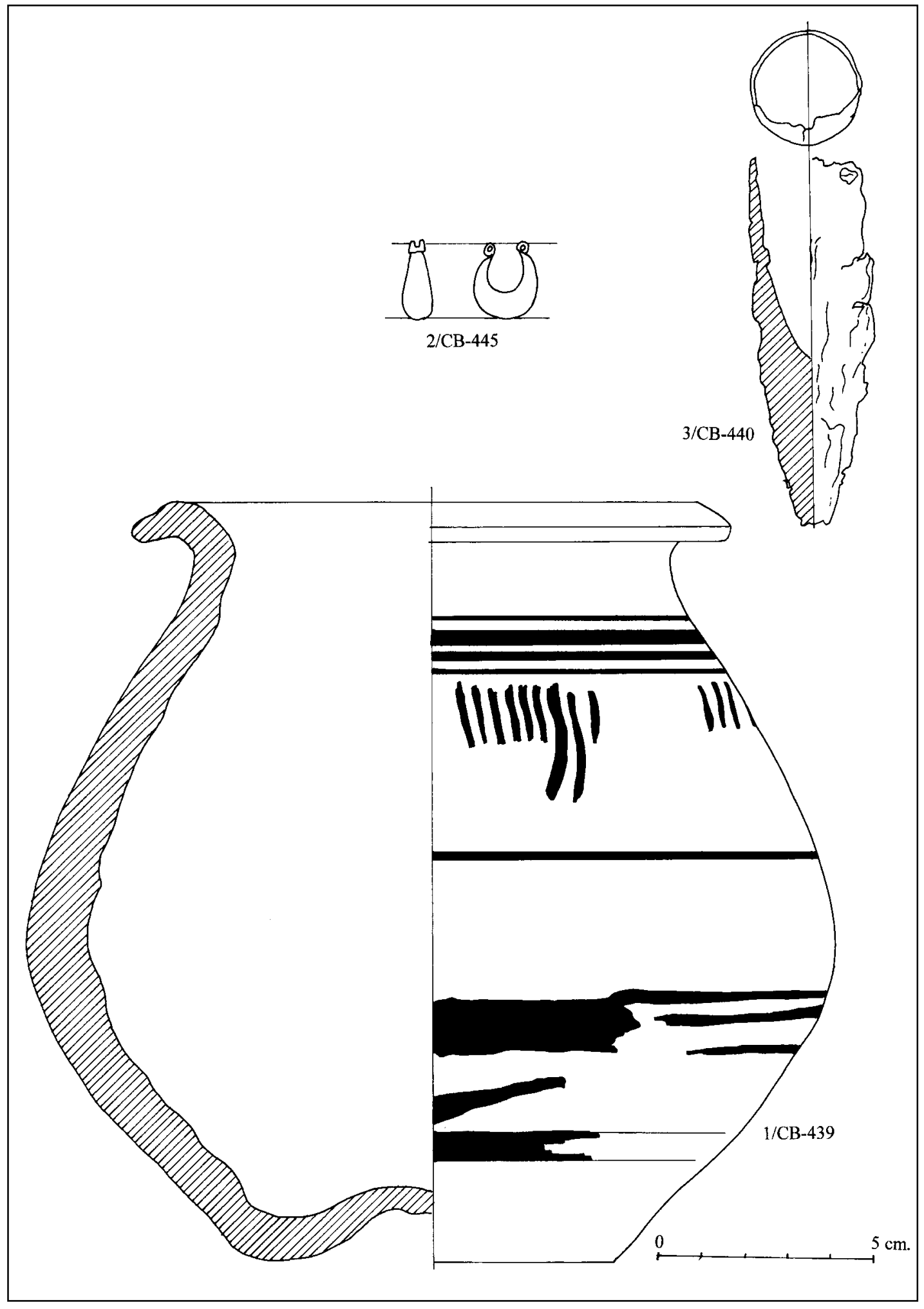

Figura 26. Ajuar tumba 36. 


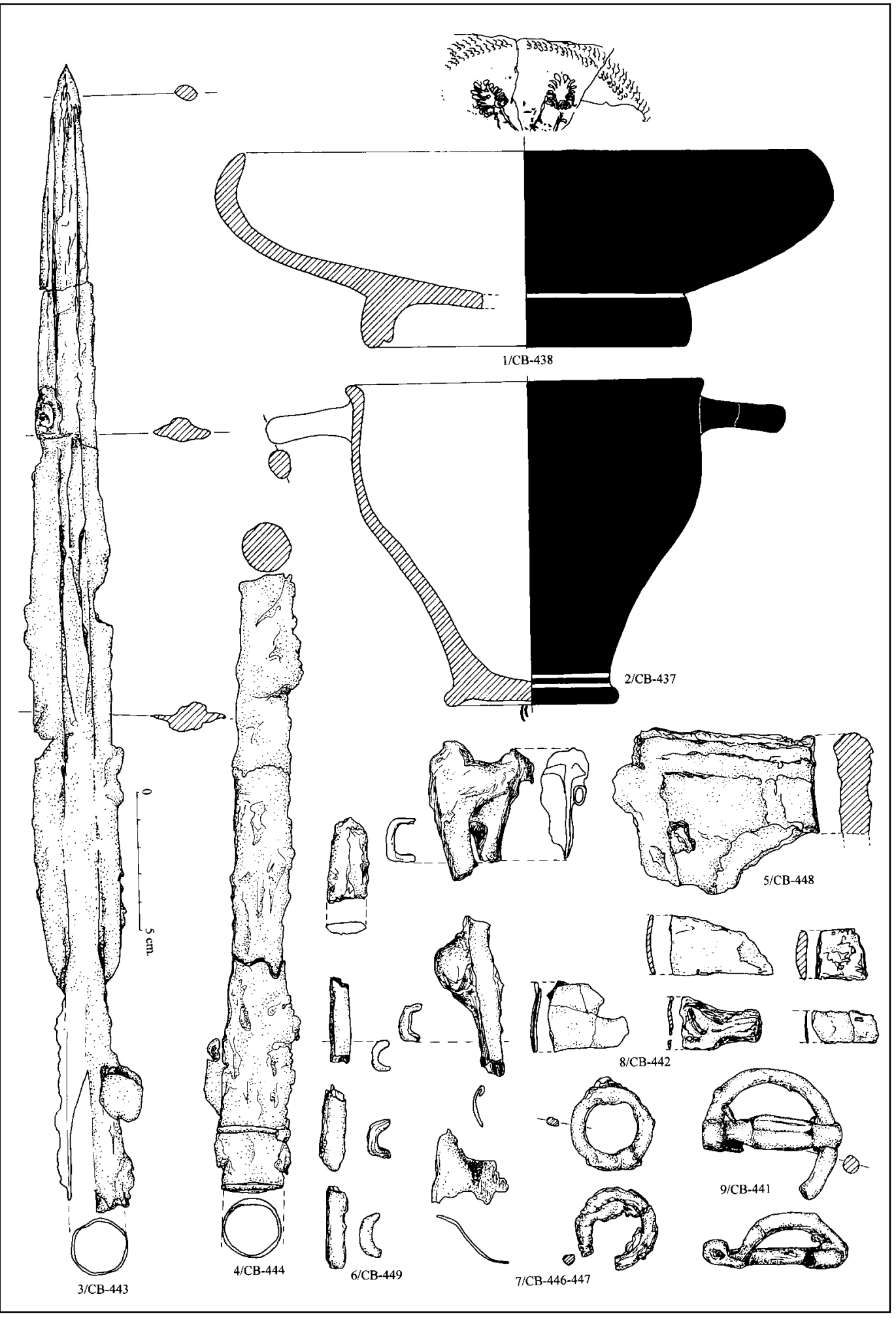

Figura 27. Ajuar tumba 36. 


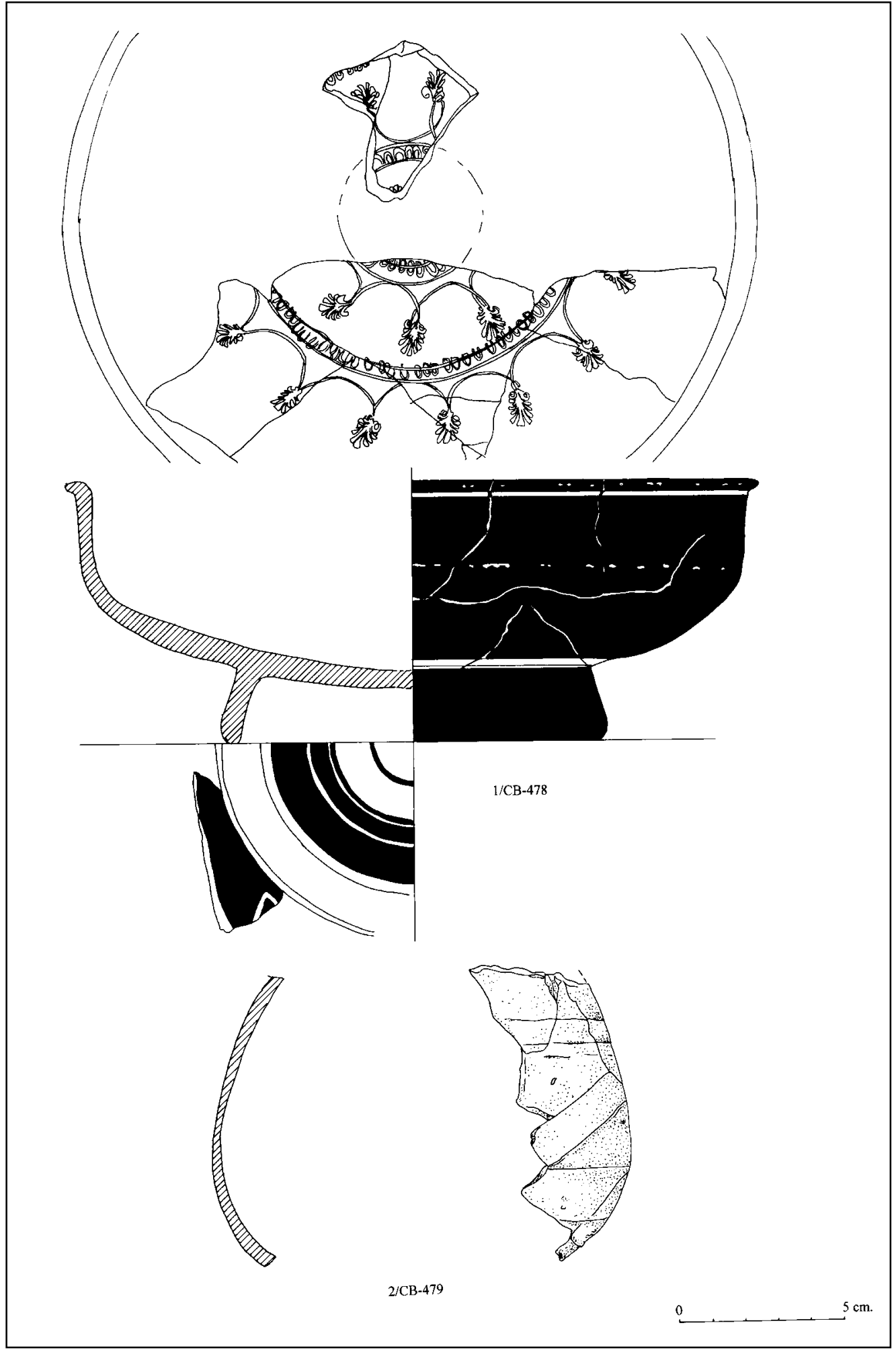

Figura 28. Ajuar tumba 42. 


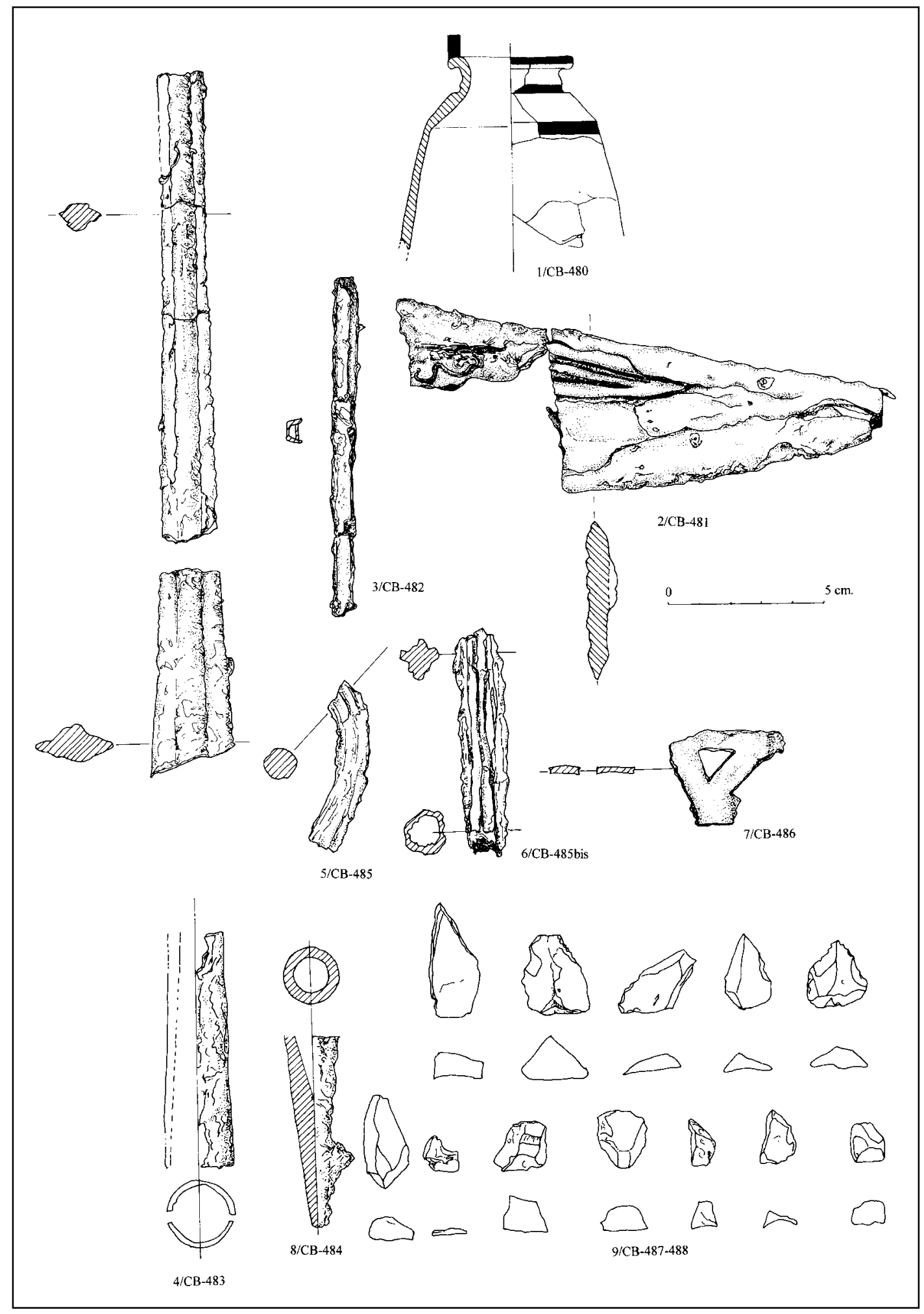

Figura 29. Ajuar tumba 42. 


\section{ABREVIATURAS EMPLEADAS}

Amáxima: Anchura máxima Amínima: Anchura mínima

D.: Diámetro

Db.: Diámetro borde

Dp.: Diámetro pie

Db.: Diámetro borde

DM.: Dimensiones máximas
H.: Altura

Hc.: Altura conservada

hp.: Altura pie

L.: Longitud

Lc.: Longitud conservada

\section{REFERENCIAS BIBLIOGRÁFICAS}

Almagro Gorbea, M. (1983): Colonizzazione e Acculturazione nella Peninsola Iberica», FORME DI CONTATTO E PROCESSI DI TRASFONAZIONE NELLE SOCIETA ANTICHE. École Francaise de Rome. Roma, pp. 429-461.

BEAZLEY, J. D. (1936): Attic Black-figure Vases. Oxford.

BLÁNQUEZ PÉREZ, J. (1992): «Las necrópolis ibéricas en el Sudeste de la Meseta». CONGRESO DE ARQUEOLOGÍA IBÉRICA: LAS NECRÓPOLIS. SERIE VARIA I. Madrid.

BLÁZQUEZ MARTíNEZ, J. M. a (1975): Cástulo I. ACTA ARQUEOLÓGICA HISPÁNICA 8. Madrid.

BOARDMAN, J. (1958-59): «Old Smyrna:The attic pottery». ANNUAL OF THE BRITISH SCHOOL AT ATHENS 53-54.

Broncano, S., A.; MARTín, M. ${ }^{\circ}$; Negrete A. y PuCh, E. (1985): «La necrópolis ibérica de «El Tesorico» (Agramón-Hellín, Albacete)». NOTICIARIO ARQUEOLÓGICO HISPÁNICO 20. Madrid, pp. 45-181.

CABre Herreros, M. ${ }^{a}$ E. (1934): «Dos tipos genéricos de falcata hsipánica». ARCHIVO ESPAÑOL DE ARTE Y ARQUEOLOGÍA X. Madrid, pp. 207-224.

CABRE DE MorÁN, M. ${ }^{a}$ E. (1990): «Espadas y puñales de las necrópolis celtibéricas». II SIMPOSIO SOBRE LOS CELTIBEROS. NECRÓPOLIS CELTIBÉRICAS. Zaragoza, pp. 205-224.

CRUZ PÉREZ, M. ${ }^{a}$ L. (1990): Necrópolis ibérica de Los Nietos (Cartagena, Murcia). EXCAVACIONES ARQUEOLÓGICAS EN ESPAÑA 158. Madrid.

CuAdRAdo DíAz, E. (1963): «Cerámicas áticas de barniz negro de la necrópolis de El Cigarralejo, en Mula (Murcia)». ARCHIVO DE PREHISTORIA LEVANTINA X. Valencia, pp. 97-164.

CUADRADO DíAZ, E.: 1977): «Dos tipos de decoración damasquinada en las hebillas de cinturón ibéricas». RIVISTA DI STUDI LIGURI 43. OMAGGIO A N. LAMBOGLIA I. Roma, pp. 233-244.

CuAdRADo DíAZ, E.: La necrópolis ibérica de «El Cigarralejo» (Mula, Murcia). BIBLIOTHECA PRAEHISTORICA HISPANA XXIII. Madrid.

CuAdRAdo DíAZ, E. (1989): La panoplia ibérica de «El Cigarralejo» (Mula. Murcia). Murcia.

CUADRADO DíAZ, E. (1989-90): «La cremación funeraria de los iberos». ANALES DE PREHISTORIA Y ARQUEOLOGÍA 5-6. Murcia, pp. 111-113.

Fletcher, D.; E. Pla y AlCACER, J. (1965): La Bastida de Les Alcuses (Mogente. Valencia) I. SIP. SERIE DE TRABAJOS VARIOS 24. Valencia.

García CANO, J. M. (1982): Cerámicas griegas de la Región de Murcia. Murcia.

García CANO, J. M. (1997): Las necrópolis ibéricas de Coimbra del Barranco Ancho (Jumilla. Murcia). I.- Las excavaciones y estudio analítico de los materiales. Murcia.

GarCía CANO, J. M. (1999a): Las necrópolis ibéricas de Coimbra del Barranco Ancho (Jumilla. Murcia). II.- Análisis de los enterramientos, catálogo de materiales y apéndices antropológico, arqueozoológico y paleobotánico. Murcia. 
GARCía CANO, J. M. (1999B): «Un aspecto poco tratado en las necrópolis ibéricas. La perduración de objetos en los ajuares: El caso de Murcia». I JORNADAS DE ARQUEOLOGÍA IBÉRICA EN CASTILLA LA MANCHA. Iniesta 1997. Toledo, pp. 169-179.

García CANO, J. M. y PAGE Del Pozo, V. (1990): «La necrópolis ibérica de Archena. Revisión de los materiales y nuevos hallazgos». VERDOLAY 2. HOMENAJE A E. CUADRADO DÍAZ. Murcia, pp. 109-147.

García Cano, J. M. y Page Del Pozo, V. (2000): «La cerámica ática de la necrópolis del Castillejo de los Baños (Fortuna, Murcia)». LA CERAMIQUE ATTIQUE DU IVe SIECLE EN MEDITERRANEE OCCIDENTALE. ACTES DU COLLOQUE INTERNATIONAL D'ARLES (1995). Nápoles, pp. 253-258.

García CANO, J. M. y PAGe Del Pozo, V. (2001): La necrópolis ibérica del Castillejo de los Baños (Fortuna. Murcia). Murcia (e.p.).

Gonzalez NavarRete, J.A. (1987): Escultura ibérica de Cerrillo Blanco (Porcuna, Jaén). Jaén.

Maluquer, J.; Picazo, M. y Martin, A. (1984): Corpus Vasorum Antiquorum. Espagne. Musée Monographique d'Ullastret. Fascículo I. Barcelona.

Matillas Seiquer, G.; y Pelegrin García, I. (1987): «Contexto arqueológico de la Cueva Negra de Fortuna». ANTIGÜEDAD Y CRISTIANISMO IV. Murcia, pp. 109-132.

Nieto Gallo, G. y EscalerA, J. (1970): «Estudio y tratamiento de una falcata de Almedinilla». INFORMES Y TRABAJOS DEL ICROA 10. Madrid, pp. 5-30.

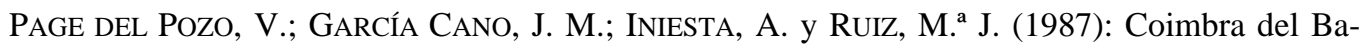
rranco Ancho. Diez años de excavaciones. Murcia.

PICAZO, M.: (1977): La cerámica ática de Ullastret. Barcelona.

QUESADA SANZ, F.: (1988): «Las acanaladuras de las hojas de las falcatas ibéricas». CUADERNOS DE PREHISTORIA Y ARQUEOLOGÍA DE LA UNIVERSIDAD AUTÓNOMA DE MADRID 15. Madrid, pp. 275-299.

QueSADA SANZ, F.: (1989): Armamento, guerra y sociedad en la necrópolis ibérica de «El Cabecico del Tesoro» (Murcia. España). BAR INTERNATIONAL SERIES 502. II Volúmenes. Oxford.

QUESADA SANZ, F.: (1990): «Falcatas ibéricas con damasquinados en plata». VERDOLAY 2. HOMENAJE A E. CUADRADO. Murcia, pp. 45-59.

QueSADA SANZ, F.: (1997): El armamento ibérico. Estudio tipológico, geográfico, funcional,social y simbólico de las armas de la cultura ibérica (siglos VI-I a.C.). MONOGRAPHIES INSTRUMENTUM 3. Montagnac. (II volúmenes).

REIG SEGUI, C.: (2000): «El armamento de la necrópolis ibérica de la Serreta de Alcoi (Alicante, España). GLADIUS XX. Madrid, pp. 74-117.

SANDARS, H.: (1913): «The weapons of the iberians». ARCHEOLOGIA LXIV. Oxford, pp. 1-105.

SORIA COMBADIERA, L. y GARCÍA MARTINEZ, H.: (1996): Broches y placas de cinturón de la edad del Hierro en la provincia de Albacete. Una aproximación a la metalúrgia protohistórica. Albacete. 